\title{
On the Dynamical Mechanism of the Southern Annular Mode, Including Seasonality; Inter-Annual Variability; and Trends
}

\author{
by \\ Joseph Kidston \\ Wellington 2009 \\ A thesis \\ submitted to Victoria University of Wellington \\ in fulfilment of the requirements of the degree of Doctor of Philosophy \\ in \\ Geophysics \\ Institute of Geophysics, School of Earth Sciences \\ Victoria University of Wellington \\ Wellington, New Zealand/Aotearoa
}





\begin{abstract}
This thesis considers the dynamics of the leading mode of extratropical atmospheric variability, the so-called annular modes, with a focus on the Southern Hemisphere (SH). Various aspects of the annular modes are addressed, from the underlying mechanism, to variability at progressively longer time-scales; ranging from the seasonality; to inter-annual variability; to the observed and predicted trends.

The underlying mechanism of the annular modes is approached in the context of the recent theory that eddy-driven jets may be self-maintaining. We show that the leading mode of variability is associated with changes in the eddy source latitude, and that the latitude of the eddy source region is organised by the mean flow. This is consistent with the idea that the annular modes should be thought of as the meridional wandering of a self-maintaining jet, and that a positive baroclinic feedback prolongs these vacillations. Further, the degree to which the eddy-driven flow is self-maintaining determines the time-scale of the leading mode in a simplified general circulation model (GCM). Preliminary results indicate that the same dynamics are important in the real atmosphere.

Secondly the seasonality of the southern annular mode (SAM) is investigated. As with previous studies, during summer the SAM is found to be largely zonally symmetric, whereas during winter it exhibits increased zonal wave number 2-3 variability. This is consistent with seasonal variations in the mean-state, and it is argued that the seasonal cycle of near-surface temperature over the Australian continent plays an important role, making the eddy driven jet, and hence the SAM, more zonally symmetric during summer than winter. During winter, the SAM exhibits little variability over the South Pacific and southeast of Australia. Dynamical reasons for this behaviour are discussed.
\end{abstract}


This seasonality is discussed in the context of New Zealand climate, where it is shown that the variability in rainfall and temperature data are impacted by the large-scale seasonality of the SAM.

Thirdly the zonally symmetric response of the SH to the El Niño Southern Oscillation (ENSO) is examined. Such a response is only observed in the mid-latitudes during austral summer and autumn, the same period when the climatological mean flow and storm-track is most zonally symmetric. During all seasons the ENSO stationary wave, or Pacific South American mode affects the baroclinicity at $850 \mathrm{hPa}$ in the South Pacific region, so that during La Niña (El Niño) events the baroclinicity is increased (reduced). During summer La Niña events the anomalous transient eddy activity is increased over the entire meridional extent of the storm-track in the South Pacific region, whereas down-stream, over the Atlantic and Indian Oceans, the storm track moves poleward.

It is suggested that during La Niña events, more vigorous eddy activity in the South Pacific leads to a poleward shift of the storm-track immediately down-stream, in the East Pacific. During summer and autumn the location of the storm-track in the Pacific region may be communicated around the hemisphere because there is a single climatological storm track, and so eddies can propagate from the Pacific region to the Atlantic region. There is some evidence of these dynamics in that the anomalous eddy activity associated with La Niña events begins in the South Pacific region and subsequently propagates zonally.

Finally the cause of the poleward shift of the mid-latitude eddy-driven jet streams under global warming is considered. GCMs indicate that the recent poleward shift of the eddy-driven jet streams will continue throughout the $21^{\text {st }}$ Century. Here it is shown that the shift is associated with an increase in the eddy length-scale. The cause of the increase in eddy length-scale is discussed. Larger eddies are shown to 
propagate preferentially poleward, and it is argued that this may induce a corresponding shift in the mean flow that they maintain. The mechanism is investigated using a simplified GCM. 



\section{Contents}

1 Introduction 1

2 Data and Methods 4

3 On the Baroclinic mechanism of Annular Modes 6

3.1 Introduction . . . . . . . . . . . . . . . . . . 6

3.2 Data and Methods .................... 11

3.3 Results . . . . . . . . . . . . . . . . . . 13

3.3.1 Hemispherically Symmetric Nature of the Annular Modes . . . 13

3.3.2 Baroclinically or Barotropically Driven Variability? . . . . . . 15

3.3.3 Baroclinic Feedbacks in the Simplified GCM . . . . . . . . 18

3.3.4 Baroclinic Feedbacks in Observations . . . . . . . . . . . . 22

3.4 Discussion and Conclusions . . . . . . . . . . . . . . . . . 24

4 Seasonality of the Southern Annular Mode 29

4.1 Introduction . . . . . . . . . . . . . . . . . . . . . 29 
4.2 Data and Methods . . . . . . . . . . . . . . . . . 30

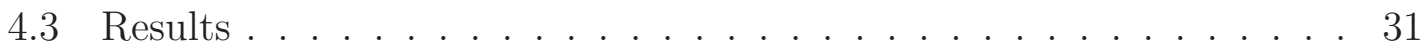

4.3.1 Zonal Asymmetry and Seasonality of the SAM . . . . . . . . 31

4.3.2 Impacts of the SAM on NZ climate . . . . . . . . . . . . 40

4.4 Discussion and Conclusions . . . . . . . . . . . . . . . . . 47

5 Inter-Annual Variability of the Southern Annular Mode: the Impact of the El-Niño Southern Oscillation

5.1 Introduction . . . . . . . . . . . . . . . . . . . . . . . . 49

5.2 Data and methods ........................ 51

5.3 Results . . . . . . . . . . . . . . . . . . . . . 53

5.3.1 Review of the seasonality of the Southern Hemisphere response to ENSO . . . . . . . . . . . . . . 53

5.3.2 The effect of the ENSO stationary wave on Southern Hemisphere mid-latitude transient eddies . . . . . . . . . . . . . 59

5.3.3 Development of the zonally symmetric mid-latitude response to $\mathrm{ENSO} \ldots \ldots \ldots \ldots \ldots \ldots$

5.4 Discussion and Conclusions . . . . . . . . . . . . . . 66

6 On the Positive Trend in the Annular Modes Under Increasing Greenhouse Gasses 
6.1 Introduction . . . . . . . . . . . . . . . . . . 69

6.2 Data and Methods ... . . . . . . . . . . . . . 71

6.3 Results. . . . . . . . . . . . . . . . . . . . . 72

6.4 Discussion and Conclusions . . . . . . . . . . . . . 80

$\begin{array}{lll}7 & \text { Conclusions } & 85\end{array}$

$\begin{array}{lr}\text { List of Figures } & 87\end{array}$

$\begin{array}{ll}\text { List of Tables } & 96\end{array}$

$\begin{array}{ll}\text { References } & 97\end{array}$

8 Acknowledgements 113 


\section{Introduction}

The atmospheric circulation in the mid-latitudes of both hemispheres is dominated by high-frequency eddies, the primary source of which is baroclinic instability (Holton, 1992; Vallis, 2006). The result is a climate that is dominated by day to day variability, much more so than at lower latitudes. The mid-latitudes also exhibit lower frequency variability, on seasonal to inter-annual time-scales, the dominant mode of which is the meridional vacillation of the jet streams and embedded storm tracks (Kidson, 1988; Mo and White, 1985; Thompson and Wallace, 2000; Baldwin, 2001; Wallace, 2000). Geostrophic balance implies that the meridional vacillation of the zonal wind-speed $(u)$ is accompanied by geopotential height $(Z)$ anomalies that are approximately annular, and e.g. in the Southern Hemisphere (SH) have opposite sign over Antarctica and the latitude circle bounded by ca. $35^{\circ} \mathrm{S}$ and $45^{\circ} \mathrm{S}$ (Kidson, 1988, 1999).

The earliest known recording of such a dipolar mode of variability in the midlatitudes referred to the Northern Hemisphere (NH) and appeared in David Crantz's The History of Greenland (1767): "It has been many times remarked, that the weather in Greenland is just the reverse to that in Europe; so that when the temperate climates are incommoded with a very hard winter, it is here uncommonly mild, and vice versa" (Vallis and Gerber, 2008). In the $\mathrm{SH}$, similar variability was first noticed by Walker in 1928 as a seesaw in the pressure anomalies between South America and the Bellingshausen Sea (Gong and Wang, 1999).

This variability is variously referred to as the annular modes (Limpasuvan and Hart- 
mann, 1999), the Antarctic or Arctic oscillations (Thompson and Wallace, 1998; Gong and Wang, 1999), and the North Atlantic oscillation (Visbeck et al., 2001; Ambaum et al., 2001; Huth, 2007). Here, the terminology "annular modes" is used. By convention a poleward displacement of the jet corresponds to a positive annular mode. These modes have a peak in their power spectrum at the seasonal time-scale of two-three months (Kidson, 1999; Kidson and Watterson, 1999).

The mid-latitude jet streams are co-located with the baroclinic eddies that drive them. These eddies include day to day weather and they are responsible for determining regional climate characteristics such as precipitation and climatological winds. Variability of the annular modes is synonymous with variability of the storm tracks, so that when the annular mode is positive, the storm tracks are displaced polewards, and regions on the equatorward edge of the climatological storm track will be subjected to fewer cyclones that usual (Sinclair et al., 1997). They are the dominant drivers of mid-latitude temperature and precipitation variability at seasonal and inter-annual time-scales (Hurrell et al., 2003; Marshall et al., 2001; Gillett et al., 2006; Thompson and Wallace, 2001). It is possible that improved understanding of annular modes would enhance weather predictability. It appears that the mode itself is chaotic and unpredictable (Kidson, 1999), but if the mode has significant persistence, this alone may enhance predictability. The principal response in the mid-latitudes to increasing atmospheric concentrations of greenhouse gasses (GHGs) is projected to be a poleward shift of the storm-tracks, which is a positive trend in the annular modes (Meehl et al., 2007b; Yin, 2005; Kushner et al., 2001; Bengtsson et al., 2006; Miller et al., 2006).

It is a matter of ongoing debate whether such a mode represents hemispherically coherent variability, or is simply due to localised dynamics (e.g. Thompson et al. (2003); Vallis and Gerber (2008)). Such an oscillation is inherent to an atmosphere 
on a rotating body with a meridional heating gradient (Robinson, 2004) and as such is readily simulated in modelling studies, both qualitatively in simple models (Gerber and Vallis, 2007; Vallis et al., 2004) and quantitatively in full global circulation models(Raphael and Holland, 2006; Kidson and Watterson, 1999). The annular modes as they are commonly defined however are not independent of other, higher order modes of variability; although the annular mode does index the meridional vacillation of the jet stream and storm tracks, it does not represent an independent mode of variability (Monahan et al., 2009).

Various aspects of the annular modes are examined in this thesis, and the focus is primarily on the $\mathrm{SH}$ annular mode (SAM). The first results chapter examines the underlying mechanism of such variability in the context of the recent theory that eddy-driven jets may be self-maintaining (Robinson, 2006). Next the seasonality of the SAM is investigated, with a focus on the New Zealand region. The third results chapter considers the mechanism by which the El Niño Southern Oscillation (ENSO) affects the SAM, contributing to inter-annual variability. Finally we consider the observed and projected trend in the annular modes, that is to say the poleward shift of the eddy-driven jet streams, and suggest that this may be caused by the coincident increase in the eddy length-scale. These chapters have all been submitted to peerreviewed journals as individual papers (Kidston et al., 2009c,d,a,b). Although they all address aspects of annular modes, there is some degree of independence between them. As such, data and methods that are common to more than one chapter are described in Chapter 2, but each results chapter retains a section describing data and methods that pertain only to that chapter. 


\section{Data and Methods}

Both daily- and monthly-mean fields from the National Centers for Environmental Prediction-National Center for Atmospheric Research (NCEP-NCAR) reanalysis data set (Kalnay et al., 1996) are used. Only data post-1979 are included due to the lower quality reanalyses prior to the assimilation of satellite information (Kanamitsu et al., 1997; Bromwich et al., 2007), giving 27 years of data (1979-2005). The grid resolution is $2.5^{\circ}$ in both longitude and latitude. The seasonal cycle is defined as the mean for each calendar month. This climatology is simply removed from monthly-mean values to obtain anomalies. To obtain daily anomalies a climatology is generated by first setting each day in a given month to the climatological monthly value, and then applying a 5th order Butterworth low-pass filter with a 50 day cutoff period. Anomalies are then calculated as e.g. $u^{\prime}=u-u_{\text {clim }}$, the ${ }_{\text {clim }}$ subscript representing the climatology described above.

Empirical orthogonal function (EOF) analysis is used to obtain the structure of the leading mode of variability and the principal component (PC) of the leading mode (PC1) is employed as its time series. It is well established that the annular modes are equivalent barotropic. As such the $\mathrm{PC}$ of the leading EOF of $u$ or $Z$ anomalies at different levels in the troposphere are well correlated (Limpasuvan and Hartmann, 2000), and the level at which the EOF analysis is applied is unimportant. This statement also applies to PCs of EOFs derived from zonally- or verticallyaveraged quantities (Lorenz and Hartmann, 2001). The anomalies used to calculate the first EOF were area weighted by $\sqrt{\cos (\phi)}$ where $\phi$ is latitude, to account for 
the convergence of meridians towards the poles. PC1 was normalized so that its standard deviation was unity.

In all of the data sets used herein, the first EOF corresponds to the meridional vacillation of the eddy-driven jet stream, with an equivalent barotropic structure that flanks the climatological flow. E.g. in the SH, when the SAM is positive, $u^{\prime}>0$ at $60 \mathrm{~S}$ and $u^{\prime}<0$ at $40 \mathrm{~S}$, with a node at the climatological maximum $\bar{u}$ at 50S (e.g. Lorenz and Hartmann (2001)).

Consistent with linear theory, baroclinicity is defined as the ratio of the vertical wind shear to the buoyancy frequency between 700 and $850 \mathrm{hPa}$.

Where general dynamics are investigated the dry baroclinic dynamical core developed at the Geophysical Fluid Dynamics Laboratory is employed as a simplified GCM. The model is a spectral model with truncation at T42, and 20 levels evenly spaced in fraction of surface pressure $(\sigma)$, as described in Held and Suarez (1994). The model is simplified in that the only forcings are Newtonian cooling, Rayleigh friction (below $\sigma=0.7$ ) and hyperdiffusivity to remove energy at small scales. The model forcings are hemispherically and zonally symmetric and steady in time. The primitive hydrostatic momentum equations are solved on the sphere, giving some confidence that large-scale dynamics relate to the real atmosphere. After a spinup period of 400 days the model was integrated for 1600 days per run. In the control run the model parameters were as in Held and Suarez (1994); the Equator-Pole equilibrium temperature $\left(T_{e q}\right)$ difference was $60 \mathrm{~K}$, the $e$-folding period for the linear drag operator at the surface was 1 day, $T_{e q}$ in the stratosphere was $200 \mathrm{~K}$, and the hyperdiffusivity operator was $\nabla^{8}$.

Because the model forcing was steady state, the time-mean output was used as the climatology, and this was removed from daily-means to give anomalies. 


\section{On the Baroclinic mechanism of Annular Modes}

\subsection{Introduction}

The underlying mechanism of annular modes of variability is an area of ongoing research. In this chapter the suggestion by Gerber and Vallis (2007), that the modes arise from the meridional wandering of a self-maintaining eddy-driven jet, is pursued. The hypothesis is investigated quantitatively for the first time, by considering whether the time scale of the annular mode is affected by the degree to which an eddy-driven jet is self-maintaining. Furthermore new evidence is presented that the real atmosphere may exhibit similar dynamics.

In this chapter annular modes are considered in the zonally-averaged framework. To first order in the quasi-geostrophic (QG) framework and ignoring the sphericity of the Earth, the equations that describe the zonal-mean zonal momentum balance (away from the Earth's surface) and mass continuity are

$$
\begin{aligned}
\frac{\partial \bar{u}}{\partial t}-f \bar{v} & =-\frac{\partial}{\partial y} \overline{u^{\prime} v^{\prime}} \\
\frac{\partial \bar{\omega}}{\partial p}+\frac{\partial \bar{v}}{\partial y} & =0
\end{aligned}
$$

where $u, v$, and $\omega$ respectively refer to the zonal, meridional, and pressure velocity, $f$ is the Coriolis parameter, primes denote departures from the zonal mean and the overbar represents zonal averaging. The R.H.S. of (3.1a) is the convergence of the meridional eddy momentum flux. It is clear that if the large scale flow organises the eddy momentum flux convergence so that $\frac{\partial \bar{u}}{\partial t}>0$ where $\bar{u}$ is maximum then a 
positive feedback exists, and any latitudinal displacement of the mean flow may be prolonged, leading to the dominance of annular modes over other variability.

Numerous authors have suggested that such a feedback is important (Robinson, 1994, 1996; Limpasuvan and Hartmann, 2000; Lorenz and Hartmann, 2001, 2003; Gerber and Vallis, 2007). There have been various mechanisms proposed for this feedback. Hartmann and co-authors first proposed a barotropic mechanism, whereby the meridional shear of the westerlies is crucial for determining the lifecycle of the eddies (e.g. Hartmann (2000)). Specifically, when the jet is displaced poleward, there is increased anticyclonic shear on the equatorward flank, which encourages anticylonic, or LC1 type (Thorncroft et al., 1993) wave breaking. LC1 type wave breaking corresponds to equatorward propagating eddies. Because the meridional flux of zonal momentum associated with wave propagation is in the opposite direction to the group velocity (Vallis, 2006), this wave breaking tends to reinforce the existing wind-speed anomaly. This can be argued from the refractive index $\left(n^{2}\right)$ viewpoint (Limpasuvan and Hartmann, 2000). The refractive index is anomalously low at high latitudes when the annular modes are positive, and so waves (which propagate towards high $n^{2}$ ) propagate preferentially equatorward. The momentum flux convergence associated with equatorward wave propagation tends to further reduce $n^{2}$ at high latitudes. Alternatively, from the potential vorticity (PV) point of view, when the jet is displaced equatorward, the relatively weak PV gradient on the poleward flank of the jet encourages increased cyclonic, or LC2 wave breaking (Hartmann, 1995), and the associated momentum flux convergence prolongs the equatorward displacement of the jet.

Other mechanisms have been suggested that are baroclinic. The primary source of large-scale eddy activity in the atmosphere is baroclinic instability. The barotropic westerlies arise due to the meridional propagation of eddies aloft, away from their 
source region. In quasi-steady state the main sink for the resulting westerly momentum flux convergence in the source region is friction near the surface. Therefore in a statistically steady state, meridional propagation aloft of eddies away from a net source region necessitates a barotropic eddy-driven jet stream (Held, 1975). If there exists a self-maintaining mechanism whereby baroclinic eddies tend to be born at the latitude of the eddy-driven jet, then their meridional transport of momentum tends to prevent the jet from shifting latitudes. If this negative feedback on the jet movement were very strong, the jet may never move, but if the latitude of the jet is subject to stochastic variability, then a positive baroclinic feedback would tend to prolong any displacement (Gerber and Vallis, 2007). This idea can be understood in terms of a simple harmonic oscillator. The jet has a mean position that is dictated by the climatological diabatic forcing. Stochastic variability causes the jet to be randomly displaced from its climatological position. If the jet is self maintaining then the restoring force encouraging the jet back to its mean position is weaker. The jet can spend more time displaced further from its climatological position, and so the variance of a mode characterising the meridional vacillation of the jet will be enhanced. Alternatively one can think of the jet as being located in a potential well. The strength of the external, or diabatic, forcing encouraging the jet back to its mean position determines the steepness of the walls of the well. Self maintenance, or a negative feedback on the movement, flattens the bottom of the well and allows the jet to remain displaced far from its climatological position.

Robinson $(2000,1996,1994)$ has suggested that such a feedback arises due to surface drag. Friction at the surface acts on the barotropic increase in wind-speed associated with the eddy life-cycle (Simmons and Hoskins, 1978) to increase the vertical shear of the westerly wind, providing a low-frequency feedback that tends to generate baroclinic instability at the core of the eddy-driven jet. 
Another baroclinic feedback mechanism, also suggested by Robinson (2006) focuses on the upper level Eliassen-Palm (EP) flux divergence. In the transformed Eulerian mean (T.E.M., Edmon et al. (1980); Andrews et al. (1987); Holton (1992); Vallis (2006)) framework (3.1a) and (3.1b) become

$$
\begin{aligned}
\frac{\partial \bar{u}}{\partial t}-f \bar{v}^{*} & =-\nabla \cdot \vec{F} \\
\frac{\partial \bar{\omega}^{*}}{\partial p}+\frac{\partial \bar{v}^{*}}{\partial y} & =0
\end{aligned}
$$

where the variables with the ${ }^{*}$ superscript are transformed Eulerian mean quantities, and can be thought of as thickness-weighted versions of their Eulerian counterparts (Edmon et al., 1980; Vallis, 2006). $\bar{\omega}^{*}$ takes account of the fact that an eddy heat flux convergence results in upward Eulerian motion simply because thicker air masses converge in the Eulerian averaging space. Thus the Eulerian vertical velocity may be non-zero even though no individual air parcel rises or falls. In the QG framework $\nabla \cdot \vec{F}$ represents the total zonal force exerted by the eddies on the mean flow; the meridional component of $\nabla \cdot \vec{F}$ is the R.H.S of (3.1a), and the vertical component of $\nabla \cdot \vec{F}$ is $\frac{\partial}{\partial p} \frac{\overline{v^{\prime} \theta^{\prime}}}{\theta_{p}} f$, where $\theta$ is the potential temperature. $\frac{\partial}{\partial p} \frac{\overline{v^{\prime} \theta^{\prime}}}{\bar{\theta}_{p}} f$ is the convergence of the vertical momentum flux that is inherent to a meridional eddy heat flux and the form drag due to the westward phase tilt with height required by hydrostatic balance. The T.E.M. represents a more Lagrangian view of fluid motion. $\nabla \cdot \vec{F}$ is generally negative in the upper atmosphere (Edmon et al., 1980; Holton, 1992; Vallis, 2006), indicative that even at the core of the storm track, where the meridional propagation of eddies gives $-\frac{\partial}{\partial y} \overline{u^{\prime} v^{\prime}}>0$, the form drag term $\frac{\partial}{\partial p} \overline{\frac{v^{\prime} \theta^{\prime}}{\theta_{p}}} f<0$ and dominates.

However, a subtle but important point arises if $-\frac{\partial}{\partial y} \overline{u^{\prime} v^{\prime}}$ is large enough in magnitude that there is a local maximum in $\nabla \cdot \vec{F}$ at the core of the jet. Then $\nabla \cdot \vec{F}$ is less negative at the core of the jet than on the flanks. If this is true (and $\nabla \cdot \vec{F}$ in the lower layers exhibits a broad maximum characteristic of the heat flux term) then it can 
be said that the eddies decrease the vertical shear (and so the baroclinic instability) more effectively on the flanks of the jet than at the core, and so incremental shifts in the latitude of the jet are discouraged (Gerber and Vallis, 2007).

An equivalent way of expressing this feedback comes from 3.2a that in quasi-steady state $\bar{v}^{*}=-\frac{1}{f} \nabla \cdot \vec{F}$. (Note that $\nabla \cdot \vec{F}<0$ requires that $\bar{v}^{*}$ is poleward in the upper troposphere, and the Ferrell cell disappears in the T.E.M., so that to first order the thickness-weighted overturning is a single thermally direct cell in each hemisphere). Thus a local maximum in $\nabla \cdot \vec{F}$ at the storm track means that $\bar{v}^{*}$ will have a local minimum, so that on the poleward flank $\frac{\partial \bar{v}^{*}}{\partial y}>0$. By $(3.2 \mathrm{~b})$ this must be associated with $\frac{\partial \bar{\omega}^{*}}{\partial p}<0$. Because the primary momentum sink is friction near the surface, this circulation must close downwards (Haynes et al., 1991), giving rising and adiabatic cooling on the poleward flank. The same reasoning gives sinking and warming on the equatorward flank. This thermally indirect motion increases the meridional temperature gradient (and so the baroclinic instability) at the core of the storm track relative to elsewhere (Robinson, 2006). It has been suggested by Gerber and Vallis (2007) that this provides a negative feedback on the meridional vacillation of an eddy-driven jet stream, thereby prolonging displacements of the jet, and causing that mode of variability to be dominant.

Here the ideas of Robinson (2006) and Gerber and Vallis (2007) are developed and it is argued that the low-frequency meridional vacillation of an eddy-driven jet stems from a baroclinic feedback. First it is shown that the annular modes are inherently baroclinic in nature. A simplified GCM is then used to show that the time-scale of the annular mode is determined by the magnitude of the baroclinic feedback described above. Observational data is also analysed and used to argue that this mechanism is important in the real atmosphere. 


\subsection{Data and Methods}

The annular mode is calculated as the first EOF of the daily zonal-mean zonal wind anomalies $\left(\bar{u}^{\prime}=\bar{u}-\bar{u}_{\text {clim }}\right.$, the ${ }_{\text {clim }}$ subscript representing the climatology described in Chapter 2). The EOF was calculated in the meridional-height plane from the equator to the pole and including all heights.

To investigate the degree of zonal symmetry of the variability, the "cross-planet cospectrum' was calculated. At a single level, the cospectrum of $u^{\prime}$ at one longitude with $u^{\prime} 180$ degrees of longitude away was calculated by splitting the time-series into sections of length 256 days and overlapping with the congruent sections using a Hamming window of width 128 days. In order to reduce noise, the cospectrum for each point on the latitude circle was averaged with the points at $180 \pm 10$ degrees of longitude away, so that the average separation was in fact 175 degrees of longitude.

As in Lorenz and Hartmann (2001, 2003) and subsequent references, a time-series of the eddy forcing of the annular mode $(F)$ was taken as the projection of the daily meridional eddy momentum flux convergence $\left(-\frac{\partial}{\partial y} \overline{u^{\prime} v^{\prime}}\right)$ onto the first EOF in the meridional-height plane. This was calculated for the total eddy field $\left(F_{t o t}\right)$ by taking eddy quantities as deviations from the zonal mean, and for the high-frequency eddies $\left(F_{h f}\right)$ where eddy quantities were calculated by applying a high-pass 5 th order Butterworth filter with a 10 day cutoff. To quantify the extent to which the eddy heat flux was latitudinally displaced, the same analysis is applied to the eddy heat flux field. The daily eddy heat flux $\left(\overline{v^{\prime} T^{\prime}}\right)$ was projected onto the first EOF in the meridional-height plane for the total eddy fields to give the time series $H_{t o t}$. When $H_{t o t}$ is positive, there is increased eddy heat flux at $60^{\circ} \mathrm{S}$, and decreased eddy heat flux at $40^{\circ} \mathrm{S}$ (these latitudes correspond to the maxima in the first EOF for the SH observations). The same analysis applied to the heat flux associated with 
high-frequency eddies yielded the time series $H_{h f}$.

The eddy-driven thermally indirect vertical motion due to the meridional momentum flux convergence $\left(\bar{w}_{e d d y}\right)$ is calculated as in e.g. Seager et al. (2003). Assuming downward control, and solving (3.1a) and (3.1b) assuming a steady state gives

$$
\bar{\omega}_{e d d y}=\int_{0}^{p}-\frac{\partial}{\partial y} \frac{1}{f} \frac{\partial}{\partial y} \overline{u^{\prime} v^{\prime}} d \omega
$$

and the hydrostatic relation is used to give the Cartesian vertical velocity $\bar{w}_{\text {eddy }}=$ $-\frac{R T}{p g} \bar{\omega}_{e d d y}$. A measure of the amount of heating attributable to this motion is given by the sum of the product of $\bar{w}_{e d d y}$ and the buoyancy frequency $\left(N^{2}\right)$. This eddydriven thermally indirect effect is referred to as $\sum \bar{w}_{e d d y} N^{2}$. It is calculated only for the rising on the poleward flank of the jet (defined as the region where there is convergence of the eddy heat flux, $\frac{\partial}{\partial y} \overline{v^{\prime} T^{\prime}}<0$, and there is rising motion, $\bar{w}_{e d d y}>0$ ) so as to be sure to avoid any downward motion at low latitudes that may be due to a closed Hadley circulation. This is compared with the total heating on the poleward flank of the jet due to the eddy heat flux convergence $\sum-\frac{\partial}{\partial y} \overline{v^{\prime} T^{\prime}}$.

For convenience the equations have thus far been written in the form that neglects the Earth's sphericity. For analysis purposes, calculations were made that took account of the Earth's geometry. Thus the R.H.S. of (3.2a) was calculated as

$$
\frac{1}{\operatorname{acos}(\phi)} \nabla \cdot \vec{F}=-\frac{1}{\operatorname{acos}^{2}(\phi)} \frac{\partial}{\partial \phi} \overline{u^{\prime} v^{\prime}} \cos ^{2}(\phi)+\frac{1}{\operatorname{acos}(\phi)} \frac{\partial}{\partial p} \frac{\overline{v^{\prime} \theta^{\prime}}}{\bar{\theta}_{p}} f a \cos (\phi)
$$

where $a$ is the Earth's radius and $\phi$ is latitude. To calculate $\bar{w}^{*}$, first of all the 
T.E.M. vertical pressure velocity was calculated as

$$
\bar{\omega} *=\bar{\omega}+\frac{1}{\operatorname{acos}(\phi)} \frac{\partial}{\partial \phi}\left(\frac{\overline{v^{\prime} \theta^{\prime}}}{\bar{\theta}_{p}}\right)
$$

and converted to Cartesian vertical velocity using the hydrostatic relation.

The temperature tendency due to latent heating $\left(\left.\frac{\partial}{\partial t} T\right|_{\text {latent }}\right)$ has been computed for the NCEP reanalysis and is provided at http://iridl.ldeo.columbia.edu/SOURCES/.NOAA/.NCEP-DOE/.Reanalysis-2/. The sum of the heating due to (i) deep convection, (ii) shallow convection and (iii) largescale condensation is taken to represent the total latent heating.

\subsection{Results}

\subsubsection{Hemispherically Symmetric Nature of the Annular Modes}

The extent to which annular modes represent a genuinely hemispherically symmetric mode of variability has been a matter of some debate (Wallace, 2000; Thompson et al., 2003). Certainly hemispherically symmetric variability is not a necessary condition to obtain annular EOFs (Cash et al., 2005; Vallis and Gerber, 2008). To investigate this the 'cross-planet cospectrum' of the zonal wind-speed anomaly is shown in Figure 3.1 (a). When taken as being coincident with the maximum surface westerlies, the eddy-driven jet lies at approximately 50 degrees from the Equator in both hemispheres, and so \pm 60 degrees lies on the poleward flank of the jet in both hemispheres. At $60^{\circ} \mathrm{S}$ and at low frequencies there is positive covariance between the wind-speed anomalies on opposite sides of the planet. At $50^{\circ} \mathrm{S}$ there is no strong positive cross-planet covariance, but there is negative covariance at periods of about 30 days, presumably due to zonal wavenumber one $(k-1$, where $k$ is the zonal wavenumber) variability. That there is no positive cross-planet covariance at $50^{\circ} \mathrm{S}$ is 
indicative that there is no zonally-symmetric pulsing of the jet. That there is positive cross-planet covariance at $60^{\circ} \mathrm{S}$ is indicative that the meridional vacillation of the jet is a genuinely zonally-symmetric mode of variability; even when the annular mode is in its extreme phase, the zonal-mean jet-stream encompasses the region at $50^{\circ} \mathrm{S}$, but when the annular mode is negative, the region at $60^{\circ} \mathrm{S}$ may no longer correspond to the eddy-driven jet. This zonal symmetry implies that the annular mode in the $\mathrm{SH}$ is a result of more interesting dynamics than simple synoptic-scale stochastic forcing. Positive cross-planet covariance is also seen at $40^{\circ} \mathrm{S}$ (not shown). A onepoint correlation map in the latitude-longitude plane for $u^{\prime}$ at $60^{\circ} \mathrm{S}$ (band-passed filtered to remove inter-annual fluctuations that may be associated with changing boundary conditions, and high-frequency noise) exhibits an annular pattern (not shown).

The Northern Hemisphere (NH) is markedly different. At $60^{\circ} \mathrm{N}$ there is a hint of positive cross-planet covariance, but it is not nearly as pronounced as at $60^{\circ} \mathrm{S}$. This is indicative of the fact that regions separated by 180 degrees of longitude are not significantly correlated in the NH (Ambaum et al., 2001). This result is insensitive to choice of latitude. It will be argued that the fact that the storm track is relatively continuous in the $\mathrm{SH}$ compared to the $\mathrm{NH}$ allows the eddy feedback to be communicated continuously around a latitude circle, and induce a hemispherically symmetric mode of variability.

Figure 3.1 (b) shows the same analysis for the model control run. Again, there is no hemispherically symmetric pulsing of the jet (which resides at $46^{\circ} \mathrm{S}$ in the timemean), but there is a hemispherically symmetric meridional vacillation of the jet, as indicated by positive cross-planet covariance on the flank of the jet (at $54^{\circ} \mathrm{S}$ ). In this regard the model is qualitatively similar to the $\mathrm{SH}$, as may be expected because both have relatively continuous storm tracks. 

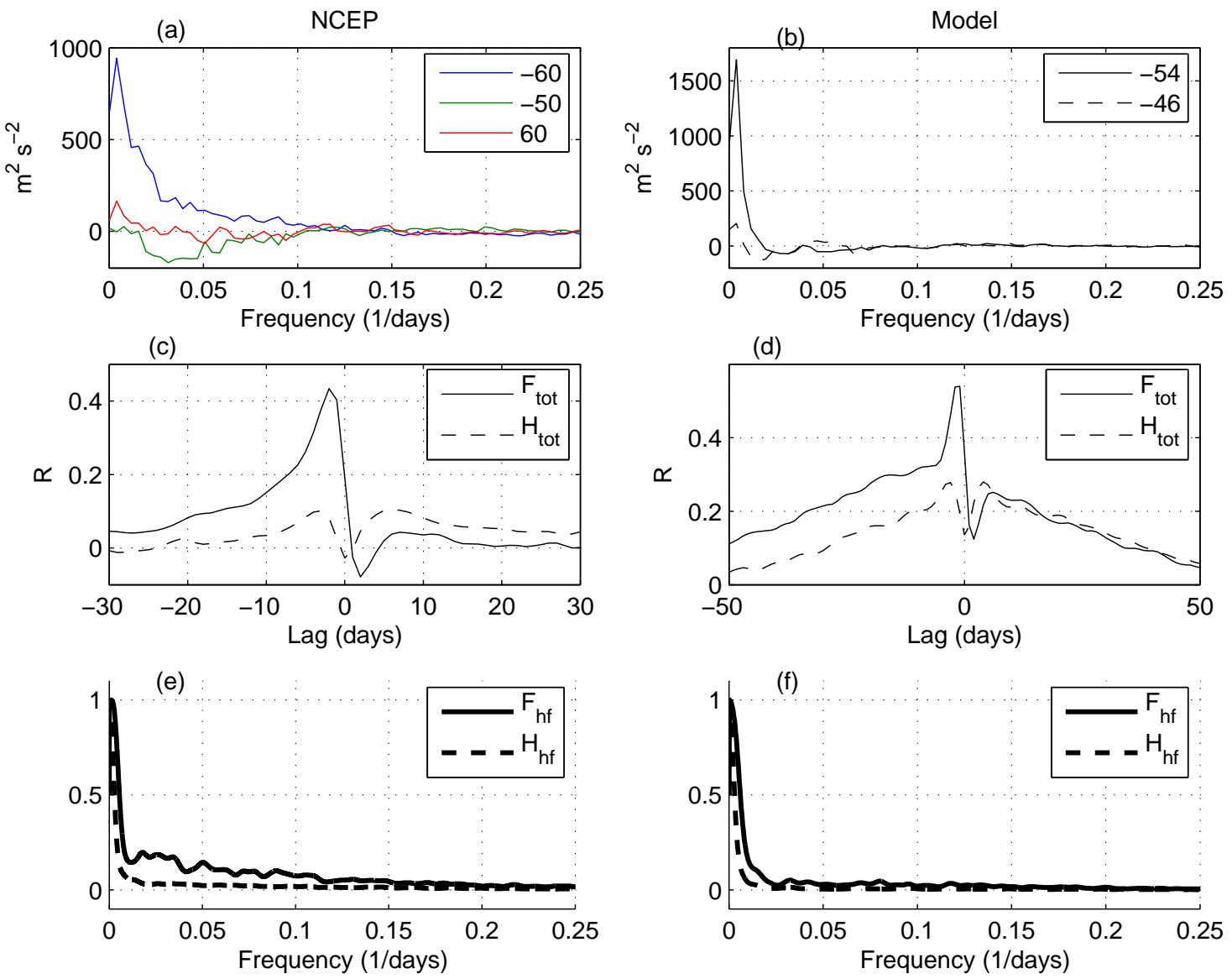

Figure 3.1: The left column shows data from the NCEP reanalysis and the right column shows output from the model control run. The top panels show the 'crossplanet cospectrum' (see text) for zonal wind-speed anomalies at $300 \mathrm{hPa}$. The central panels show the lead/lag correlation coefficient (R) between PC1 (see text), the momentum flux forcing $F_{\text {tot }}$ (see text) and the poleward displacement of the eddy heat flux $H_{t o t}$ (see text). The bottom panels show the power spectrum for $F_{h f}$ and $H_{h f}$ (see text), normalised so that the maximum spectral density is unity.

\subsubsection{Baroclinically or Barotropically Driven Variability?}

Figure 3.1 (c) addresses whether PC1 is a baroclinic mode of variability. The solid line shows the correlation coefficient between $F_{\text {tot }}$ and PC1 as a function of lead 
and lag, and is essentially the same as shown in Lorenz and Hartmann (2001). As expected when $F_{t o t}$ forces the time derivative of PC1, the strongest positive correlations occur when $F_{\text {tot }}$ leads PC1 by a few days. Given that the auto-correlation of $F_{t o t}$ drops to zero after just two or three days, the small but positive correlations between $F_{\text {tot }}$ and PC1 at positive lags were identified by Lorenz and Hartmann (2001) as a positive feedback between $\mathrm{PC} 1$ and $F_{\text {tot }}$, reddening $\mathrm{PC} 1$ and giving rise to the dominance of annular modes.

Also, the correlation between $H_{\text {tot }}$ and PC1 is shown (dashed line). When $H_{t o t}$ leads PC1 there are positive correlations, implying that preceding a poleward displacement of the jet, there is an anomalously strong meridional eddy heat flux at $60^{\circ} \mathrm{S}$. The peak correlation between $H_{\text {tot }}$ and PC1 leads that between $F_{\text {tot }}$ and PC1, consistent with the idea that an anomalously strong heat flux at $60^{\circ} \mathrm{S}$, or generation of baroclinic eddy activity, precedes the divergence of eddy activity aloft and associated momentum flux convergence that drives PC1 positive. At zero lag the eddy heat flux is not latitudinally displaced, likely because the meridional temperature gradient in the region of $60^{\circ} \mathrm{S}$ is diminished at zero lag following the increased heat flux a few days previously. However, the correlation does not drop below zero, and at positive lags there is again a positive heat flux anomaly at $60^{\circ} \mathrm{S}$. This is indicative that a baroclinic feedback may enhance the temperature gradient at the latitude of the anomalous wind-speed maximum (causing the increased heat flux).

Limpasuvan and Hartmann (2000) looked at the regression of the EP flux vector onto PC1 at zero lag. They found no anomalous wave source at $60^{\circ} \mathrm{S}$ associated with a positive PC1, but simply anomalous propagation aloft, thereby suggesting a barotropic mechanism. However, it is clear from Figure 3.1 (c) that if the EP flux anomaly were averaged over e.g. lag -7 to lag +7 , there would be an anomalous heat flux (i.e. source of wave activity) at $60^{\circ} \mathrm{S}$ associated with a positive PC1. Subsequent 
meridional eddy propagation must drive an increase in the barotropic wind-speed that sustains the annular mode. Figure 3.1 (d) shows the same analysis for the model control run. The correlation coefficients are higher at all lead/lags, but the basic behaviour is the same. The increased correlations in the model may be because the model is dry and the forcings steady in time, so that any underlying eddy-mean flow feedbacks are strong and not diminished by stochastic noise to the same extent as in the real atmosphere. Again, the positive correlations with $H_{t o t}$ imply that a positive PC1 is associated with increased heat flux poleward of its climatological position. The reduction in $H_{t o t}$ occurs at zero lag, but it remains positive. Thus it appears to be simply coincidental that in the observations $H_{t o t}$ drops to approximately zero (and so there is no anomalous source of eddy activity) at zero lag, rather than due to fundamental dynamics. When the temperature gradient at $60^{\circ} \mathrm{S}$ was regressed onto PC1 (not shown), it increases at small positive lags, implying that the meridional temperature gradient is dynamically enhanced at the anomalous jet core, consistent with $H_{t o t}>0$ at positive lags.

Lorenz and Hartmann (2001) showed that the power spectrum of PC1 is red. They also showed that the power spectrum of $F_{\text {tot }}$ is red only due to contributions from $F_{h f}$. This fact was used to argue that the large scale $u$ anomalies must organise the high-frequency eddies, indicative of a positive feedback between the mean flow and the high-frequency eddies. The power spectrum of $F_{h f}$ is shown in Figure 3.1 (e) for the observations, and Figure 3.1 (f) for the model control run. Also shown is the power spectrum of $H_{h f}$. Both $F_{h f}$ and $H_{h f}$ exhibit power at the longest time-scales. Because the model forcings are steady in time, a strong statement can be made that the high-frequency heat flux must be organised by the mean flow, reddening $H_{h f}$. $H_{h f} \neq 0$ corresponds to a change in the eddy source latitude, and must cause the barotropic jet to change latitude. In this metric, and in the behaviour of $H_{t o t}$, the annular modes are seen to be a baroclinic mode of variability. Given 
that the observational data exhibit such similar behaviour, it appears that the same statement can be made about the real atmosphere.

\subsubsection{Baroclinic Feedbacks in the Simplified GCM}

Attention is now focused on the question of whether the model exhibits the hypothesized eddy-driven thermally indirect circulation that encourages the largest meridional temperature gradients to be co-located with the eddy-driven jet. This is easier to evaluate in the model first, because latent heating provides an additional complication in the real atmosphere, and because one can change parameters in the simplified GCM and evaluate the effects on the simulated annular modes. The meridional temperature gradient averaged over the lower half of the model domain is shown in Figure 3.2 (a) for the equilibrium temperature $\left(\nabla T_{e q}\right)$ and the output temperature of the run $(\nabla T) . \quad \nabla T$ is less than $\nabla T_{e q}$ at all latitudes, consistent with the fact that eddies are generated through baroclinic instability and the poleward transport of heat. $\nabla T_{e q}$ exhibits a broad maximum in the mid-latitudes. In comparison $\nabla T$ has a much more sharply peaked maximum. The eddy heat flux convergence is shown in Figure 3.2 (b) and shows that in the lower atmosphere the transport of heat by the eddies acts primarily to cool the region $20-30^{\circ} \mathrm{S}$ and heat the region $50-60^{\circ} \mathrm{S}$, which would act to reduce the temperature gradient at $40^{\circ} \mathrm{S}$. The mid-latitude node of the eddy heat flux convergence can be taken as the location of the storm track or eddy driven jet. The temperature gradient is reduced least effectively where the direct transport of heat by the eddies acts to reduce it the most. The same phenomenon whereby $\nabla T$ is a maximum at the latitude of the storm track was also observed in Panetta (1993) and references therein, and appears to be a fundamental feature of baroclinically unstable planetary atmospheres. When the model was run in a zonally-symmetric configuration, with no eddies, $\nabla T$ was a little 
less than $\nabla T_{e q}$, but qualitatively similar, with a broad maximum in mid-latitudes (not shown). So the net effect of the eddies is to reduce $\nabla T$ everywhere, but they do so least effectively where they are most active. This is consistent with the notion that there exists an eddy-driven thermally indirect meridional overturning that transports enough heat to significantly offset the direct effect of the eddies at the jet core, giving the jet some degree of self-maintenance.

The positive baroclinic feedback can be seen in the climatology of $\bar{w}^{*} \cdot \bar{w}^{*}>0$ on the poleward flank of the eddy-driven jet, with $\bar{w}^{*}<0$ on the equatorward flank is indicative of a local Lagrangian thermally indirect circulation. If the thermally indirect circulation flanks the jet core, it may offset the direct effect of the eddy heat flux to the extent that the temperature gradient is reduced least effectively at the jet core, and encourage further baroclinic growth. As described above, Robinson (2006) and Gerber and Vallis (2007) argued that a local maximum in $\nabla \cdot \vec{F}$ in the upper atmosphere at the jet core must lead to such motion. On the other hand, Edmon et al. (1980) proposed that the observed $\bar{w}^{*}>0$ in the mid-latitudes may be due to latent heating and the divergence of the vertical transport of heat by baroclinic eddies. $\bar{w}^{*}$ for the model control run (Figure 3.2 (c)) shows rising on the poleward flank of the jet and sinking on the equatorward flank of the jet, and is consistent with the local maximum in $\nabla \cdot \vec{F}$ in the storm track in this model (Gerber and Vallis (2007) their Figure 12). This rising motion gives the characteristic "U" shape in the T.E.M streamfunction in the mid-latitudes, identified by Robinson (2006) as necessary for a self-maintaining eddy-driven jet. To address the proposal in Edmon et al. (1980) that this "U" may be due to the divergence of the vertical eddy heat flux, $\frac{\partial}{\partial z} \overline{w^{\prime} T^{\prime}}$ is shown in Figure $3.2(\mathrm{~d})$. The spatial pattern of the thermally indirect $\bar{w}^{*}$ does not match that of $\frac{\partial}{\partial z} \overline{w^{\prime} T^{\prime}}$, which is a maximum at the jet core, and so it may be concluded that the rising on the poleward flank of the jet is not due solely to $\frac{\partial}{\partial z} \overline{w^{\prime} T^{\prime}}$. Given that there is no latent heating, this is indicative of a baroclinic 
feedback in this model.
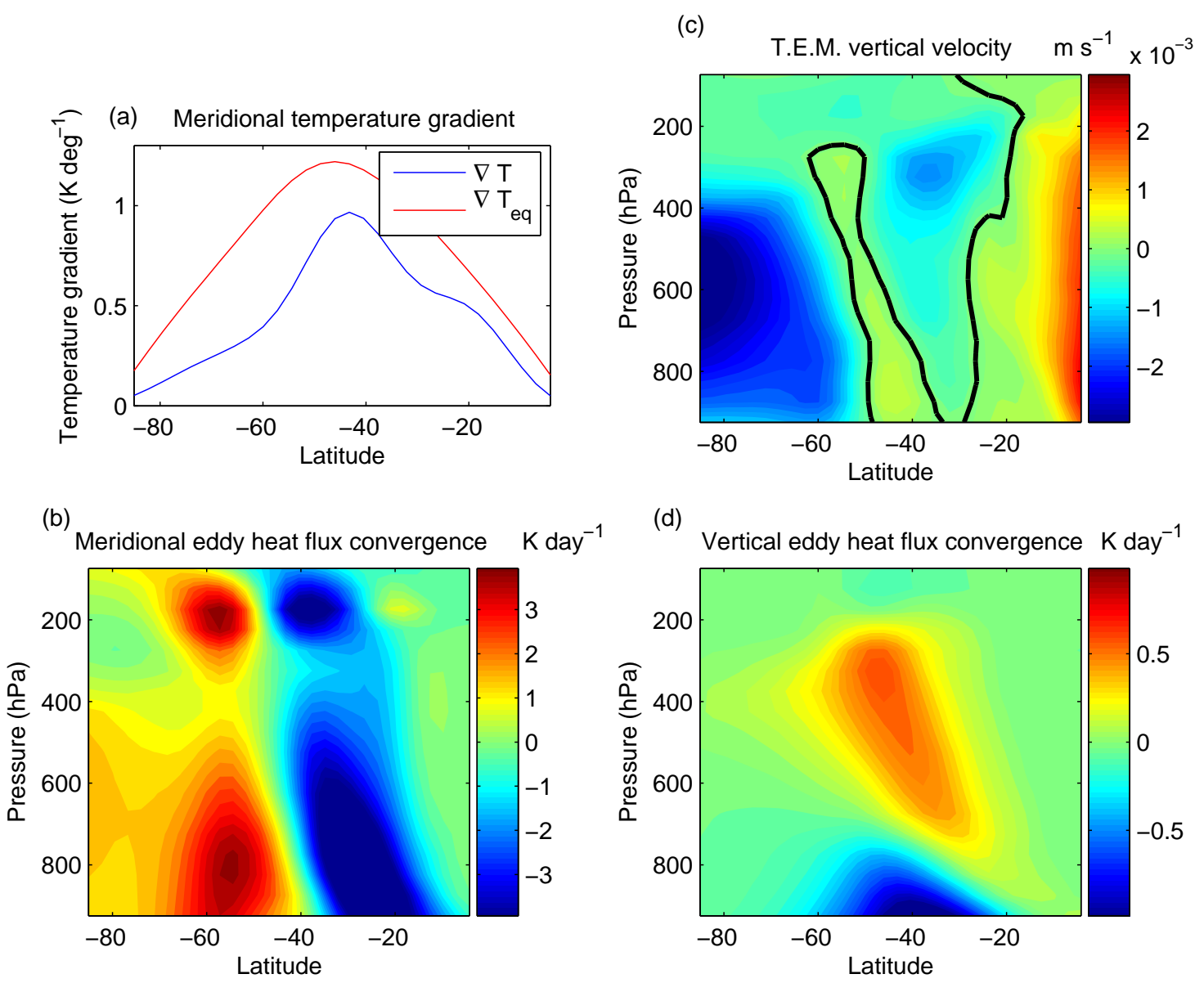

Figure 3.2: Model control run diagnostics. (a) The meridional gradient of the equilibrium temperature $\left(\nabla T_{e q}\right)$ and the output temperature $(\nabla T)$ averaged over the lower half of the model domain. (b) The climatological transformed Eulerian mean (T.E.M.) vertical velocity ( $\bar{w}^{*}$, see text). (c) The convergence of the meridional eddy heat flux $\left(-\frac{\partial}{\partial y} \overline{v^{\prime} T^{\prime}}\right)$. (d) The climatological divergence of the vertical eddy heat flux $\left(\frac{\partial}{\partial z} \overline{w^{\prime} T^{\prime}}\right)$

If the annular mode is due to the meridional wanderings of a self-maintaining jet, it is expected that the characteristic time-scale, the $e$-folding period for the autocorrelation of PC1, would be increased when the self-maintenance mechanism is 
stronger. To investigate this a suite of experiments are presented where $\nabla T_{e q}$ is kept the same in the troposphere, but other parameters were varied in the hope of changing the strength of the feedback. The strength of the baroclinic feedback is expected to vary with the magnitude of the local maximum of $\nabla \cdot \vec{F}$ in the upper atmosphere. This depends on the profile of $\frac{\partial}{\partial y} \overline{u^{\prime} v^{\prime}}$, which can be altered by changing e.g. the separation between eddy source and sink latitudes (Robinson, 2006). Therefore it is expected that the strength of the feedback will vary with changes in mean state that affect the zonal wind-speed climatology, or the eddy length-scale (which affects propagation characteristics such as phase-speed). These in turn affect location of critical latitudes where eddies are dissipated (linear theory predicts that wave-breaking, or eddy dissipation, occurs where the zonal phase-speed (c) of the eddy equals the background zonal wind-speed (Randel and Held, 1991)). To this end, experiments were conducted with changes to (i) the tropopause height, (ii) the spatial scale at which energy was removed from the model, (iii) the $e$-folding time for Newtonian friction, and (iv) the static stability. The caption of Figure 3.3 details the specific changes in forcing for each run. Given that $\nabla T_{e q}$ is kept the same for each simulation, the maximum value of $\nabla T$ for each run is related to the strength of the baroclinic feedback; when there is more self-maintenance, the maximum value of $\nabla T(\max (\nabla T))$ should be higher as more heat is transported in a thermally indirect sense. Figure 3.3 (a) shows the $e$-folding time for PC1 for the different experiments as a function of $\max (\nabla T)$. Although it is not expected that the relationship be simple and linear, there is a clear positive correlation between the $e$-folding time of $\mathrm{PC} 1$ and $\max (\nabla T)$. This is taken as further evidence that the annular mode in this model is a result of a baroclinic feedback, and that the stronger that feedback, the more persistent the annular mode. When the feedback is strong, the self-maintaining jet can wander to latitudes away from where the diabatic forcing acts to generate maximum baroclinic instability, and can remain displaced for long 
periods of time.

Figure 3.3 (b) shows $\max (\nabla T)$ on the ordinate for each model run and $\sum \bar{w}_{\text {eddy }} * N^{2}$ on the poleward flank of the jet on the abscissa. There is a clear negative relationship, indicating that variations in the eddy-driven thermally indirect circulation (and thus the strength of the baroclinic feedback) are likely responsible for the variations in $\max (\nabla T)$. Figure 3.3 (c) shows the $e$-folding time as a function of $\sum \bar{w}_{\text {eddy }} * N^{2}$ on the poleward flank, confirming the deduction that can be made from Figures 3.3 (a) and (b) that a stronger eddy-driven thermally indirect overturning is associated with a more persistent PC1. Figure $3.3(\mathrm{~d})$ shows $\max (\nabla T)$ on the ordinate and $\sum-\frac{\partial}{\partial y} \overline{v^{\prime} T^{\prime}}$ on the abscissa, showing that variations in the direct eddy transport of heat are not responsible for variations in $\max (\nabla T)$. This is expected to be a conservative relationship anyway, because as $\nabla T$ increases, the eddy heat flux would be expected to increase to reduce $\nabla T$.

\subsubsection{Baroclinic Feedbacks in Observations}

The question of whether a similar mechanism appears to be important in the real atmosphere is now addressed. The climatology for $\bar{w}^{*}$ in the $\mathrm{SH}$ is shown in Figure 3.4 (a). Consistent with the "U" shaped T.E.M. streamfunction in Edmon et al. (1980), $\bar{w}^{*}>0$ in the mid-latitudes. Also shown in Figure 3.4 (a) is $-\frac{1}{f} \nabla \cdot \vec{F}$ averaged from $300 \mathrm{hPa}$ to $20 \mathrm{hPa}$, which in steady state is equal to the T.E.M. northward meridional velocity $(\bar{v} *)$. The observed profile of $-\frac{1}{f} \nabla \cdot \vec{F}$ between $55 \mathrm{~S}$ and $45 \mathrm{~S}$ is expected to drive rising motion below $300 \mathrm{hPa}$ at those latitudes, as is observed. However, in addressing whether this rising motion constitutes the same positive baroclinic feedback diagnosed in the model, it is also important to consider the latent heating $\left(\left.\frac{\partial}{\partial t} T\right|_{\text {latent }}\right)$. The climatology of $\left(\left.\frac{\partial}{\partial t} T\right|_{\text {latent }}\right)$ is shown in Figure 3.4 (b), along with the zero contour of $\bar{w}^{*}$ (from Figure 3.4 (a)). There is a maximum 
in the storm-track, nearly coincident with $\bar{w}^{*}>0$, and so it may not be concluded that the region of $\bar{w}^{*}>0$ in the observed climatological mean is eddy-driven in the sense discussed above.

An alternative approach is to examine the variability of $\bar{w}^{*}$. Figure 3.5 (a) shows the regression coefficient for $\bar{w}^{*}$ and $\mathrm{PC} 1$. The tripolar pattern of the $\bar{w}^{*}$ anomalies is expected for a poleward shift of a single thermally indirect cell. The $\bar{w}^{*}$ anomalies are nearly, although not quite, in quadrature with the $u$ anomalies, which are maximum (minimum) at $60^{\circ} \mathrm{S}\left(40^{\circ} \mathrm{S}\right)$. Given that the changes in $\bar{w}^{*}$ are primarily below 300 $\mathrm{hPa}$, the regression coefficient of $\frac{1}{f} \nabla \cdot \vec{F}$ averaged from $500-300 \mathrm{hPa}$, with PC1 is also shown. The regions where the regression coefficient for $\frac{1}{f} \nabla \cdot \vec{F}$ increases towards the equator (and is expected to drive rising motion below) correspond well to the regions of anomalous $\bar{w}^{*}>0$.

The regression coefficient for $\left.\frac{\partial}{\partial t} T\right|_{\text {latent }}$ and PC1 is shown in Figure 3.5 (b). When the eddy-driven jet is displaced poleward there is increased latent heating at $60^{\circ} \mathrm{S}$ and decreased latent heating at $50-40^{\circ} \mathrm{S}$. The spatial pattern of the $\bar{w}^{*}$ anomalies is not consistent with being solely due to the the $\left.\frac{\partial}{\partial t} T\right|_{\text {latent }}$ anomalies, and it is concluded that the $\bar{w}^{*}$ anomalies must be at least partly eddy driven, as suggested by the $\frac{1}{f} \nabla \cdot \vec{F}$ anomalies. The $\bar{w}^{*}$ anomalies are not quite in quadrature with the $u$ anomalies. This is likely because the $\left.\frac{\partial}{\partial t} T\right|_{\text {latent }}$ anomalies contribute to $\bar{w}^{*}$ anomalies at the core of the jet. $\bar{w}^{*}$ anomalies in quadrature with the $u$ anomalies constitute a positive baroclinic feedback, as diagnosed in the model output above. A large portion of the $\bar{w}^{*}$ anomalies associated with a positive PC1 are in quadrature with the associated $u$ anomalies, and so it appears that there is a baroclinic feedback, which would act to redden the power spectrum of PC1. The diabatic heating processes in the real atmosphere are complicated, and it is perhaps not surprising that the $\bar{w}^{*}$ associated with a positive baroclinic feedback cannot be definitively ascer- 
tained from the climatological picture. However, examining the variability of $\bar{w}^{*}$ has revealed that such a feedback is manifest in the real atmosphere. Quantifying the importance of this feature is the subject of ongoing work.

\subsection{Discussion and Conclusions}

The characteristics of the leading mode of extra-tropical circulation variability have been examined in the context of recent theories that a positive baroclinic feedback results in the self-maintenance of eddy-driven jets (Robinson, 2006) and discourages the latitudinal movement of the jet (Gerber and Vallis, 2007). Given that the equivalent-barotropic westerlies are a consequence of there being a net eddy source region (Held, 1975), it may be expected that their variability be associated with changes in the eddy source region. A time series of the latitudinal displacement of the high-frequency eddy heat flux was shown to have most power at the longest time-scales, implying that generation of high-frequency eddies must be organised by the mean flow. When the jet is displaced poleward, so is the eddy heat flux, implying that eddies are generated poleward of the climatological position. Meridional propagation of these eddies aloft encourages the jet to remain displaced. This feedback is expected if baroclinic eddies tend to be born at the latitude of the eddy-driven jet stream. This in turn is expected if there exists a thermally indirect circulation that ensures that the largest meridional temperature gradient (and thus baroclinic instability) occurs at the jet core. It was first argued by Robinson (2006) that such a circulation follows from a local maximum in $\frac{1}{f} \nabla \cdot \vec{F}$ at the core of the jet in the upper troposphere. Then, by the conservation of mass and the principle of downward control, in the T.E.M. circulation there must be thermally indirect rising and cooling on the poleward flank of the jet and sinking and warming on the equatorward flank. It was shown that the strength of this circulation is directly related to the time-scale 
for persistence of the annular mode in a GCM, and appears to be important in the real atmosphere.

In this metric the annular modes are seen to be fundamentally the variability of a baroclinic storm-track, as discussed in e.g. Vallis and Gerber (2008). Because there is a degree of self-maintenance, the storm track can wander meridionally for prolonged periods. From this point of view it is not surprising that the NH does not exhibit genuine zonal symmetry, whereas the $\mathrm{SH}$ does, because the storm-track in the $\mathrm{NH}$ is broken by the location of continents. It also is expected that down-stream regions of a longitudinally localised storm-track exhibit the maximum variance, as this is where the eddies from upstream can influence where new eddies are most likely to be generated.

It is worth considering whether this baroclinic feedback is a fundamental feature of atmospheric circulation. From the arguments outlined above, the feedback is a result of the convergence of the meridional flux of momentum (due to meridional wave propagation) being confined to a narrower latitude band than the divergence of the downward flux of momentum (due to the heat flux form drag). Over a hemisphere, the meridionally-propagating eddies must have both source and sink (dissipation) latitudes, whereas the heat flux is generally one sign. So it is expected that the meridional momentum flux term has sharper meridional gradients than the vertical heat flux term. This means that the EP flux divergence will tend to have a local maximum where the meridional momentum flux term is maximum (at the core of the jet in the upper atmosphere) and the self-maintaining flow may be a feature that occurs in baroclinically unstable planetary atmospheres over a wide range of conditions. Indeed, these same dynamics may also be the cause of latitudinally localised storm-tracks in what would be a broad baroclinically unstable zone in the absence of a positive baroclinic feedback. 

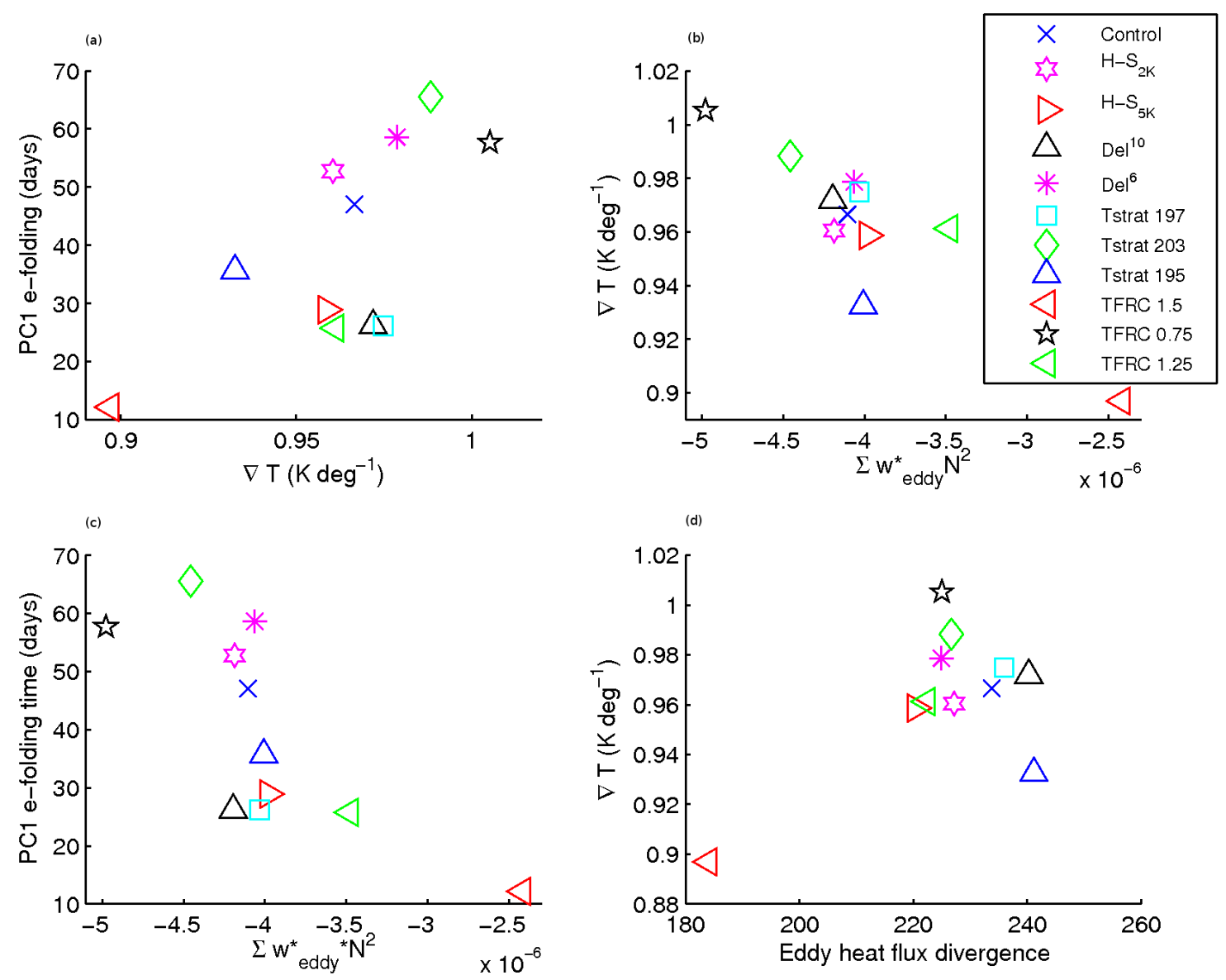

Figure 3.3: Comparison of a suite of model runs. Relative to the control run, in the H-S experiments, the subscripted value in the legend was added to $T_{e q}$ at the tropopause and stratosphere, and decreased to zero at the surface. In the Del experiments, the power of the hyperdiffusivity operator was changed to the superscripted value. In the Tstrat experiments $T_{e q}$ in the stratosphere was changed to the succeeding value. In the TFRC experiments the $e$-folding time of the linear drag operator was changed to the succeeding value. (a) The $e$-folding period of PC1 on the ordinate and the maximum value of $\nabla T(\max (\nabla T))$ on the abscissa. $(\mathrm{b})(\max (\nabla T))$ on the ordinate and the sum of the eddy-driven thermally indirect cooling $\left(\sum \bar{w}^{*} N^{2}\right.$, see text) on the abscissa. (c) $e$-folding period of $\mathrm{PC} 1$ on the ordinate and $\sum \bar{w}^{*} N^{2}$ on the abscissa. $(\mathrm{d})(\max (\nabla T))$ on the ordinate and $\sum-\frac{\partial}{\partial y} \overline{v^{\prime} T^{\prime}}$ on the poleward flank of the jet (see text) on the abscissa. 


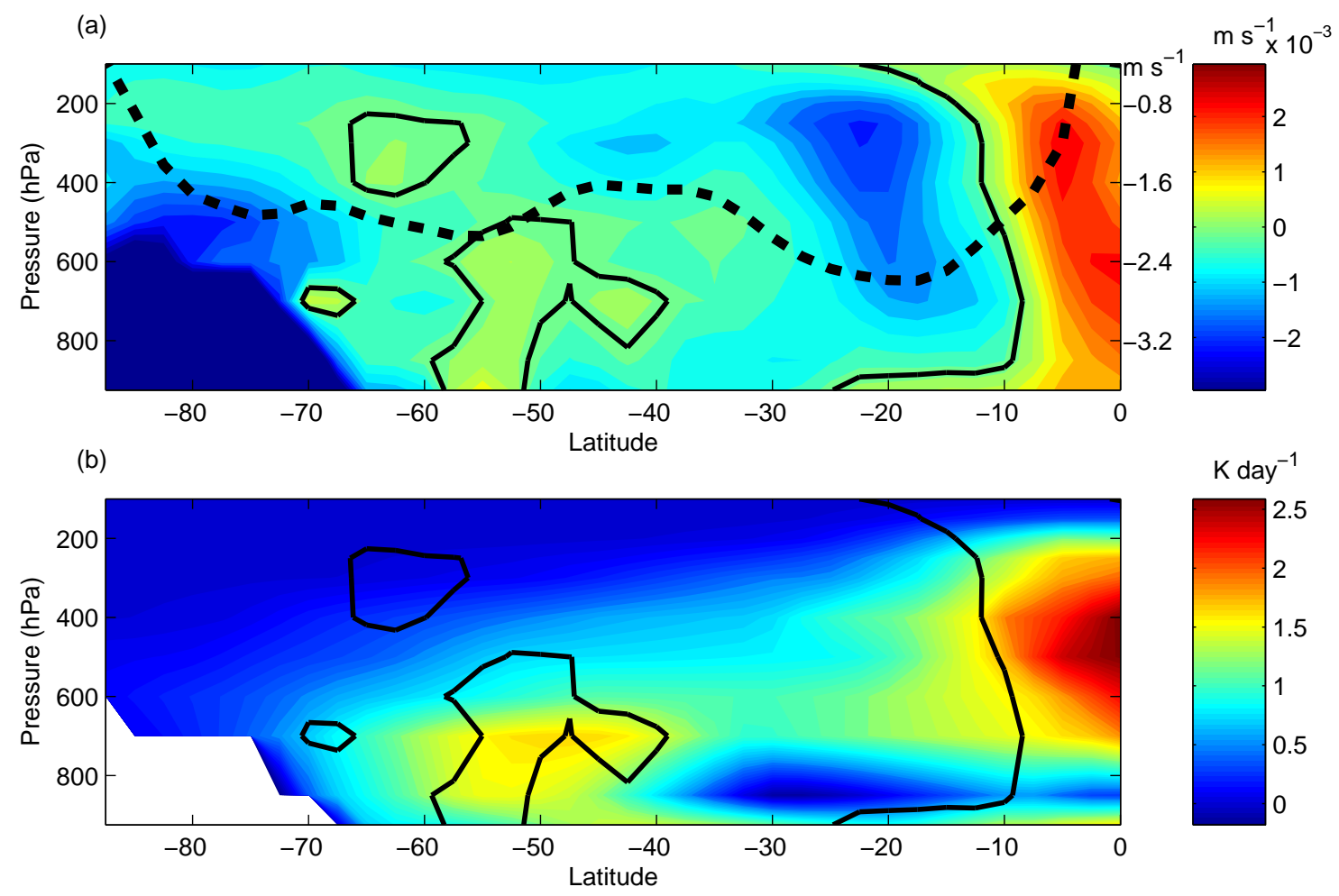

Figure 3.4: (a) The climatological mean $\bar{w}^{*}$ for the NCEP reanalysis data is shaded with the zero contour bolded. The dashed line shows the T.E.M. meridional velocity required to balance the Eliassen-Palm flux divergence $\left(\frac{1}{f} \nabla \cdot \vec{F}\right)$, see text). (b) the climatological mean temperature tendency due to latent heating $\left(\left.\frac{\partial}{\partial t} T\right|_{\text {latent }}\right)$. Also shown is the zero contour from panel (a). 


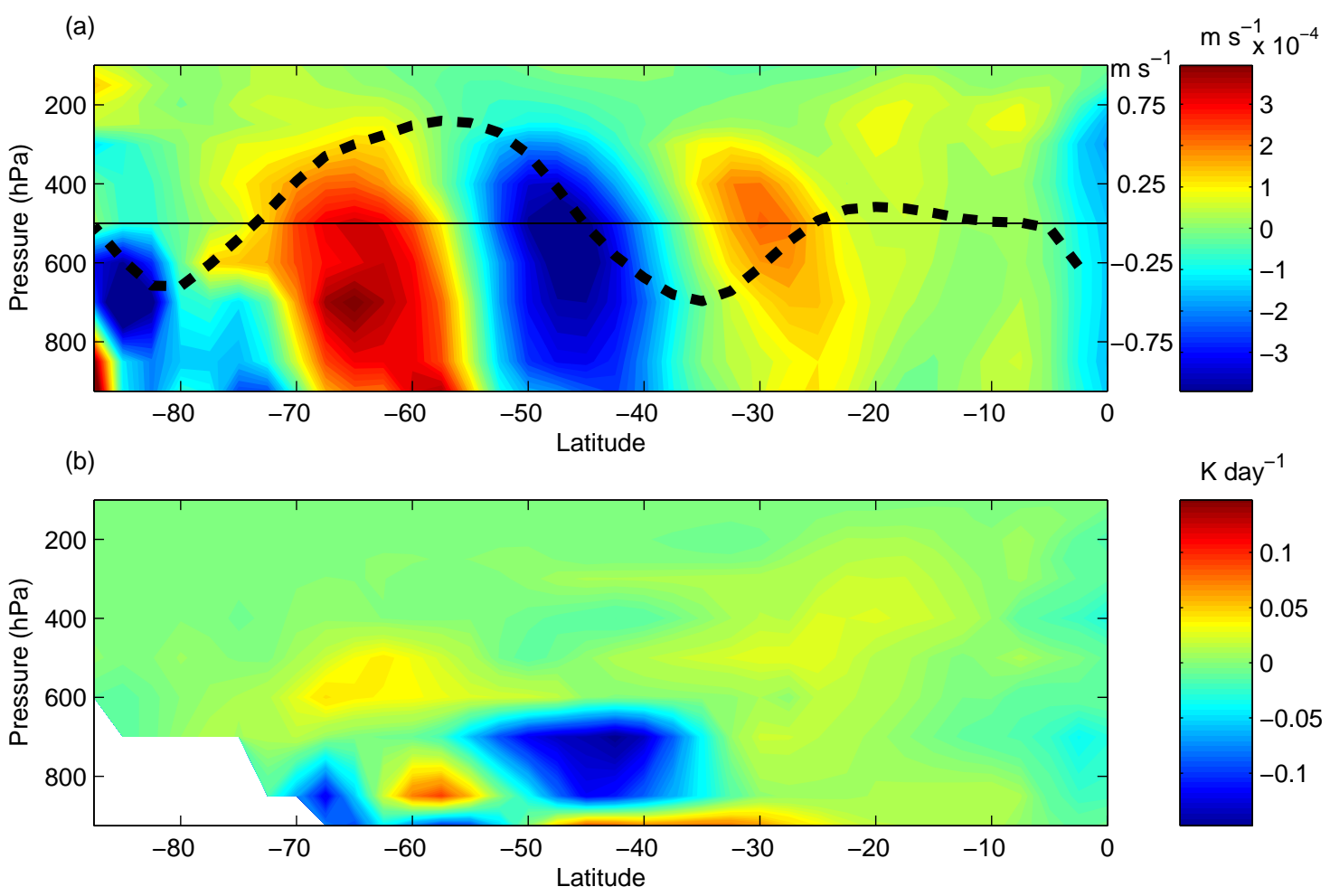

Figure 3.5: (a) The regression coefficient for $\bar{w}^{*}$ for the NCEP reanalysis data and PC1 is shaded. The dashed line shows the regression coefficient for $\frac{1}{f} \nabla \cdot \vec{F}$ averaged between 500-300 hPa and PC1. The solid horizontal line is the zero line for $\frac{1}{f} \nabla \cdot \vec{F}$ . (b) The regression coefficient for $\left.\frac{\partial}{\partial t} T\right|_{\text {latent }}$ and PC1. 


\section{Seasonality of the Southern Annular Mode}

\subsection{Introduction}

Here the focus is on the seasonality of the SAM in the latitude-longitude plane. The SAM is the variability of the background state and as such changes in that background state (and hence the mean jet position) are accompanied by changes in the SAM (Codron, 2005, 2007). In this chapter new results are presented that attempt to explain the causes of the seasonal variation in the background state. New results are also presented on the impact of the SAM on NZ climate.

Both the SAM and the NH counterpart the Northern Annular Mode (NAM), have considerable impacts on regional climate (Thompson and Wallace, 2001; Gillett et al., 2006; Hendon et al., 2007; Ummenhofer and England, 2007). Many of the regional impacts stem from the zonal asymmetry and the seasonality of the structure of the SAM. This is the case for precipitation over southeast South America (Silvestri and Vera, 2003), temperature and precipitation over Australia (Meneghini et al., 2007; Hendon et al., 2007) precipitation over western South Africa (Reason and Rouault, 2005), and temperature, precipitation, and sea ice formation over the Antarctic peninsula Lefebvre et al. (2004). The magnitude of SAM-related climate anomalies can be comparable to those associated with high latitude ENSO teleconnections (Meneghini et al., 2007). The trend in the SAM in recent decades (Marshall, 2003; Thompson and Solomon, 2002) explains much of the observed temperature trends at southern mid-high latitudes (Thompson and Solomon, 2002; 
Kwok and Comiso, 2002).

\subsection{Data and Methods}

The SAM is defined as the leading EOF of the $500 \mathrm{hPa} Z$ anomalies south of $20^{\circ} \mathrm{S}$, with PC1 employed as the time series.

The UK Met Office Hadley Centre HadISST V1.1 dataset was used to define the latitude of the sea-ice edge (Rayner et al., 1996) as the latitude where ice concentration reaches 15\% (Renwick, 2002).

In order to examine the effect of the SAM on NZ climate, data from 112 weather stations across NZ are utilized. The temperature $(T)$ data were recorded as daily maxima and the rainfall $(\mathrm{RF})$ data were recorded as total within a 24-hour period to 9 a.m. These have been averaged to give monthly values. In order to allow for the noisy nature of the station data, where they have been regressed on to the SAM timeseries, results were rejected when the probability that the true correlation between the two variables was zero (the p-value) was greater than 0.5. The justification for the high p-value is that the aim is to illustrate spatial patterns of response to the SAM, rather than to test statistical significance at individual stations. Throughout this chapter only 2 seasons are studied; summer designates months DJF, and winter JJA. These were chosen as they are the seasons when the SAM exhibits the greatest seasonal differences. 


\subsection{Results}

\subsubsection{Zonal Asymmetry and Seasonality of the SAM}

a. Overview of seasonality

Compared with the NAM, the SAM is more zonally symmetric and displays less seasonality in the troposphere (Thompson and Wallace, 2000). However, the SAM is not a pure zonal wave number zero $(k-0)$ oscillation. Kidson (1988) observed $k-3$ superposition, particularly at mid-latitudes, and that the location of the extrema of the $k$-3 component varied seasonally. Codron (2005) examined the seasonality of the SAM from the point of view of the basic state, in particular noting differences in the Pacific sector where during summer a single jet vacillates about the climatological mean, whereas during winter the split jet (Van Loon, 1972; Trenberth, 1991; BalsElsholz et al., 2001; Nakamura and Shimpo, 2004) leads to a dipolar oscillation of the wind-speed anomaly between the 2 favoured jet positions.

The seasonality of the structure of the SAM is shown in Figure 4.1, which is the regression coefficient of the monthly-mean geopotential height anomalies at $500 \mathrm{hPa}$ regressed onto the SAM index, during summer (a) and winter (b). That Figure 4.1 (a) and (b) utilise the same contour interval is indicative that the magnitude of the oscillation shows little seasonality. However, the structure shows marked differences between the seasons; the pattern is more zonally symmetric during summer than winter. To determine the relative importance of $k-0$ to $k-4$ in the regression patterns shown in Figure 4.1, Fourier decomposition was performed. The magnitudes of the $k$-0 to $k$-4 components were calculated for latitude circles from $35-75^{\circ} \mathrm{S}$, and the mean for an individual $k$ over those latitude circles is taken to represent the percentage of total SAM variance attributable to an individual $k$ (Table 4.1). The percentage of the variance attributable to individual $k>4$ was less than $7 \%$ for both seasons 
(not shown) and they have been omitted from the analysis. The principal feature elucidated in Table 4.1 is that a larger percentage of the pattern is due to $k$-2 and $k$-3 during winter than summer (nearly double), thereby confirming the visual observations from Figure 4.1.

(a)

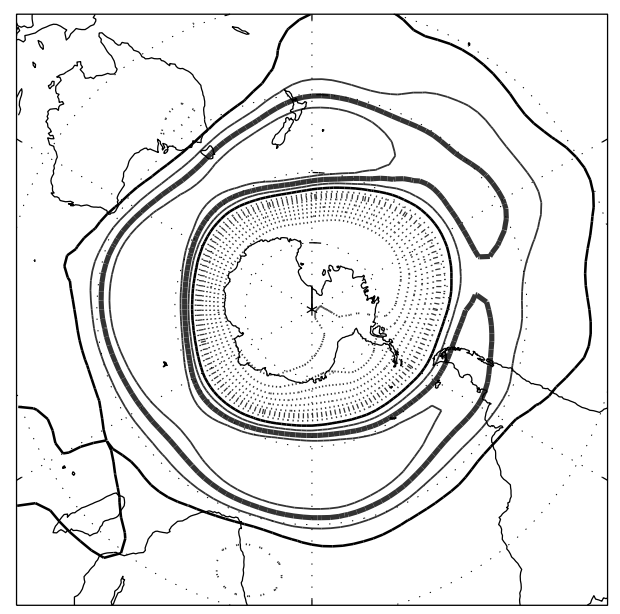

(b)

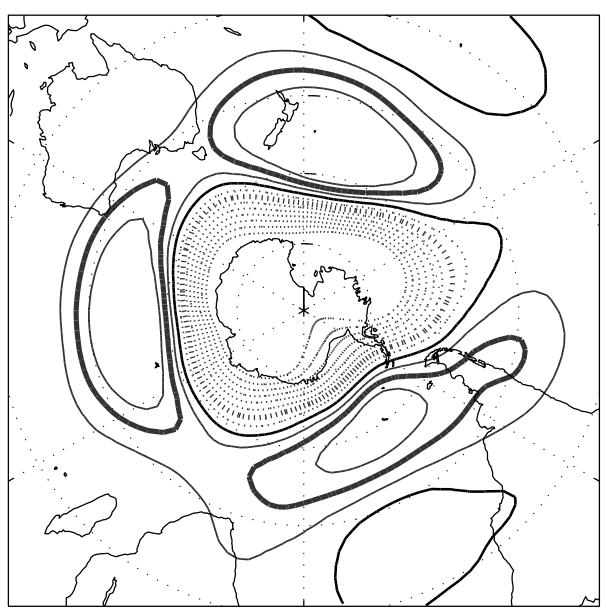

Figure 4.1: Regression coefficient for monthly mean $500 \mathrm{hPa}$ geopotential height anomalies and the southern annular mode (SAM) during summer (DJF, (a)) and winter (MJJ, (b)). The contour interval is $5 \mathrm{~m} \mathrm{std}^{-1}$ with the zero contour omitted and the $\pm 10 \mathrm{~m} \mathrm{std}^{-1}$ bolded.

The features that give rise to the zonal asymmetry in the SAM during winter are the troughs and weak meridional gradients at longitudes ca. $30^{\circ} \mathrm{E}, 110^{\circ} \mathrm{W}$ and $150^{\circ} \mathrm{E}$. The regression coefficient between the $500 \mathrm{hPa}$ wind-speed anomaly and the 
Table 4.1: The percentage of the total variance of the regression patterns shown in Figure 4.1 attributed to the first five Fourier components. Values have been averaged over latitudes $35-75^{\circ} \mathrm{S}$.

\begin{tabular}{r|rrrrr}
\multicolumn{7}{|c}{ Wave-number } & & \\
Season & 0 & 1 & 2 & 3 & 4 \\
\hline Summer & 61.3 & 11.2 & 8.4 & 5.4 & 6.9 \\
Winter & 49.7 & 12.9 & 11.1 & 14.7 & 6.3
\end{tabular}

SAM index is shown in Figure 4.2 for summer (a) and winter (b). The wind-speed anomalies are low in the same regions as the anomalous pressure gradient is low (Figure 4.1), as implied through geostrophic balance. The remainder of this section investigates the zonal symmetry during summer, and the causes of the small SAM related wind-speed anomalies at $110^{\circ} \mathrm{W}$ and $150^{\circ} \mathrm{E}$ during winter. The cause of the small SAM wind-speed anomalies at $30^{\circ} \mathrm{E}$ is beyond the scope of this study.

The correlation coefficient $(\mathrm{R})$ between the wind-speed anomaly and the SAM is shown in Figure 4.2 for summer (c) and for winter (d). During summer R is largely zonally symmetric, indicating that the SAM dictates the strength of the wind-speed anomalies to the same extent at most longitudes. The low values of $\mathrm{R}$ during winter coincide with the longitudes where the wind-speed anomalies associated with the SAM are weakest, indicating that the SAM has less impact on determining variability at these longitudes, as opposed to e.g. simply acting on a reduced background flow. The climatological wind-speed at $500 \mathrm{hPa}$, shown in Figure 4.3, is helpful for understanding the patterns of SAM activity seen in Figure 4.2. As seen in other studies (Van Loon, 1972; Trenberth, 1991; Nakamura and Shimpo, 2004) during summer there is a single jet that is largely zonally symmetric, whereas during winter the climatological mean jet splits at around $100^{\circ} \mathrm{E}$, with an associated wind-speed min- 
imum in the NZ region.

b. Summer zonal symmetry

(a)

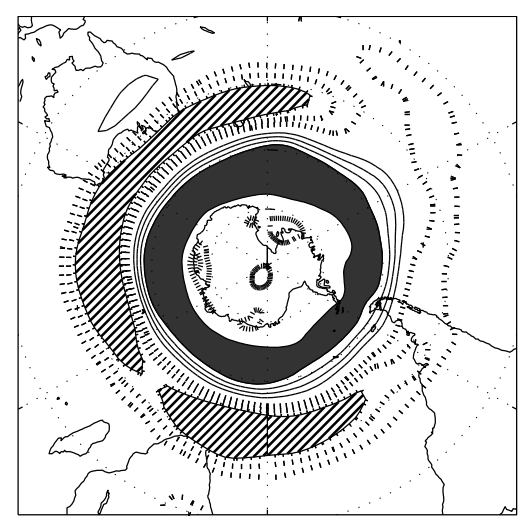

(c)

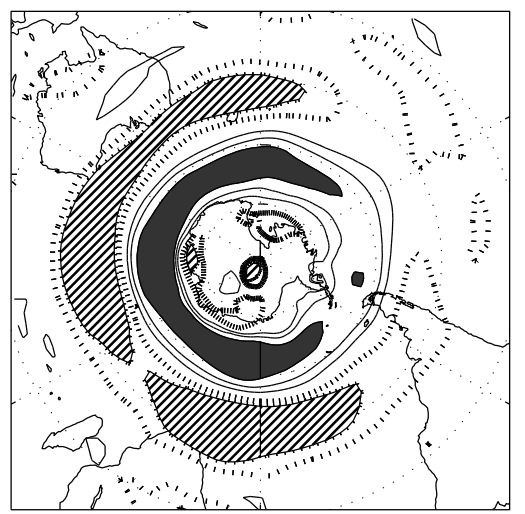

(b)

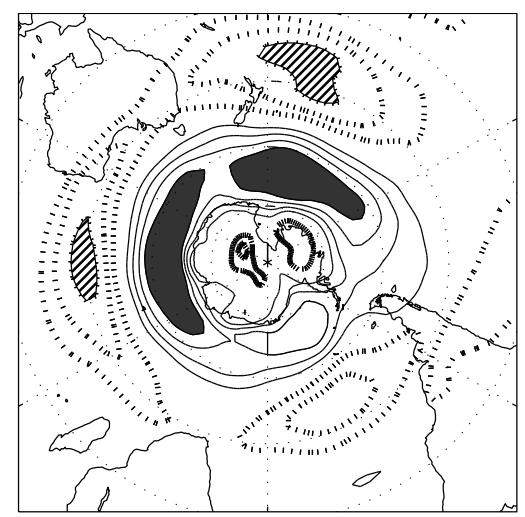

(d)

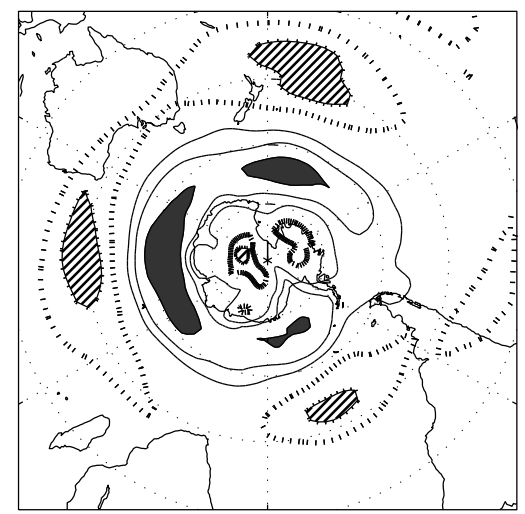

Figure 4.2: Regression coefficient for monthly mean wind-speed anomalies at 500 $\mathrm{hPa}$ and the SAM during summer (a) and winter (b). The contour interval is every $0.5 \mathrm{~m} \mathrm{~s}^{-1} \mathrm{std}^{-1}$ with negative values dashed and positive values solid and the zero contour omitted. The contours $\pm 1 \mathrm{~m} \mathrm{~s}^{-1} \mathrm{std}^{-1}$ are bold, and regions where the regression coefficient $<1.5 \mathrm{~m} \mathrm{~s}^{-1} \mathrm{std}^{-1}$ are hatched, and regions $>2 \mathrm{~m} \mathrm{~s}^{-1} \mathrm{std}^{-1}$ are shaded. Correlation coefficient (R) for the monthly mean wind-speed anomalies at $500 \mathrm{hPa}$ with the SAM during summer (c) and winter (d). Contour interval is every 0.2 with the zero contour omitted. $0.4>\mathrm{R}>0.6$ are hatched/shaded. 
During summer there is a single jet that is eddy-driven at all longitudes (Trenberth, 1991), and the SAM then manifests itself as a zonally symmetric oscillation, as expected when the mode arises due to interactions between transient eddies and the mean flow. While previous studies have investigated the causes of the zonal asymmetry seen in the background-state during winter (Bals-Elsholz et al., 2001; Sinclair, 1996; Inatsu and Hoskins, 2004), a reason for the increased zonal symmetry in summer has not been previously put forward. The mean baroclinicity between 700 and $850 \mathrm{hPa}$ during summer and winter is shown in Figure 4.4 (a) and (b) re-

(a)

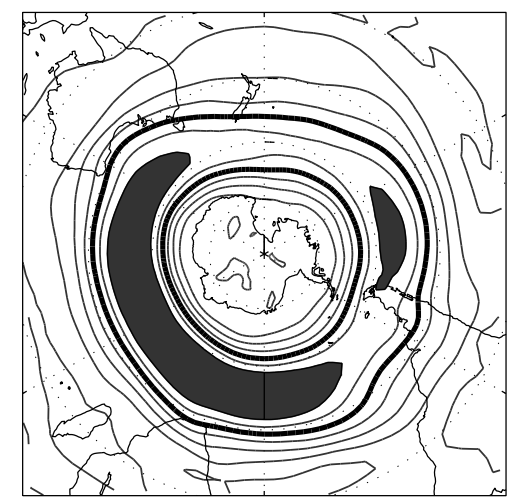

(b)

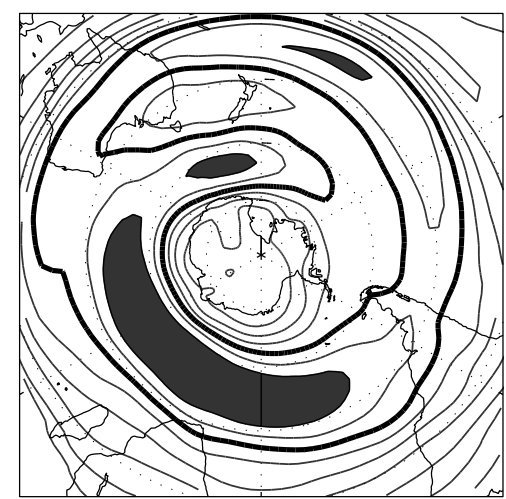

Figure 4.3: Mean windspeed at $500 \mathrm{hPa}$ during summer (a) and winter (b). Contours are every $3 \mathrm{~m} \mathrm{~s}^{-1}$ with the $15 \mathrm{~m} \mathrm{~s}^{-1}$ contour bolded and values over $21 \mathrm{~m} \mathrm{~s}-1$ shaded. 
spectively. As with the mean wind-speed, the situation during summer shows much greater zonal symmetry than during winter. The seasonal cycle is most pronounced over the Australian region, with high summertime baroclinicity over Australian continent and downstream over the South Pacific, which acts to move the baroclinic zones equatorward at these longitudes. At other longitudes the seasonal cycle of baroclinicity is less pronounced. The corresponding temperatures and meridional temperature gradients at $1000 \mathrm{hPa}$ are shown in Figure 4.4 (c)-(f) and go some way to explaining why the baroclinicity is more zonally symmetric during summer than winter. During summer the temperature over the mid-latitude continents is higher than the zonal-mean temperature, whereas during winter they are roughly equal to or less than the zonal-mean temperature. This arises because the seasonal cycle of temperature is much greater over landmasses than oceans due to the reduced heat capacity and transport at the surface (Hartmann, 1994). This has the effect that during summer the meridional temperature gradient is large at the southern flanks of the continents (Figure $4.4(\mathrm{e})$ ). This is most pronounced in the Australian region, likely because the cyclogenisis induced by the Andes and the South African plateau (Sinclair, 1996; Inatsu and Hoskins, 2004) occurs year-round, inducing a downstream jet, and constrains the meridional temperature gradient to show less latitudinal variation in these regions than in the Australian region. The high baroclinicity over the Australian region during summer induces an eddy-driven jet that is at the same latitudes as the southern flanks of the other continents, contributing to a zonally symmetric summertime climatology.

\section{c. Winter zonal asymmetry}

During winter the meridional temperature gradient is reduced at the southern flank of the continents, and subsequently the baroclinic zone moves south. This is most pronounced in the Australian region (see previous section). Without the baroclinic 
(a)

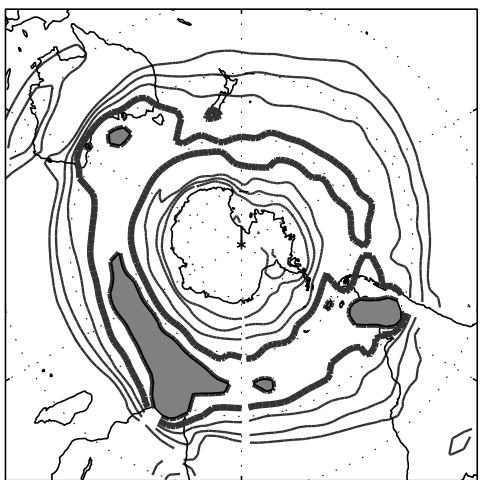

(c)

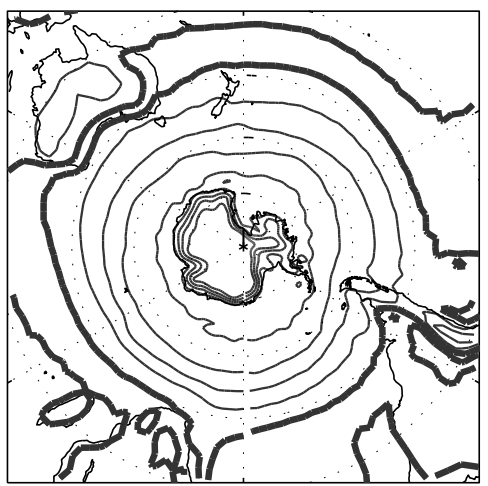

(e)

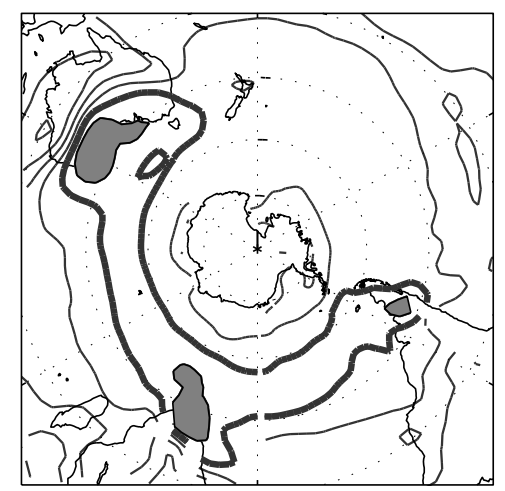

(b)

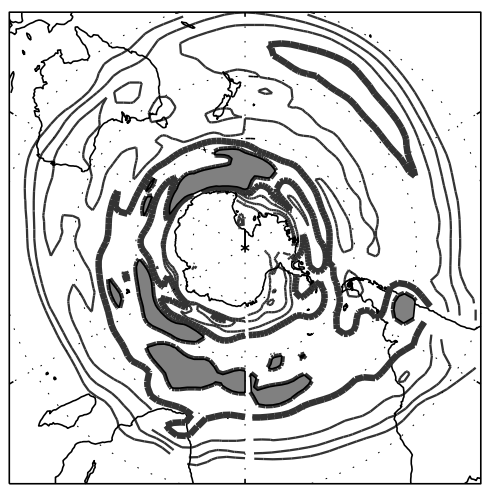

(d)

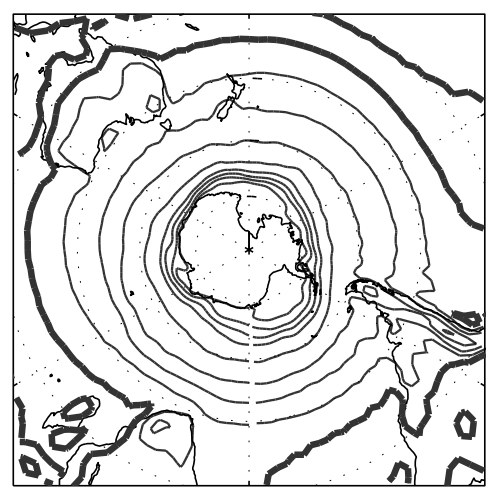

(f)

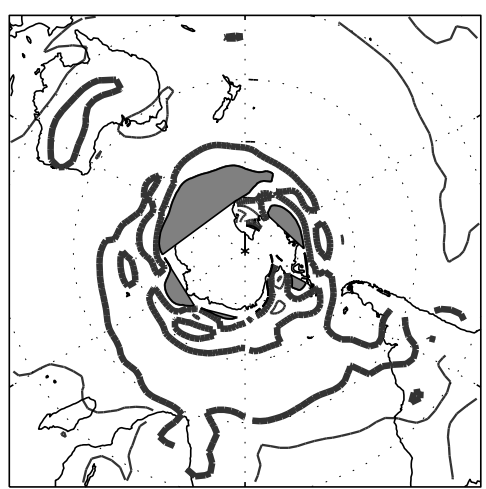

Figure 4.4: Mean baroclinicity between 700 and $850 \mathrm{hPa}$ during summer (a) and during winter (b). Contours are every 0.02 with the 0.1 contour bolded and values over 0.18 shaded. Mean temperature at $1000 \mathrm{hPa}$ during summer (c) and during winter (d). Contours are every $5^{\circ} \mathrm{C}$ with the $20^{\circ} \mathrm{C}$ and $25^{\circ} \mathrm{C}$ contours bolded. (e),(f) as (c),(d), but meridional gradient of temperature. Contours are every $3 * 10^{-6}{ }^{\circ} \mathrm{C}$ $\mathrm{m}^{-1}$ with the $6 * 10^{-6}{ }^{\circ} \mathrm{C} \mathrm{m} \mathrm{m}^{-1}$ contour bolded and values above $9 * 10^{-6}{ }^{\circ} \mathrm{C} \mathrm{m}^{-1}$ shaded. The zero contour is omitted. 
region to the south of Australia, the eddy-driven jet moves south in that region during winter. The existence of the thermally driven sub-tropical jet (STJ) then results in an apparent split jet (Figure 4.3). This separation may be augmented by Rossby waves initiated in the tropical Indian Ocean (Inatsu and Hoskins, 2004). The southern branch of the winter eddy-driven jet dies away in the southeast Pacific. It has been suggested by Nakamura and Fukamachi (2004) that this is because the STJ acts as a waveguide to upper level eddy activity. A reduction in upper level eddy activity entering the Pacific region leads to a reduction in seeding, or phase-locking opportunities between disturbances near the surface and those in the upper atmosphere, thereby diminishing baroclinic eddy generation, and preventing a vigorous eddy-driven jet forming across the Pacific (Nakamura and Shimpo, 2004). Therefore it seems the SAM is inactive near $110^{\circ} \mathrm{W}$ simply because there is no eddy-driven jet in the region which can vacillate. That the lack of a defined jet in the region is associated with a lack of eddy activity can be seen in analyses of SH wintertime eddy statistics, as in e.g. Trenberth (1991); Nakamura and Shimpo (2004); Hoskins and Hodges (2005).

A composite of the mean wind-speed for periods when the SAM was greater than 1 or less than -1 during winter is shown in Figure 4.5 and illustrates why the SAM is inactive near $150^{\circ}$ E. Figure 4.5 (a) shows the mean wind-speed for positive phases of the SAM. When the SAM is positive the eddy-driven jet is clearly separated from the thermally driven STJ, and the eddy-driven jet extends across the South Pacific. When the SAM is negative (Figure $4.5(\mathrm{~b})$ ) the eddy-driven jet moves north, blending into the STJ. This point was made by Codron (2007), who further found that the strength of the eddy-driven jet in the Pacific sector was partly forced by the phase of the SAM in the Indian Ocean sector. However, at ca. $150^{\circ} \mathrm{E}$ there remains a local wind-speed maximum, which is the reason the SAM appears inactive at these longitudes. 
The feature is apparent throughout the depth of the troposphere (not shown). The local maximum is located immediately equatorward of the mean sea-ice edge, and the sea-ice edge has a somewhat protruded shape there. Qualitative insight into the dynamics underlying this phenomenon can be gained by examining the mean wintertime near-surface wind-speed and the gradient of the surface temperature normal to the local wind-direction, shown in Figure 4.6 (a) and (b) respectively. Figure 4.6 (a) suggests that the sea-ice edge protrudes because the katabatic flows over the Antarctic continent maximise with a northward flow at ca. $150-160^{\circ} \mathrm{E}$ at high latitudes (Parish and Walker, 2006), where the sea-ice boundary is displaced equatorward. As seen in Figure 4.6 (b) the convergent flow leads to the gradient of surface temperature perpendicular to the local wind-speed being a maximum at ca. $150^{\circ} \mathrm{E}$, which would drive vertical wind shear thereby inducing a local jet (BalsElsholz et al., 2001). The temperature advection associated with outflow from the Antarctic continent is also seen at $500 \mathrm{hPa}$ (not shown), and the fact that this drives increased westerlies above explains why the local wind-speed maximum is also seen at the tropopause height of ca. $300 \mathrm{hPa}$ (not shown).

In explaining why this local wind-speed maximum results in inactivity in the SAM it is important to note that in the Pacific sector during winter the SAM is associated with a dipolar oscillation between the eddy-driven jet and the STJ (Codron, 2007). However, the local wind-speed maximum in the eddy-driven jet at $150^{\circ} \mathrm{E}$ is induced by the Antarctic katabatic flow, which is present regardless of the phase of the SAM, and therefore the eddy-driven jet in the region does not exhibit SAM-induced wind-speed anomalies to the same extent as at other longitudes. It is posited that the dipolar behaviour arises because the flow at the entry to the STJ is thermally forced (Vallis, 2006), and so does not exhibit vacillations associated with the SAM. Therefore as the eddy-driven jet migrates equatorward over the Indian Ocean and approaches the latitude of the STJ, the STJ acts as a waveguide to the eddy-driven 
jet baroclinic eddies (Hartmann and Lo, 1998; Nakamura and Fukamachi, 2004) and the eddy-driven jet becomes merged with the STJ. Meridional propagation of eddies downstream in the STJ then will cause momentum flux convergence, and the observed increase in wind-speed associated with the negative phase of the SAM. Because the wind-speed maximum in the eddy-driven jet at $150^{\circ} \mathrm{E}$ is not eddydriven in the same sense as elsewhere in the storm-track, it is not subject to the same meridional vacillations.

\subsubsection{Impacts of the SAM on NZ climate}

The influence that the seasonal changes in the large-scale flow and the SAM have on regional climate are now investigated by taking New Zealand as an example. NZ is well situated for this means as (i) it lies in the region where the SAM displays the largest seasonality, and (ii) the orography of NZ results in strong dependence of climate anomalies on wind-speed and direction (Kidson, 2000).

The near-surface wind anomalies composited for SAM $>1$ are shown in Figure 4.7 for summer (a) and winter (b). The relationship between the SAM and NZ winds is approximately linear, and so only the anomalies for the positive phase are shown for brevity. Being in the mid-latitudes, the climatological surface winds in the NZ region are westerly, and the impact of the SAM on NZ climate is explained as the anomalous departure from the climatological westerlies. During summer when the SAM is positive there is an easterly wind anomaly across the entire country. During winter the wind anomaly is north-easterly over the North Island (NI), but becomes progressively north-westerly towards the south of the South Island (SI). Comparison with Figure 4.1 reveals that the near-surface wind anomalies are in approximate geostrophic balance with the $Z$ anomalies at $500 \mathrm{hPa}$, as expected with an equivalent barotropic mode of variability. As well as these flow anomalies 
the results of Sinclair et al. (1997) are born in mind, which show that cyclone density anomalies closely follow the spatial patterns in Figure 4.1, such that there are fewer cyclones occupying the anomalous high pressure area in the region of NZ when the SAM is positive. The impact of these features on NZ climate is examined using the regression coefficient for precipitation and temperature anomalies and the SAM index.

(a)

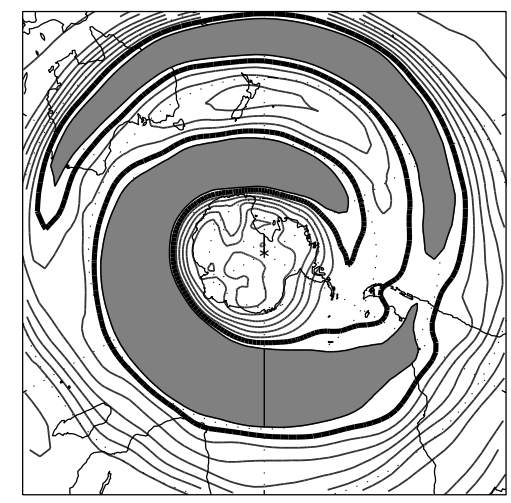

(b)

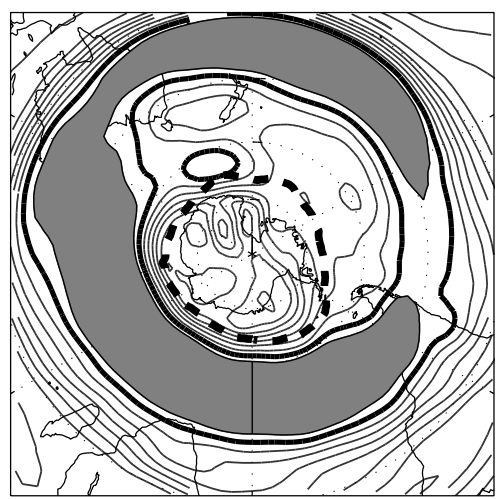

Figure 4.5: Composite wind-speed at $500 \mathrm{hPa}$ during winter for the positive SAM phase (greater than the standard deviation, $\sigma$ ), (a) and the negative SAM phase $(<-\sigma)$, (b). Contours are every $2 \mathrm{~m} \mathrm{~s}^{-1}$, with the $16 \mathrm{~m} \mathrm{~s}^{-1}$ contour bolded and values over $18 \mathrm{~m} \mathrm{~s}^{-1}$ shaded. The latitude of the mean sea-ice edge during winter is shown in heavy dashed in (b). 
Figure 4.8 shows the regression coefficients for RF and the SAM for summer and winter. During summer RF was less when the SAM was positive over the majority of the country, except in the far north and east coast of the NI, and the north and northeast coast of the SI. A general reduction in RF would be expected because there were fewer cyclones and more anticyclones in the region (Sinclair et al., 1997). The positive anomalies therefore require further explanation. The positive anomaly

(a)

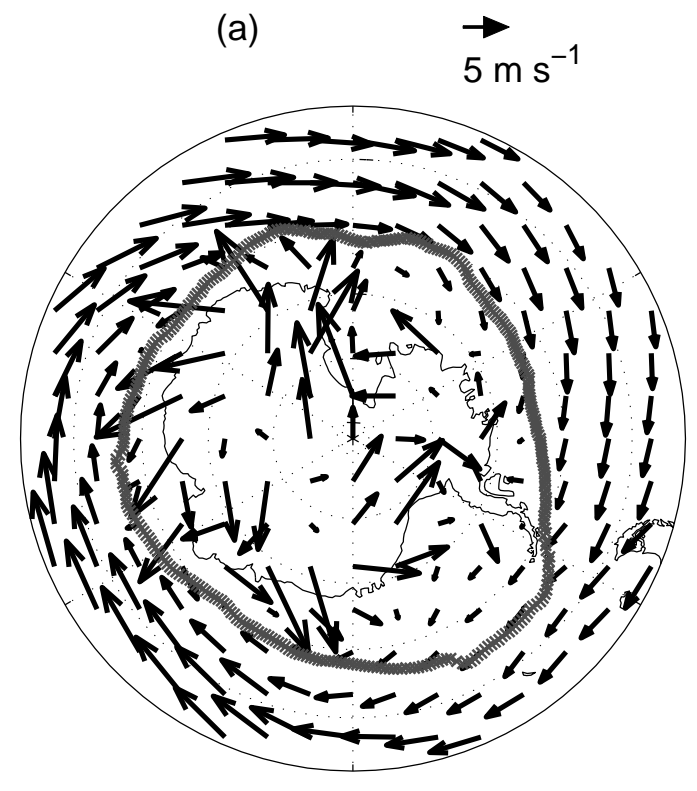

(b)

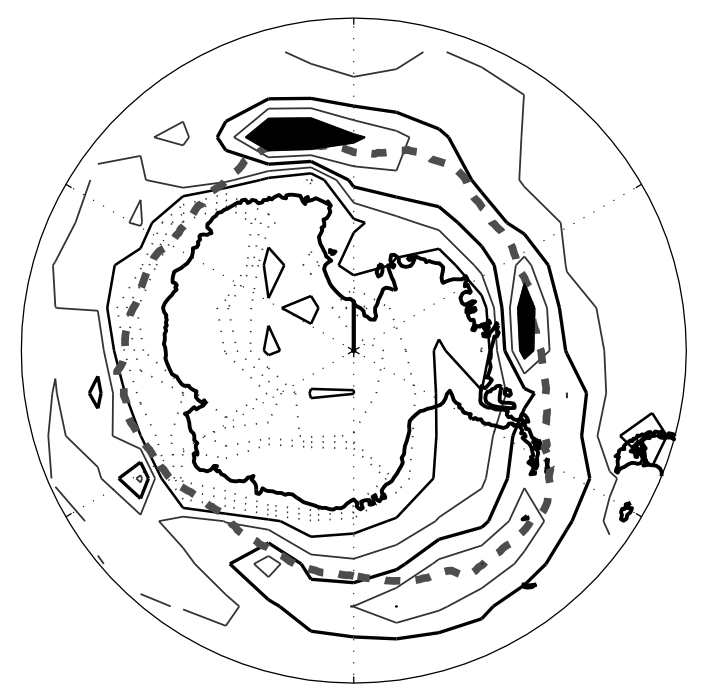

Figure 4.6: (a) Vectors of mean wintertime wind. (b) Cross product of the gradient of mean wintertime surface temperature with a unit vector parallel to the local wind direction. Contours are every $3.8^{*} 10^{-4}{ }^{\circ} \mathrm{C} \mathrm{m} \mathrm{m}^{-1}$ with the zero contour omitted. Values greater than $14^{*} 10^{-4}{ }^{\circ} \mathrm{C} \mathrm{m}^{-1}$ are shaded. In both plots the latitude of the mean wintertime sea ice edge is dashed bold. 
in the far north of the NI may be because the RF in the area is characterised more by convective systems than the rest of the country (Kidson, 2000), and convection may be enhanced during the positive phase of the SAM if the increased anticyclone density leads to reduced cloudiness and increased radiation, and this destabilising forcing overcomes any increased large scale subsidence. The positive anomalies on the east coast of the NI, and northeast coast of the SI are explained by the topography of NZ inducing a rain-shadow effect. With a positive SAM and northeast flow anomaly there is reduced orographic subsidence of dry air along the east coast and so rainfall is more likely. Conversely when the SAM is negative there is a

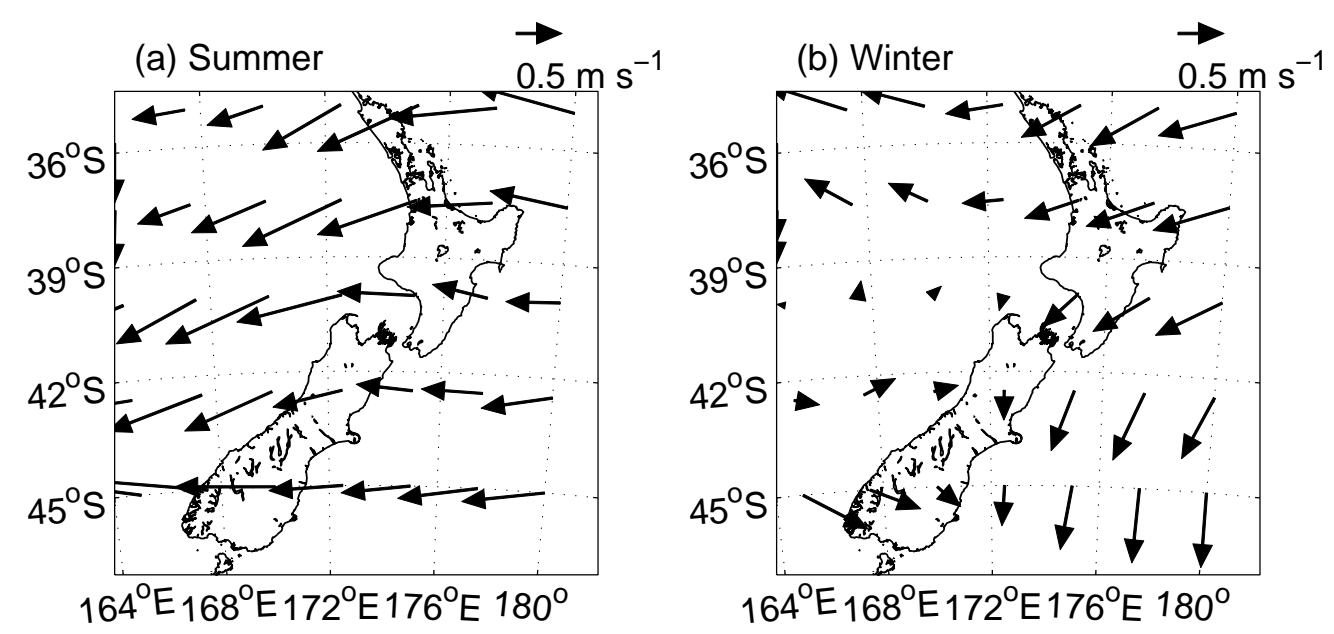

Figure 4.7: Near-surface wind anomaly vectors for SAM $>1$ during summer (a) and winter (b). 
southwest flow anomaly, and the rain-shadow effect gives reduced RF. It is unclear why this is not seen in the southeast of the SI. However the coefficients are generally close to zero in this area, indicating there is no strong effect.

During winter the same orographic effects came into play as during summer, but the NW flow anomaly over the south of the SI is seen to be associated with a positive $\mathrm{RF}$ anomaly on the west coast and negative on the east coast.

Hence a rain-shadow effect was seen for the entire year, so that during summer the west coast received less RF when the SAM was positive and the east coast received less RF when the SAM was negative, but during winter this was reversed for the south island due to a more north-south than east-west flow anomaly.

Figure 4.9 shows the slope of the regression for $T$ and the SAM index for summer and winter. During summer there is a positive correlation for the majority of the country, with the largest effect on the west coast of the SI, and a negative correlation on the east coast in the middle of the country. This is consistent with a Föhn wind effect the lapse rate is higher on the leeward side of mountains due to reduced moisture content, and so at a given height the temperature is higher on the leeward side. This is not seen as strongly in the north of the NI because there is less orographic forcing there. The Föhn wind effect is qualitatively similar to the impact of the SAM on temperatures on the Antarctic Peninsula (Marshall et al., 2006; Orr et al., 2008; van Lipzig et al., 2008).

During winter there are positive $T$ anomalies across the entire country when the SAM is positive. There is a northerly component to the flow anomaly during winter, which would be associated with direct temperature advection, leading to a positive temperature anomaly. The anomalous high pressure over the county would also be associated with increased solar radiation, and these two effects clearly overwhelm 
any Föhn wind effect during winter.

The large-scale seasonality of the SAM may be expected to give rise to seasonal variability in the modes of variation of NZ climate. This is investigated this using the second EOF of $T$ anomalies, which is shown in Figure 4.10. The EOF values are positive in the west of the country and negative in the east, which, given the orographic effects already described, is consistent with variations in the strength of the westerly winds. The first EOF (not shown) has the same sign everywhere, which is to be expected because a change in the north-south flow is associated with direct temperature advection and so has the largest impact on temperature. Con-

(a) summer

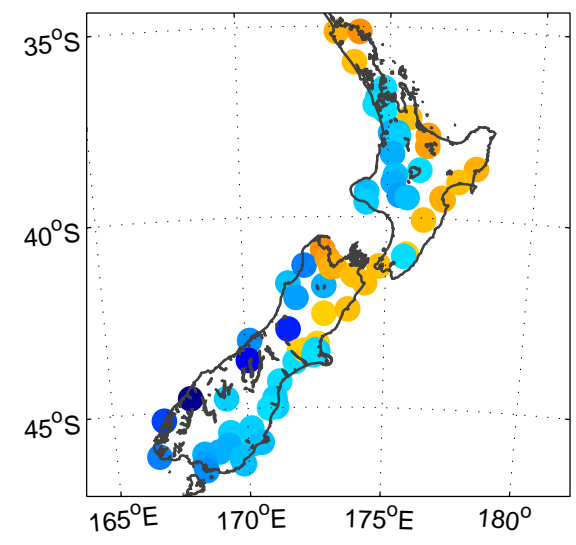

(b) winter

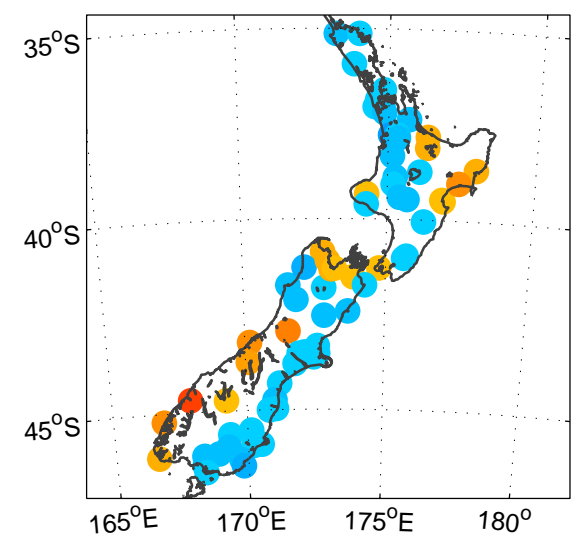

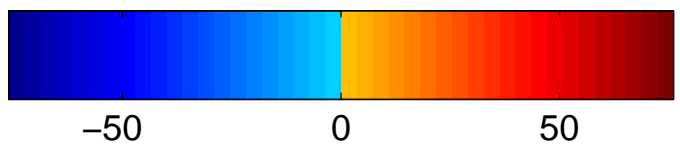

$\mathrm{mm}$ month $^{-1} \mathrm{std}^{-1}$

Figure 4.8: Regression coefficients of monthly total rainfall anomalies and the SAM index during summer (a) and winter (b). 
sistent with the large-scale seasonal changes in the SAM, the SAM was significantly correlated with the principal component of the second EOF (PC2) during summer $(R=0.52)$, but not during winter $(\mathrm{R}=0.08)$. Moreover the variance of the PC2 shows distinct seasonality consistent with that expected due to the SAM. When normalised by the average variance for all months, the variance during summer was 1.43, whereas during winter it was 0.33 . This is consistent with the notion that the seasonality of the SAM influences the seasonality of the variability of NZ surface climate.

(a) summer

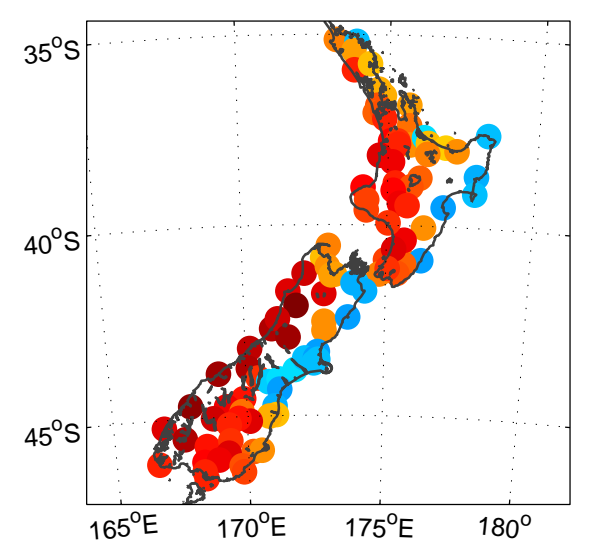

(b) winter

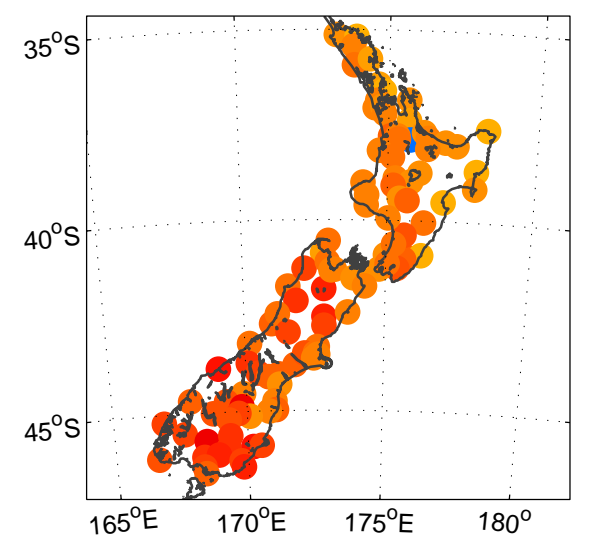

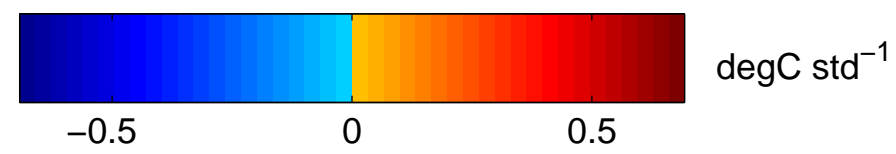

Figure 4.9: Regression coefficients of monthly-mean maximum temperature anomalies and the SAM index during summer (a) and winter (b). 


\subsection{Discussion and Conclusions}

As has previously been pointed out, the spatial structure of the SAM shows distinct seasonality. This is expected as the SAM is an oscillation of the atmospheric cir-

culation about the seasonally varying time-mean state. Here it has been suggested that the seasonality of the surface temperature of Australia induces increased zonal symmetry in the mean wind-speed during summer relative to winter, resulting in a more zonally symmetric SAM. During winter the SAM acquires a greater $k-2-3$ component, which is due to (i) the lack of an eddy-driven jet in the southeast pacific,

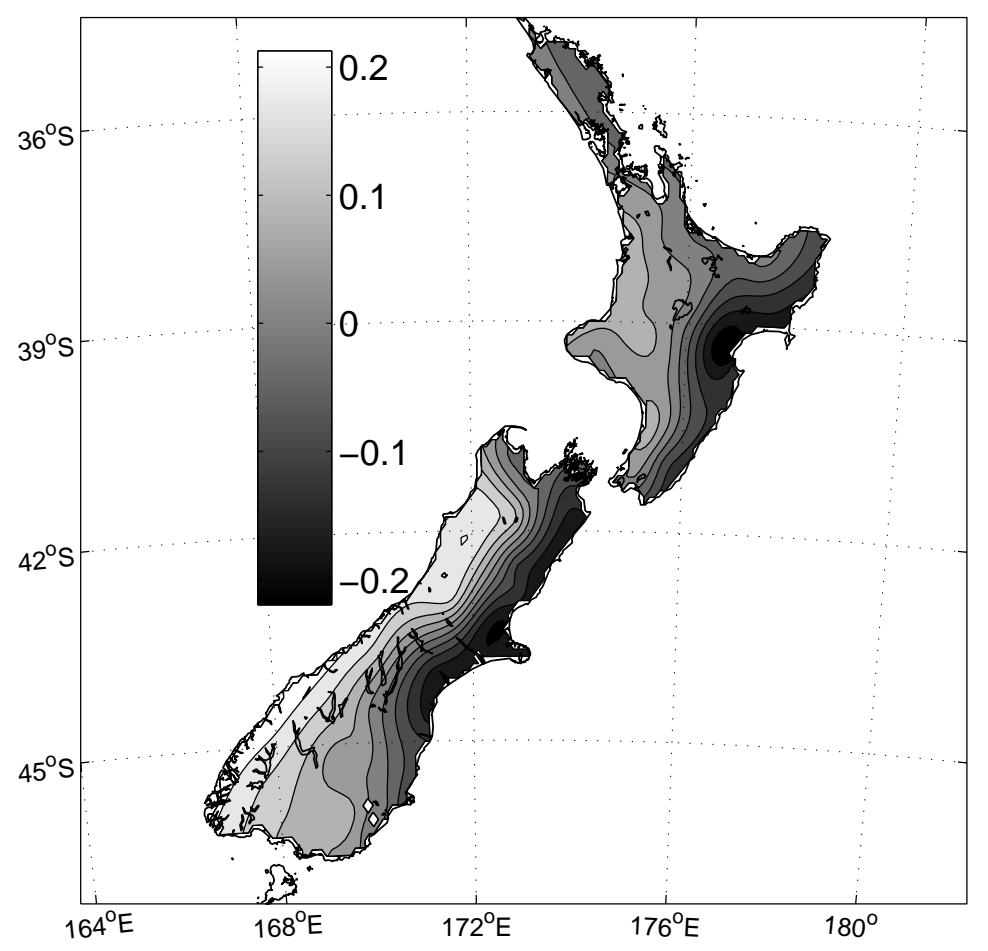

Figure 4.10: The second EOF of monthly mean station data temperature anomalies. 
and (ii) a lack of vacillation in the wind-field with the SAM at ca. $150^{\circ} \mathrm{E}$ because it is forced by the large horizontal temperature gradient induced by the Antarctic katabatic winds, which are present regardless of the phase of the SAM. The lack of SAM activity at ca. $30^{\circ} \mathrm{E}$ has not been addressed.

For the NZ region this seasonality implies that during summer the SAM is associated with an approximately east-west wind-speed anomaly whereas during winter the SAM is associated with a more north-south wind-speed anomaly. These seasonal differences in the large-scale structure of the SAM were clearly discernable in the $T$ and RF station data because of the large impact of orography upon NZ surface climate. Moreover the EOF of $T$ corresponding to a zonal wind-speed anomaly was much more significantly correlated with the SAM, and had over four times more variance during summer than winter, which is consistent with the notion that the seasonality of the SAM impacts the variability of the regional climate. 


\section{Inter-Annual Variability of the Southern Annu- lar Mode: the Impact of the El-Niño Southern Oscillation}

\subsection{Introduction}

The El Niño Southern Oscillation (ENSO) is observed to have far-reaching teleconnections (Bjerknes, 1969, 1972; Yulaeva and Wallace, 1994; Kidson and Renwick, 2002). This chapter presents new results and ideas on the mechanism of these teleconnections; it is suggested that a zonally asymmetric forcing in the mid-latitudes can induce a zonally symmetric response.

The primary mechanism of ENSO teleconnections are Rossby waves (Horel and Wallace, 1981; Mo and White, 1985; Karoly, 1989). The waves are initiated by vorticity sources arising from anomalous divergence in the tropical upper-troposphere (Sardeshmukh and Hoskins, 1988), and propagate meridionally across the Pacific region to higher latitudes (Hoskins and Ambrizzi, 1993). The resulting stationary circulation anomalies are sometimes called the Pacific North American and Pacific South American patterns (PNA and PSA respectively, (Horel and Wallace, 1981; Renwick and Wallace, 1996; Mo, 2000)).

It is also observed that in addition to the zonally asymmetric wave-like teleconnection, during some seasons there is a zonally symmetric extratropical response to ENSO (Karoly, 1989; Seager et al., 2003; L'Heureux and Thompson, 2006; Chen 
et al., 2008; Lu et al., 2008). This is particularly true in the SH during austral summer (Karoly, 1989). L'Heureux and Thompson (2006) have pointed out that during austral summer the teleconnection influences the phase of the SAM; La Niña events are generally associated with a poleward shift of the eddy-driven jet stream, or positive SAM, and El Niño events are associated with a negative SAM. Fogt and Bromwich (2006) point out that there may be decadal variability in the strength of this teleconnection.

To date, investigations into the dynamics behind the zonally symmetric response of the mid-latitudes to ENSO have taken the view that a zonally symmetric ENSO signal in the sub-tropics affects mid-latitude eddy propagation and dissipation characteristics (Robinson, 2002; Seager et al., 2003; L'Heureux and Thompson, 2006; Chen et al., 2008; Lu et al., 2008). Specifically, it is argued that during La Niña events the deep tropics are anomalously cool, reducing the strength of the thermally driven STJ. Because mid-latitude eddies dissipate approximately where their phase speed $(c)$ equals the background zonal wind-speed (Randel and Held, 1991), equatorward propagating eddies must then dissipate at higher latitudes. Where these eddies dissipate, they exert an easterly torque (Vallis, 2006), and can thereby be expected to shift the low-latitude surface easterlies poleward. It is argued that the poleward shift of the eddy dissipation region moves the upper level disturbances poleward. This shifts the opportunities for phase-locking between disturbances in the upper and lower troposphere, and so the region of baroclinic eddy generation. The eddy source region and the eddy-driven jet stream thus shift poleward (Chen and Held, 2007; Chen et al., 2008; Lu et al., 2008)).

Here evidence is presented that the zonally symmetric mid-latitude response to ENSO may not be caused by a zonally symmetric sub-tropical forcing, but by internal (to the mid-latitudes) wave-mean flow dynamics that are forced by the zonally 
asymmetric Rossby wave teleconnection. The work is motivated by the following observations: the eddy propagation model described above can not easily incorporate the fact that the degree of zonal symmetry in the mid-latitudes is strongly dependent on seasons (Karoly, 1989; Seager et al., 2003; L'Heureux and Thompson, 2006); zonally symmetric modes of (mid-latitude) climate variability do not necessarily require zonally symmetric forcing (Chapter 3); and as will be pointed out, the tropical ENSO signal does not in fact exhibit genuine zonal symmetry on the time-scale that the SAM is impacted. This chapter develops the arguments of Hoerling and Ting (1994), and Bhaskaran and Mullan (2003), who find that the mid-latitude transient eddy response to ENSO is driven by the stationary Rossby wave emanating from the tropics, as has also been suggested in (Robinson, 2007). Analysis is focused on the SH during austral summer because, as noted in Karoly (1989) and Seager et al. (2003), that is when the strongest zonally symmetric response to ENSO is observed.

\subsection{Data and methods}

The southern oscillation index (SOI, (Troup, 1965; Mullan, 1995)) is used as a timeseries of ENSO, smoothed with a five-month running mean to reduce noise.

Seasonally averaged (DJF, MAM, JJA or SON) composite fields are used. The El Niño (La Niña) composites are taken as the four years when the seasonally averaged SOI was lowest (highest). This gives a threshold of the SOI for composite phases that varies by season. E.g. for the summer (DJF) season, El Niño and La Niña conditions were taken as occurring when the (seasonally averaged) SOI $<-1.2$, and when the SOI $>1$, respectively (the different values being due to the negative skewness of the SOI; (Mullan, 1995)). The summertime El Niño events occurred during 1982/3, 1986/7, 1991/2 and 1997/8, and the La Niña events during 1988/9, 1998/9, 
1999/2000 and 2000/1. In order to include the full effect of any non-linearity, the climatological mean field was not removed. Instead the composites were calculated as the difference between the mean during the appropriate ENSO events and the mean during quiescent (i.e. non-El Niño or La Niña) periods.

A daily time-series of the strength of the forcing of the ENSO stationary wave in the tropics was obtained by projecting the daily-mean $u$ at $300 \mathrm{hPa}$ onto the mean La Niña $u$ anomaly in the region bounded by the equator, $30^{\circ} \mathrm{S}$, the dateline, and $115^{\circ} \mathrm{W}$. The resulting time-series is referred to as $T S_{n i n a}$. This represents the strength of the cyclonic circulation anomaly in the region due to anomalous upperlevel convergence during La Niña events (Yulaeva and Wallace, 1994).

In order to examine the development of mid-latitude circulation anomalies associated with the tropical forcing, $T S_{\text {nina }}$ is used to construct lead-lag composites. The lagzero $\left(\operatorname{lag}_{0}\right)$ day of the composites is taken as all days during NDJF when $T S_{\text {nina }}>2 \sigma$ (standard deviations), giving $74 \operatorname{lag}_{0}$ days. The summer period is extended to include November in order to increase the sample size, and because the ENSO teleconnection is observed to first impact the SAM during November (L'Heureux and Thompson, 2006). A justification for the high threshold of $T S_{\text {nina }}$ for $\operatorname{lag}_{0}$ days is that it is difficult to decipher the high-frequency response to a low-frequency forcing, but by looking only at very strong forcing events, one is able to at least get a qualitative picture of development. $T S_{\text {nina }}$ has an $e$-folding time of 30 days, implying that some $\operatorname{lag}_{0}$ days will not represent separate events. Justification for not having explicitly separated events is provided later, when considering the variation of $T S_{\text {nina }}$ over the lead-lag composites.

The SAM time-series is defined as the projection of daily $850 \mathrm{hPa}$ geopotential height $\left(Z_{850}\right)$ anomalies onto the leading EOF of monthly-mean $Z_{850}$ anomalies. 
To obtain the high-frequecy anomalies the data was filtered using a 5th order Butterworth high-pass filter with a cutoff of 8 days.

\subsection{Results}

\subsubsection{Review of the seasonality of the Southern Hemisphere response to ENSO}

In order to clarify some aspects of the impact of ENSO on the general circulation, a review of the seasonality of the low-frequency SH response is presented. Particular attention is paid to the response during summer (DJF) because that is when there is the highest degree of zonal symmetry (Karoly, 1989; Seager et al., 2003).

Comparison of the anomalous $300 \mathrm{hPa}$ temperature $(T)$ during La Niña and El Niño (Figure 5.1 (a) and (b) respectively) reveals a high degree of linearity in the response to ENSO, particularly at low latitudes, as seen in e.g. Bradley et al. (1987). During both La Niña and El Niño events, the tropical $T$ anomaly is strongest in the Pacific, and has the same sign in the Atlantic region. Over the Indonesian region however, it has opposite sign, and so is not zonally symmetric in the tropics. The signal becomes progressively more zonally symmetric at higher latitudes, particularly for the La Niña composite.

The 300 hPa $u$ anomalies for the same La Niña and El Niño periods (Figure 5.1 (c) and (d)) are more zonally symmetric than the corresponding $T$ anomalies at low latitudes, and similarly symmetric to the corresponding $T$ anomalies at high latitudes. At low-latitudes it can be seen that e.g. the same $u$ anomaly is manifest on the poleward flank of a warm $T$ anomaly, as is on the equatorward flank of a cold $T$ anomaly (c.f. Figure 5.1 (b) and (d) in the region from $90^{\circ} \mathrm{E}$ to $120^{\circ} \mathrm{W}$ at low 

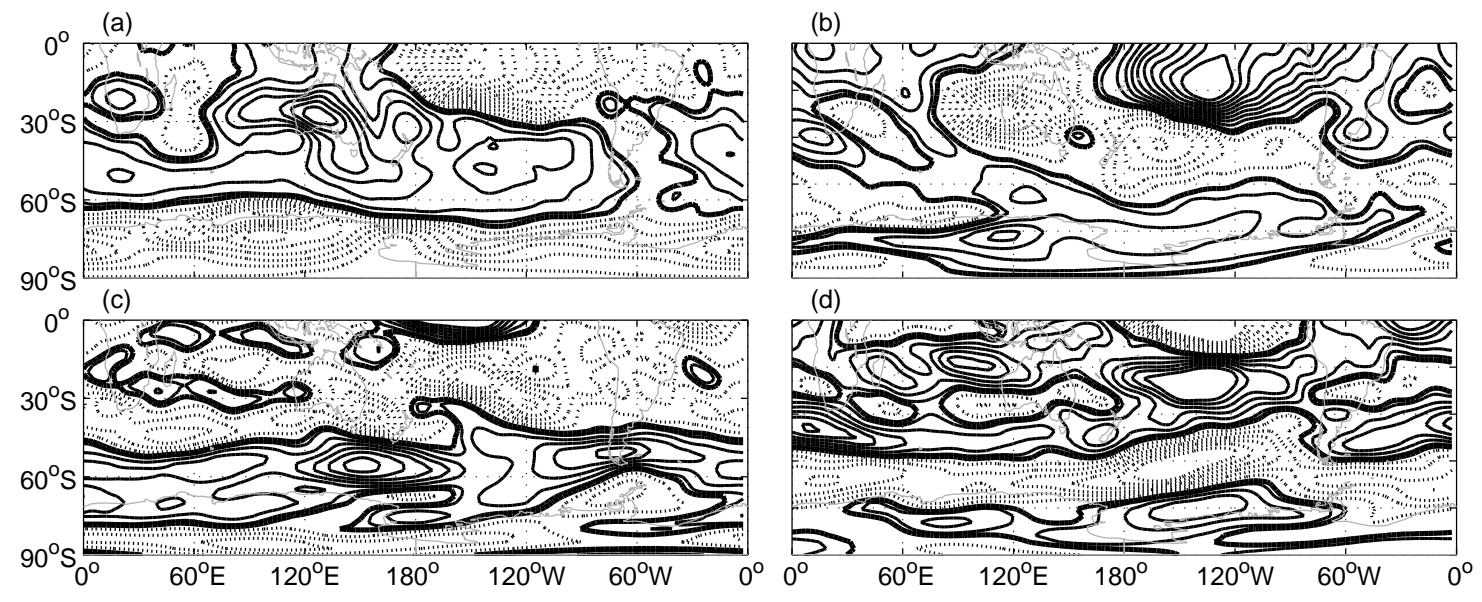

Figure 5.1: (a) Difference between mean DJF temperature $(T)$ at $300 \mathrm{hPa}$ for La Niña conditions and quiescent ENSO conditions (see text for the definition of La Niña, El Niño, and quiescent ENSO conditions. (b) Same as (a) but for El Niño conditions. (c) and (d) Same as (a) and (b), but for the zonal wind-speed (u). The $T$ contours are from $\pm 0.1 \mathrm{~K}$ with $0.2 \mathrm{~K}$ interval, and the zero contour is bolded. The $u$ contours are from $\pm 0.5 \mathrm{~m} \mathrm{~s}^{-1}$ with $1 \mathrm{~m} \mathrm{~s}^{-1}$ interval and the zero contour is bolded. Dotted contours correspond to negative values and solid contours correspond to positive values throughout the chapter.

latitudes), as expected from thermal wind balance. Even though the response of $u$ is more zonally symmetric than that of $T$ in the tropics, it is not the case that the sub-tropical $u$ anomalies are of the same sign around latitude circles. This point is 
made clear in Figure 5.2, which shows the fraction of the composite $u$ anomaly fields that are attributable to $k$-0. The fields in Figure 5.1 (c) and (d) were decomposed into Fourier components around latitude circles, and the ratio of the $k-0$ to $\sum k>0$ taken, before smoothing with a running mean over $20^{\circ}$ of latitude. During both La Niña and El Niño events, in the deep tropics, less than $10 \%$ of the $u$ response is due to $k$-0, but as the higher latitudes are approached, the $k-0$ component becomes progressively more dominant.

Figures 5.1 and 5.2 do not show a zonally symmetric tropical ENSO signal. Yulaeva and Wallace (1994) and Seager et al. (2003) find zonally symmetric tropical anomalies associated with time-series that were derived from the zonal-mean of $T$ and $u$ respectively. These time-series were also correlated with the SOI. Robinson (2007) shows that when seasonal averaging is extended to include DJFMAM, a regression of $Z$ onto the SOI reveals a zonally symmetric tropical response. However, the averaging period used in Figure 5.1 is presumably sufficiently long that the dynamics forcing the mid-latitude response are included, and thus if zonally symmetric tropical anomalies were responsible for the mid-latitude response, it would be evident in Figure 5.1. Both Figures 5.1 and 5.2 are consistent with the idea that the midlatitudes react to a zonally asymmetric sub-tropical forcing and produce a zonally symmetric response.

To put the summertime response into context, and for completeness in the discussion of seasonality, the SH response to ENSO during other seasons is shown in Figure 5.3, as the difference between the $u$ composite for La Niña and El Niño events. During SON and JJA (austral spring and winter, Figure 5.3 (a) and (c), respectively) there is no indication of a zonally symmetric mid-latitude response to ENSO. During MAM (autumn, Figure 5.3 (b)) there is some suggestion of a zonally symmetric mid-latitude response, although it is less prominent than during summertime (DJF, 


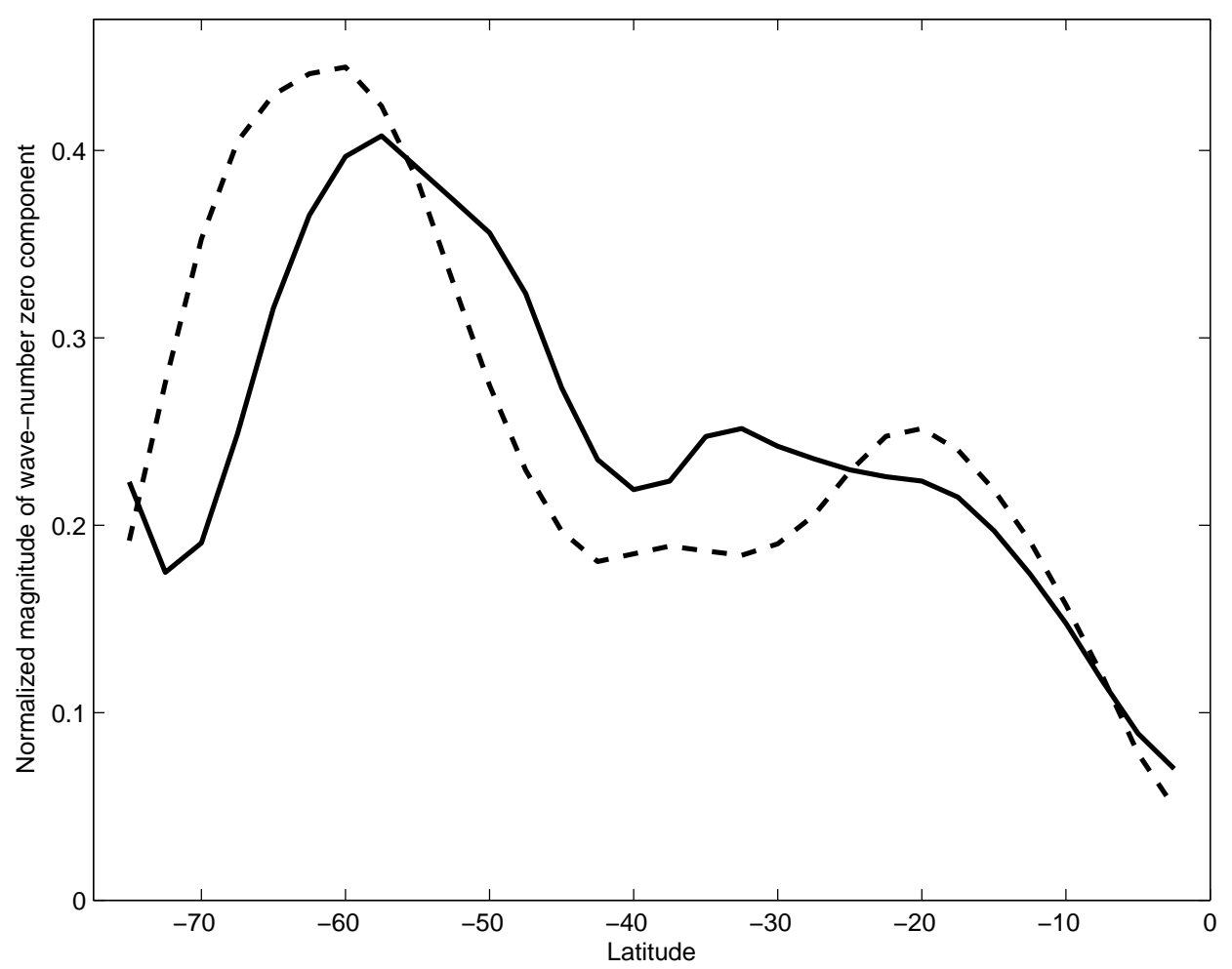

Figure 5.2: Fraction of composite DJF $u$ anomalies attributable to zonal wavenumber zero for La Niña (solid line) and El Niño (dashed line). Values have been smoothed with a running mean over $20^{\circ}$ of latitude.

Figure 5.1 (c) and (d)).

The common feature in all of the $u$ composites in Figure 5.3 is a wave-train that originates in the tropical Pacific and propagates to high latitude (i.e. the PSA pattern). The wave is also apparent during summertime El Niño conditions (Figure $5.1(\mathrm{~d}))$, and it will be shown that it is present during the summertime La Niña conditions, but becomes obscured through the effect of high-frequency eddies. The wave is approximately invariant in both phase and magnitude under the changing of the seasons, which implies that the seasonality of the mid-latitude response is due to 

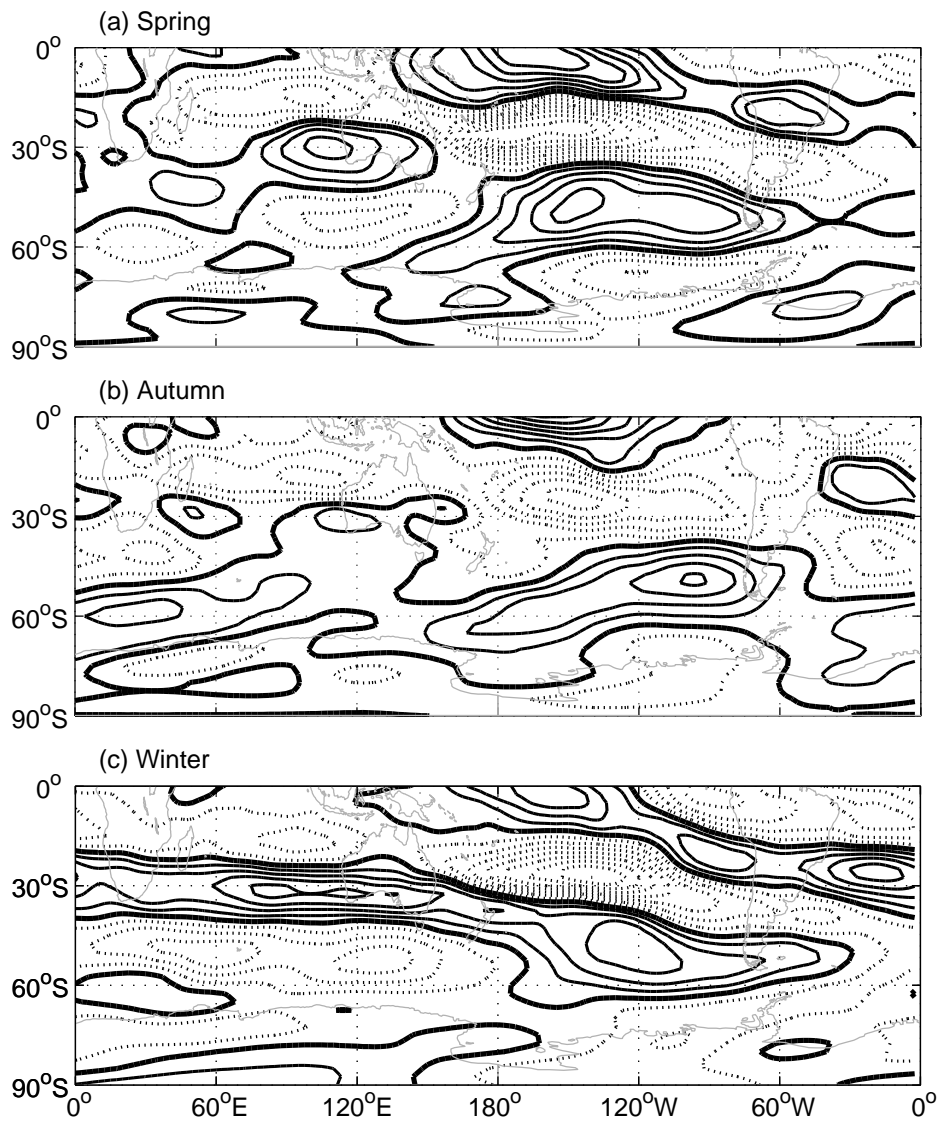

Figure 5.3: Difference between $u$ during La Niña and El Niño events during SON (a), MAM (b) and JJA (c). Contours are every $2 \mathrm{~m} \mathrm{~s}^{-1}$ with the zero contour omitted.

the mid-latitude climatology acting to enable a zonally symmetric response during summer and autumn, but preventing such a response during winter and spring.

The climatology of the high-frequency variance of $Z_{300}$ is shown in Figure 5.4 for all seasons, and is taken as a proxy for the location of the storm-track. One obvious feature of the storm-track seasonality is the increased zonal symmetry during summer (DJF) and autumn (SON) compared to winter (JJA) and spring (MAM), as seen in Trenberth (1991). This is due to the presence of the split jet in the SH across the Pacific, which is particularly prominent during winter and spring (Bals-Elsholz 
et al., 2001; Yang and Chang, 2006), and causes a reduction in the the eddy-driven jet (Nakamura and Shimpo, 2004; Yang and Chang, 2006; Codron, 2007).
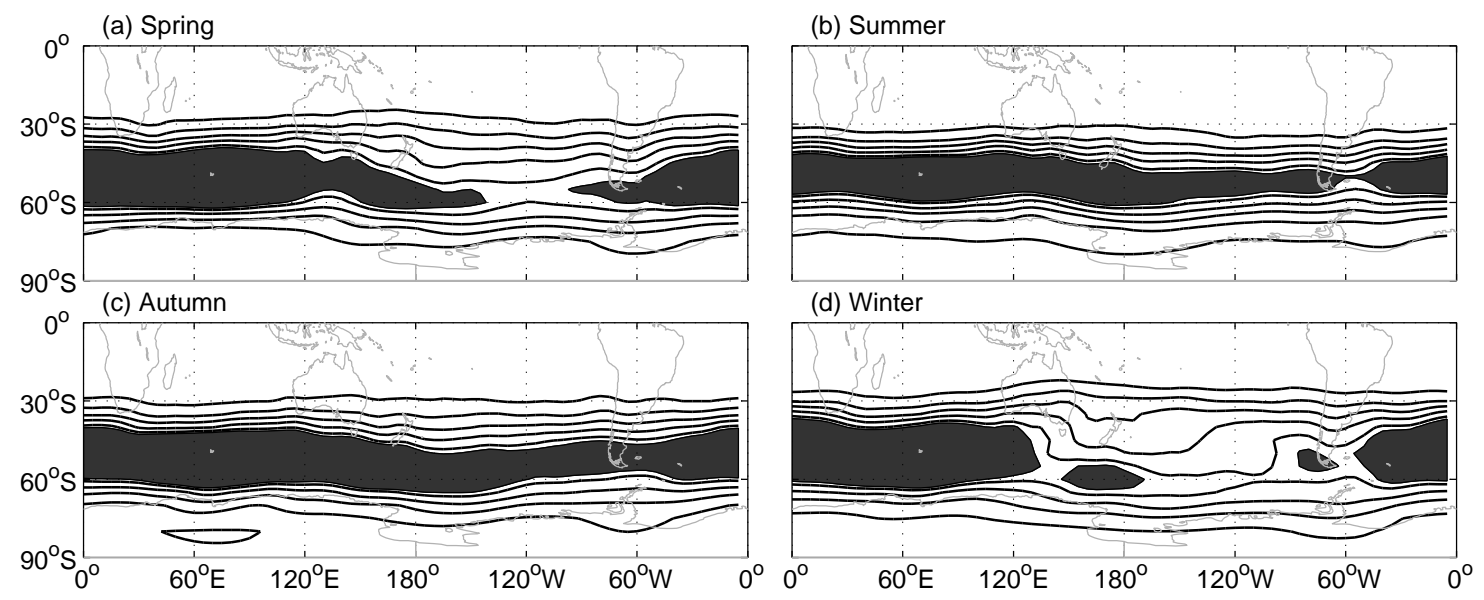

Figure 5.4: Variance of the high-pass ( $<8$ days) filtered $300 \mathrm{hPa}$ geopotential height $\left(Z_{300}\right)$ during SON (a), DJF (b), MAM (c) and JJA (d). Contours are every 1000 $\mathrm{m}^{2}$ and values over $5500 \mathrm{~m}^{2}$ are shaded.

In consideration of how the seasonality of the storm-track can impact the degree of zonal symmetry in the ENSO response, it is noted that the mid-latitude portion of the ENSO stationary wave during La Niña events is characterised by a positive $u$ anomaly in the Pacific region from ca. $40^{\circ} \mathrm{S}$ to $60^{\circ} \mathrm{S}$, and a corresponding negative $u$ anomaly during El Niño. It is clear from Figure 5.4 that during summer (DJF) and autumn (MAM) the $u$ anomalies associated with the ENSO stationary wave (Figures 
5.1 and 5.3) coincide with the storm-track. During these seasons the storm-track (and eddy-driven jet) has increased zonal symmetry, implying that eddies born in the S. Pacific are more likely to propagate to the Atlantic Ocean region and downstream, and therefore are potentially better able to communicate any localized forcing in the Pacific region (like a change of latitude) around the entire hemisphere.

\subsubsection{The effect of the ENSO stationary wave on Southern Hemisphere mid-latitude transient eddies}

A composite of the high-frequency eddy activity during DJF for the opposing phases of ENSO (Figure 5.5), reveals the effect that ENSO has on the SH storm track during summertime. During La Niña events the eddy activity forms one continuous stormtrack around the hemisphere, whereas during El Niño events there is reduced eddy activity in the South Pacific, and the storm-track is less zonally symmetric. This is consistent with the findings that there are more 'blocking' anti-cyclones in the S. Pacific during El Niño events (Renwick, 1998; Renwick and Revell, 1999). The difference between the eddy activity during the two phases (Figure 5.5 (c)) shows that during a La Niña, across the Pacific region, there is simply more eddy activity over the entire meridional extent of the storm-track, and it is downstream, over the Atlantic and Indian Ocean region that the storm track is displaced poleward (i.e. there is increased eddy activity at $60^{\circ} \mathrm{S}$ and decreased activity at $40^{\circ} \mathrm{S}$ ).

To elucidate how the ENSO stationary wave impacts eddy activity, the correlation coefficient between baroclinicity in the $850-700 \mathrm{hPa}$ layer and the SOI is shown in Figure 5.6. During summertime (DJF, Figure 5.6 (b)) La Niña conditions, there is increased baroclinicity in the S. Pacific, and also in a zonal band around $60^{\circ} \mathrm{S}$, consistent with the eddy activity composite of Figure 5.5 (c). During other seasons, there is increased baroclinicity in the same region of the S. Pacific, but no zonally 

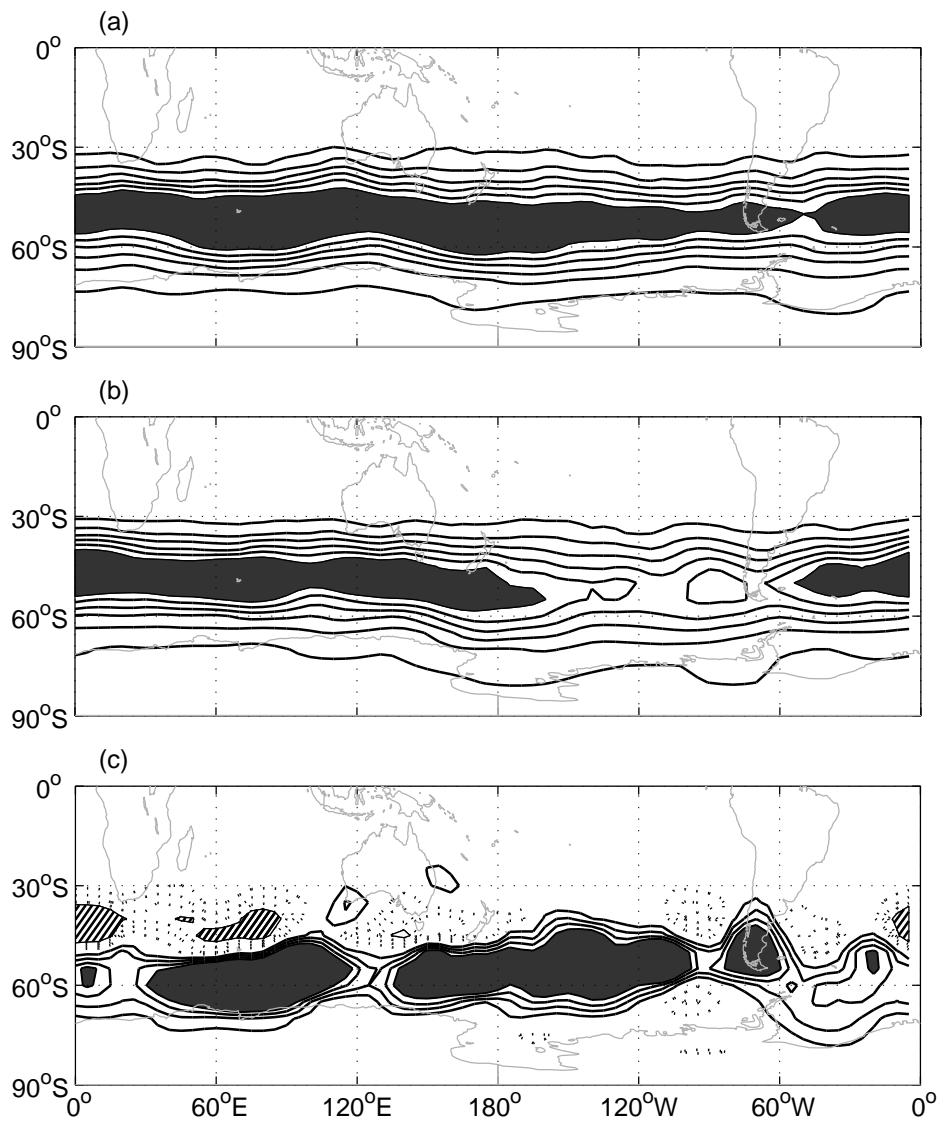

Figure 5.5: Variance of the high-pass filtered $Z_{300}$ during DJF for La Niña events (a), El Niño events (b) and their difference (c). Contours in (a) and (b) are every $1000 \mathrm{~m}^{2}$ and values over $6000 \mathrm{~m}^{2}$ are shaded. Contours in (c) are every $300 \mathrm{~m}^{2}$ with the zero contour omitted Values less than $-1200 \mathrm{~m}^{2}$ or greater than $1200 \mathrm{~m}^{2}$ are hatched and shaded respectively.

symmetric signal along $60^{\circ} \mathrm{S}$. This reinforces the statement (based on Figure 5.3) that the stationary wave imparts similar forcing during all seasons, and it is the mid-latitude background mean circulation that determines whether the response is zonally symmetric.

In consideration of how the ENSO stationary wave impacts baroclinicity, it is important to note that it is equivalent-barotropic (Karoly, 1989; Garreaud and Battisti, 
1999), i.e. not actually barotropic, and so changes the vertical shear of $u$. In the tropics, the ENSO-induced circulation anomalies are fully baroclinic in that they change sign between the surface and the upper troposphere (Rasmusson and Wallace, 1983). Hence the wave is an upper-level feature in the tropics, but is equivalent barotropic in the mid-latitudes. Figure 5.6 shows that the wave does not become fully barotropic and so is a source of baroclinicity in the mid-latitudes. That this is apparent in all seasons suggests that it is the wave itself that influences the baroclinicity, as the wave is the consistent feature across seasons.

Figures 5.5 and 5.6 suggest that during La Niña events, because the PSA has greater magnitude aloft, it induces increased eddy activity in the S. Pacific region. Downstream, over the Atlantic and Indian Ocean regions, the jet moves poleward. Similarly, during El Niño conditions, the eddy activity in the S. Pacific region is suppressed, and downstream, the jet moves equatorward. This happens only during seasons when the climatological-mean storm track dictates that eddies from the Pacific region are able to pass (relatively) unimpeded to the Atlantic and Indian Ocean regions.

\subsubsection{Development of the zonally symmetric mid-latitude response to ENSO}

In this section it is shown that the time-development of a zonally symmetric $u$ anomaly in the mid-latitudes begins in the Pacific region, and then develops in the zonal direction.

To give an impression of the development of the circulation anomalies associated with strong La Niña-like conditions in the tropics, the normalised $T S_{\text {nina }}$ composite for $\operatorname{lag}_{-16}$ to $\operatorname{lag}_{13}$ is shown in Figure 5.7 (dashed line). Although the $e$-folding time 

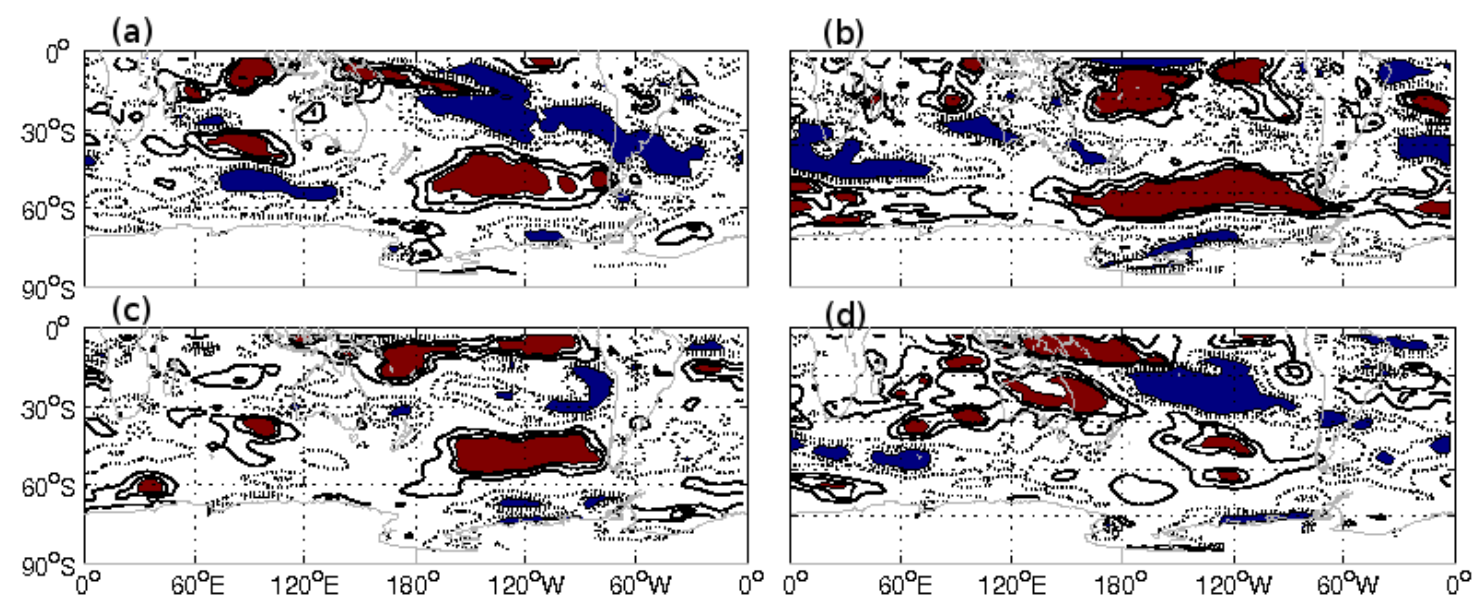

Figure 5.6: Correlation coefficient $(R)$ between the baroclinicity in the 850-700 hPa layer and the southern oscillation index during austral spring (a), summer (b), autumn (c) and winter (d). Contours are every 0.1 with the zero contour omitted. $|R|>0.25$ are red and blue for positive and negative $R$, respectively.

of $T S_{\text {nina }}$ is 30 days, $T S_{\text {nina }}$ changes by a factor of 2 from $\operatorname{lag}_{0}$ to $\operatorname{lag}_{10}$, so when such a high threshold is used to define $\operatorname{lag}_{0}$ days, the wave effectively has a much shorter time-scale than the $e$-folding time suggests, and the daily lead-lag composites are meaningful.

Also shown in Figure 5.7 is the composite SAM time series (solid line), and a timeseries of the $300 \mathrm{hPa}$ tropical $T$, zonally- and meridionally-averaged between the equator and $15^{\circ} \mathrm{S},\left(T_{\text {tropics }}\right.$, dotted line). Over the course of a strong wave event 


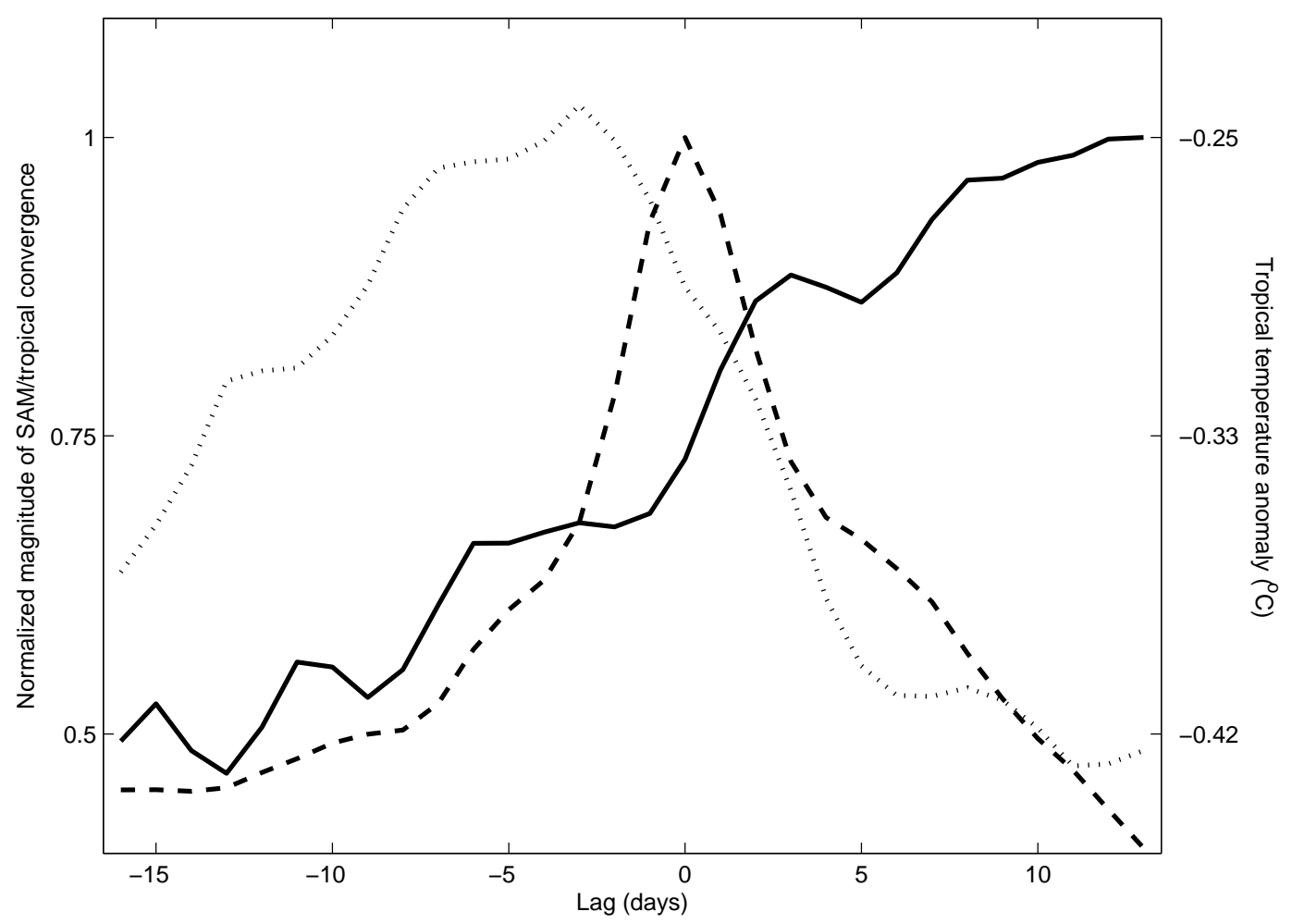

Figure 5.7: Lead-lag composites based on the strength of the La Niña-like forcing in the tropical Pacific ( $T S_{\text {nina }}$, see text for definition). The lag-zero $\left(\operatorname{lag}_{0}\right)$ day is all days during NDJF when $T S_{\text {nina }}>2 \sigma$ (standard deviations). $T S_{\text {nina }}$ (dashed line), time series of southern annular mode (SAM, see text for definition, solid line), and the mean $\mathrm{T}$ at $300 \mathrm{hPa}$ between the equator and $15^{\circ} \mathrm{S}$ (dotted line).

during La Niña conditions, the SAM increases. Given that $T S_{\text {nina }}$ has an $e$-folding time of 30 days, it is expected that the SAM be positive at the beginning of the period shown. The (negative) $T_{\text {tropical }}$ anomaly has a maximum at lag -3 . If the SAM were forced by $T_{\text {tropical }}$, then it would be anti-correlated with $T_{\text {tropical }}$ (when $T_{\text {tropical }}$ was negative, the STJ would become weakened, reducing equatorward propagation of mid-latitude eddies). Figure 5.7 covers nearly a month of lags, which presumably 
is enough time for the hypothesized anti-correlation between $T_{\text {tropical }}$ and the SAM to be apparent, and so the fact that there is none implies that the SAM may not be forced by the zonal-mean tropical temperature. A positive SAM is driven by increased momentum flux convergence near $60^{\circ} \mathrm{S}$, so the fact that the SAM continues to increase throughout the period shown is consistent with the notion that the wave causes enhanced momentum flux convergence at $60^{\circ} \mathrm{S}$, and the eddy response has a positive feedback.

Composite $u$ anomalies averaged over 2 day intervals between lag -1 and $\operatorname{lag}_{4}$ (Figure 5.8) show that, contrary to what was seen in the seasonal mean of Figure 5.1 (c), La-Niña-like convergence in the tropics is indeed associated with a large-scale, meridionally propagating wave-train. At $\operatorname{lag}_{-1}$ to $\operatorname{lag}_{0}$ there is some suggestion that the wave is reflected at ca. $70^{\circ} \mathrm{S}$, just east of the dateline, which may be the critical turning latitude (on the poleward flank of the jet) discussed by Ambrizzi and Hoskins (1997). At $\operatorname{lag}_{-1}$ to $\operatorname{lag}_{0}$, the $\mathrm{SAM}$ is weakly positive (Figure 5.7). Figure 5.8 shows this is primarily due to a positive $u$ anomaly over the southern tip of South America (the positive $u$ anomalies near the date-line would largely cancel one another out at $40^{\circ} \mathrm{S}$ and $\left.60^{\circ} \mathrm{S}\right)$. By $\operatorname{lag}_{3}$ to $\operatorname{lag}_{4}$ the $u$ anomaly in the Pacific region has developed along $60^{\circ} \mathrm{S}$, and clearly contributes to the increasing SAM shown in Figure 5.7. Far from being a zonally symmetric process, accompanied by corresponding negative $u$ anomalies in the sub-tropics, the response begins in the South Pacific, and subsequently spreads out.

The high-frequency eddy activity anomaly for $\operatorname{lag}_{1}$ to $\operatorname{lag}_{6}$ (Figure 5.9) shows a similar picture to $u$ (Figure 5.8). Initially there is increased eddy activity only in the Pacific region, and over the tip of South America (which may be a result of increased lee-cyclogenisis, as on these days, $u$ is already elevated in the region). By $\operatorname{lag}_{5}$ to $\operatorname{lag}_{6}$, the increased eddy activity has spread out, to cover almost all longitudes. 

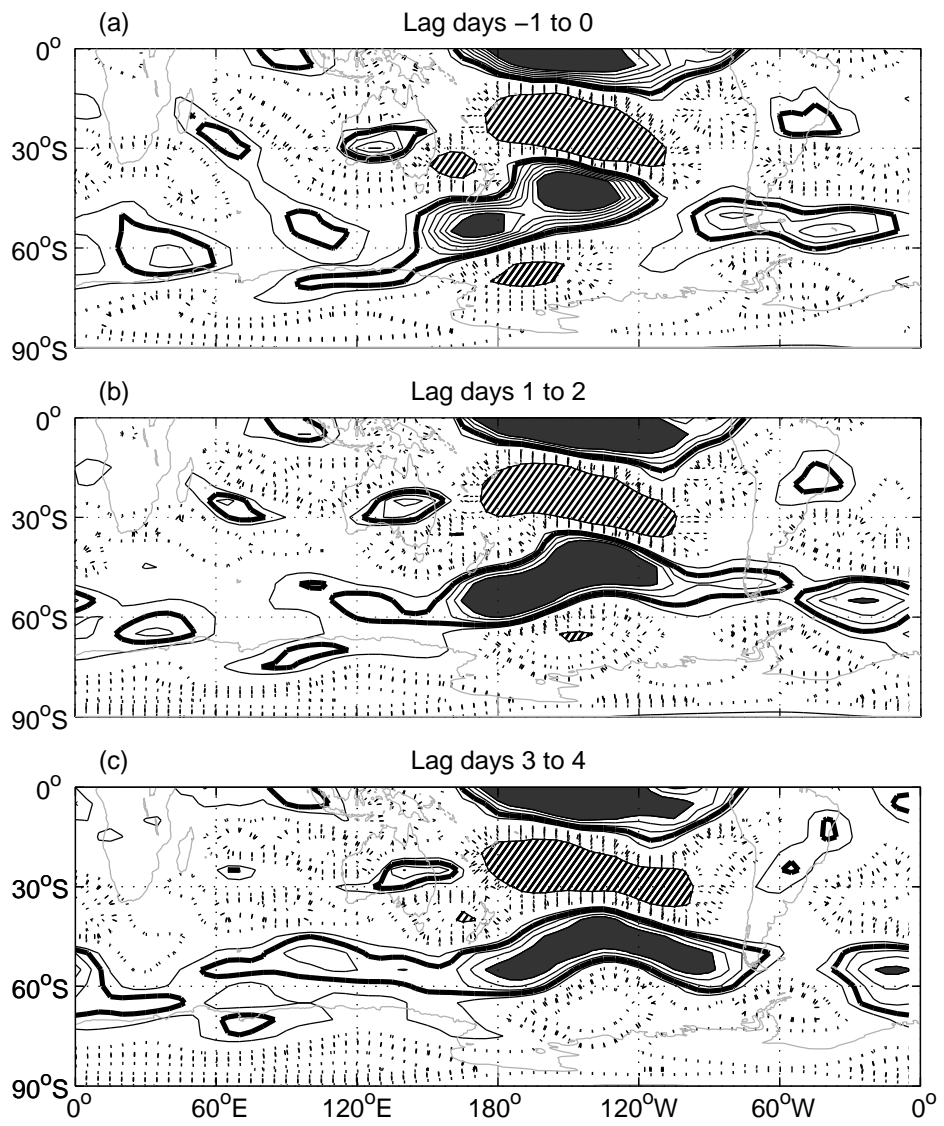

Figure 5.8: Lead-lag composite of $u$ anomaly (difference from the monthly-mean climatology) for $\operatorname{lag}_{-1}$ to $\operatorname{lag}_{0}$ (a), $\operatorname{lag}_{1}$ to $\operatorname{lag}_{2}$ (b) and $\operatorname{lag}_{3}$ to $\operatorname{lag}_{4}$ (c). See text for definition of $\operatorname{lag}_{0}$. Contours are every $1 \mathrm{~m} \mathrm{~s}^{-1}$, with the zero contour omitted, \pm 2 $\mathrm{m} \mathrm{s}^{-1}$ bolded, values less than $5 \mathrm{~m} \mathrm{~s}^{-1}$ hatched, and greater than $8 \mathrm{~m} \mathrm{~s}^{-1}$ shaded.

Although somewhat ambiguous, there is a suggestion that the development occurs in the downstream direction. The increased eddy-activity in the Atlantic and Indian Ocean regions is poleward of that in the Pacific region, and Figure 5.5 (c) shows that this feature is robust at longer time-scales.

The fact that Figures 5.8 and 5.9 show this process happening over a time-scale of c. one week may be misleading. Not only has the average been taken over many different events, it has been stated that $T S_{\text {nina }}$ has an $e$-folding time of 30 days, 
and so some of the development processes leading to increased eddy activity around the hemisphere would already be well underway at the beginning of the lead-lag composites shown in Figures 5.8 and 5.9. On the other hand, the SAM does have significant power at periods as short as one week (Kidson and Watterson, 1999), and so organized, large-scale processes may effect variations of the zonal-mean $u$ at these time-scales.

The analysis thus far suggests that the La Niña events are associated with increased eddy activity in the Pacific region, and the signal then develops zonally. Full dynamical analysis of the feedback mechanisms responsible for the eddy activity and $u$ response to ENSO will be tackled using a simplified modeling approach, but are beyond the scope of this study. The analysis presented here does suggest though that during La Niña events, increased eddy activity across the Pacific region tends to result in a poleward displacement of the eddy-driven jet down stream, across the Atlantic and Indian Ocean sectors.

\subsection{Discussion and Conclusions}

The SH zonally symmetric response to ENSO has been reviewed, and it was argued that this is not caused by a zonally symmetric response in the sub-tropics, but by the ENSO stationary wave, or PSA pattern, combined with a storm-track climatology that is conducive to the zonal propagation of a forcing in the S. Pacific during the summer (DJF) and autumn (MAM) seasons.

The $u$ anomalies induced by the PSA pattern are stronger aloft, so that during La Niña conditions, as the wave induces a positive $u$ anomaly over the S. Pacific, vertical wind-shear, or baroclinicity, is also enhanced. The opposite is true during El Niño conditions. This induces anomalous eddy activity in the South Pacific region, and 

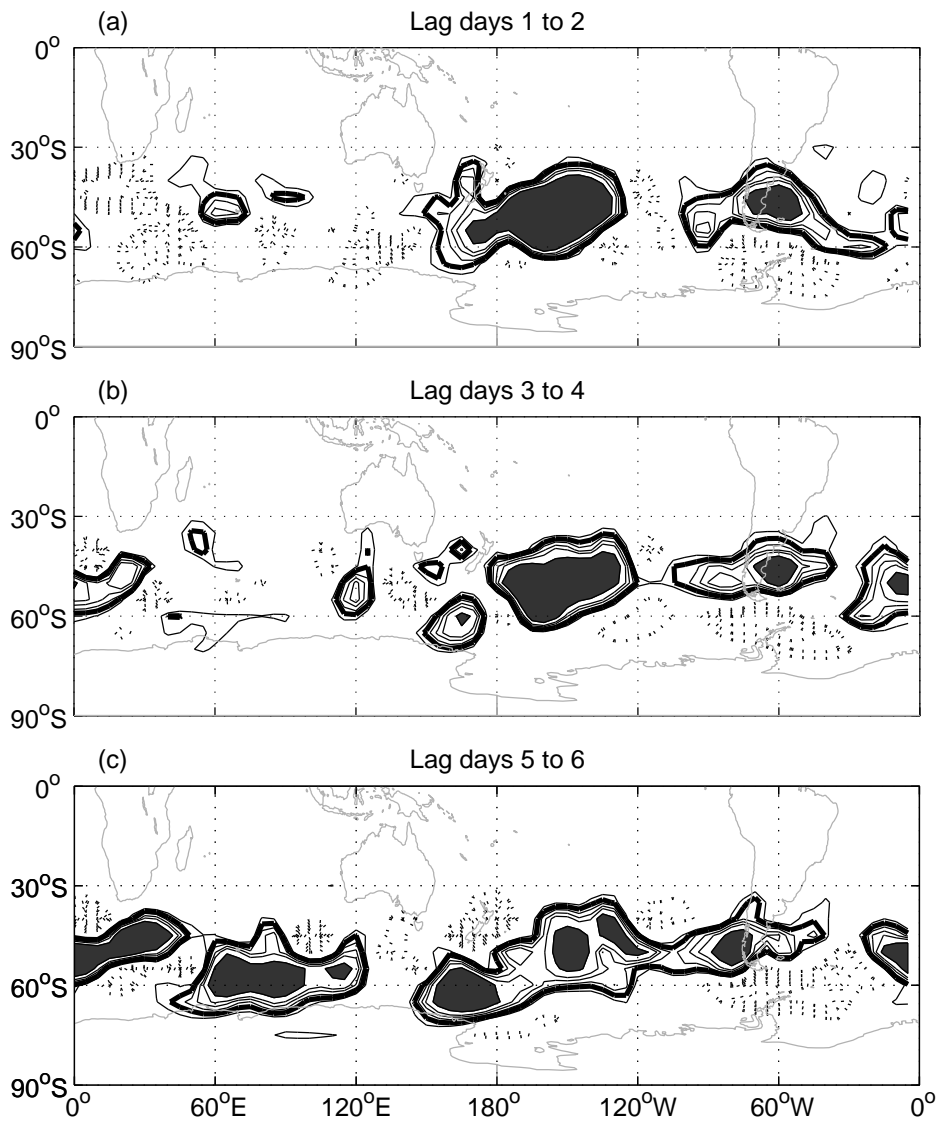

Figure 5.9: Lead-lag composite of the anomalous (difference from the monthly-mean climatology) high-frequency variance of $Z_{300}$ for $\operatorname{lag}_{1}$ to $\operatorname{lag}_{2}(\mathrm{a}), \operatorname{lag}_{3}$ to $\operatorname{lag}_{4}$ (b) and $\operatorname{lag}_{5}$ to $\operatorname{lag}_{6}$ (c). Contouring begins at $\pm 400 \mathrm{~m}^{2}$, with $200 \mathrm{~m}^{2}$ interval, and values over $1600 \mathrm{~m}^{2}$ shaded.

during summer the effect is able to propagate zonally, and a poleward shift of the storm track is observed downstream, over the Atlantic and Indian Ocean regions.

The affect of an individual baroclinic eddy is to transport momentum poleward, and this transport occurs primarily towards the end of the eddy life cycle (Simmons and Hoskins, 1978). Thus the increased eddy activity across the South Pacific associated with La Niña conditions may cause a poleward shift of the jetstream immediately downstream (in the E. Pacific). It is then plausible that the feedback mechanisms 
discussed in Chapter 3 come into play, and cause the poleward displacement of the jet around the rest of the latitude circle; if one longitudinal portion of a selfmaintaining jet (that is free to wander meridionally) is pinned to a specific latitude, the rest may be expected to follow suit.

The aim of this study is not to dismiss the previous work that has focused on a zonally-symmetric change in the STJ and thence the eddy dissipation region (Robinson, 2002; Seager et al., 2003; L'Heureux and Thompson, 2006; Robinson, 2007; Chen et al., 2008; Lu et al., 2008). Some of this previous work has been supported by modelling studies (Robinson, 2007), which make a strong case that that mechanism is at least plausible. The aim here has been to present a careful analysis of the observational data, and this has suggested that an alternative mechanism is worthy of consideration. It is important that the mechanism proposed herein is further investigated using a GCM in order to establish whether it is dynamically sound. This will be addressed at a later date. 


\section{On the Positive Trend in the Annular Modes Under Increasing Greenhouse Gasses}

\subsection{Introduction}

There has been a poleward shift of the jet-streams and embedded storm-tracks during the last three decades (Fyfe et al., 1999; Thompson et al., 2000; Trenberth et al., 2007; Archer and Caldeira, 2008). In this chapter new results are presented which show that associated with a poleward shift of the jet streams is an increase in the eddy length scale. A dynamical mechanism is proposed whereby the increase in the eddy length scale may cause the poleward shift of the jet.

Many GCMs, including those used in the IPCC AR4 report predict that the poleward shift will continue throughout the 21st Century (Meehl et al., 2007b; Yin, 2005; Kushner et al., 2001; Bengtsson et al., 2006; Miller et al., 2006; Lorenz and DeWeaver, 2007). However, Son et al. (2008) have shown that when ozone recovery is properly taken into account, the poleward shift of the jet streams seen in the AR4 models becomes less certain. On the other hand, Johanson and Fu (2008) show that the AR4 models underestimate the observed poleward shift of the sub-tropical jet streams. Planning for regional climate changes depends largely on the direction and magnitude of the jet shift, and as such it is critical that the theory of the underlying mechanisms behind circulation changes is established, in order to asses their robustness. 
It is well established that both ozone depletion, and increasing atmospheric concentrations of GHGs cause a poleward shift of the barotropic jets (Kushner et al., 2001; Arblaster and Meehl, 2006; Brandefelt and Kallen, 2004; Cai et al., 2003; Roscoe and Haigh, 2007), although the underlying dynamical causes of these effects are often less clear, and are an active research topic.

There have been several mechanisms suggested thus far. Hartmann et al. (2000) have suggested that a decrease in the refractive index at high latitude may be responsible.

Chen and Held (2007); Chen et al. (2008); Lu et al. (2008) have suggested that raising the tropopause increases the wind-speed in the upper troposphere and thus the eastward phase-speed of the mid-latitude eddies. As described in Chapter 3, this would mean that those eddies must dissipate, and exert an easterly torque, at higher latitudes, thereby shifting the low-latitude easterlies to higher latitudes. It is then suggested that the eddy source region (and thus the barotropic jet stream) would move poleward due to the upper level disturbances being on average shifted poleward and so the opportunities for phase-locking being shifted poleward.

Lu et al. (2008) also suggest that the shift may be caused by the direct change in baroclinic forcing associated with a preferential increase in static stability at lowlatitudes. This occurs because the static stability at low-latitudes approximately conforms to a moist adiabat. The changes in specific humidity at low-latitudes associated with global warming are predicted to scale with the Clausius-Clapeyron equation, and so increase approximately exponentially with temperature. (This is because the relative humidity is expected to remain approximately constant; lower relative humidity would imply increased surface evaporation, but the subsequent atmospheric latent heating would over compensate for atmospheric radiative cooling, and violate energy balance closure). The moist adiabat in a warmer (and therefore moister) climate, has a lower lapse rate (Holton, 1992), and so the (dry) static sta- 
bility is increased. At higher latitudes the static stability is less than that of a moist adiabat (Holton, 1992; Vallis, 2006), and so there is expected to be a preferential increase in static stability at low-latitudes. The reciprocal of the static stability enters the calculation of baroclinicity, or Eady growth rate (Holton, 1992; Vallis, 2006), and so one may expect that baroclinic eddy generation be moved to higher latitudes.

Additionally Lu et al. (2008) showed a strong relationship with the change in the extratropical tropopause height, which may imply that the cause is rooted in the mid- rather than low-latitudes. Here it is suggested that changes in the mean state cause an increase in the eddy length-scale, and a mechanism is proposed by which this may effect a poleward shift of the jet-streams. Evidence for this is provided through numerical modelling.

\subsection{Data and Methods}

Output from GCMs used in the World Climate Research Programme's (WCRP's) Coupled Model Intercomparison Project phase 3 (CMIP3) multi-model dataset (Meehl et al., 2007a) is used. The A2 ('business as usual') scenario is analysed, which gives 12 separate model runs. The names of these models, as used in the CMIP3 dataset, are: bccr_bcm2_0; mri_cgcm2_3_2a; mpi_echam5; miroc3_2_medres; ipsl_cm4; ingv_echam4; giss_model_e_r; gfdl_cm2_0; gfdl_cm2_1; csiro_mk3_0; cnrm_cm3; cccma_cgcm3_1. I would like to acknowledge the modeling groups, the Program for Climate Model Diagnosis and Intercomparison (PCMDI) and the WCRP's Working Group on Coupled Modelling (WGCM) for their roles in making available the WCRP CMIP3 multi-model dataset. Support of this dataset is provided by the Office of Science, U.S. Department of Energy. The dry dynamical core developed at the Geophysical 
Fluid Dynamics Laboratory is also used as a simplified GCM. The model control run was set up as in Chapter 3.

To investigate the eddy length-scale, the daily meridional wind-speed $(v)$ was decomposed into Fourier components around latitude circles. The magnitude of an individual Fourier component at a latitude $(\phi)$ and $k$ is $|\tilde{V}(\phi, k)|$, which is refered to as the "eddy activity". This should not be confused with "wave activity", which has a distinct meaning in atmospheric dynamics (Andrews et al., 1987). To obtain the fractional contribution to the eddy $v$ at each $\phi, k$ these were weighted by $\cos (\phi)$ and normalized by the sum of the daily mean hemispheric (area weighted) eddy activity. To remove the complications of spherical geometry, $|\tilde{V}(\phi, k)|$ is displayed as a function of $\phi, \lambda$ by plotting over $\phi, 2 \pi a \cos (\phi) / k$ where $a$ is the Earth's radius. The hemispheric mean wavelength was obtained by first calculating the mean $k$ at each $\phi, \bar{k}(\phi)=\sum_{k} k *|\tilde{V}(k)| / \sum_{k}|\tilde{V}(k)|$, with the mean wavelength given by $\bar{\lambda}(\phi)=2 \pi \operatorname{acos}(\phi) / \bar{k}(\phi)$, and the hemispheric mean wavelength $\bar{\Lambda}=\sum_{\phi} \bar{\lambda} *|\tilde{V}(\phi)| / \sum_{\phi}|\tilde{V}(\phi)|$.

The latitude of the eddy-driven jet was calculated as the mean latitude of the ver-

tically averaged momentum flux convergence, $\sum_{\phi} \phi *\left[\frac{\partial}{\partial y} \overline{u^{\prime} v^{\prime}}\right] / \sum_{\phi}\left[\frac{\partial}{\partial y} \overline{u^{\prime} v^{\prime}}\right]$ where the primes denote deviations from the zonal-mean, and the overbar and square brackets denote the zonal- and vertical-mean, respectively.

\subsection{Results}

The climatological $\bar{u}$ from the NCEP/NCAR reanalysis data and the CMIP3 GCMs used in the IPCC AR4 report are shaded in Figure 6.1. The CMIP3 model ensemblemean reproduces climatology satisfactorily, and the predicted trend in the coming century in the mid- to high-latitudes, throughout the bulk of the troposphere, is 
similar in nature and magnitude to those observed in the $\mathrm{SH}$ reananlysis data. The trend represents a poleward shift of the eddy-driven jet, and also a decrease in the wind-speed at very high latitudes. The observed trend in the $\mathrm{NH}$ is more complicated, and exhibits more seasonality than in the SH and more than seen in the CMIP3 model output (not shown). For the SH reanalysis data and CMIP3 models the trend occurs across all seasons (Yin, 2005), and so the data are not decomposed the data into seasons. All of the individual model runs exhibit a poleward shift of their eddy-driven jet, implying that the large GHG forcing in the A2 scenario more than compensates for ozone recovery where it is prescribed (Meehl et al., 2007b), which tends to induce an equatorward shift of the eddy-driven jet (Son et al., 2008).

The eddy activity climatology and trend are shown in Figure 6.2 (a). The maximum eddy activity occurs at $\bar{\lambda}=3000-10000 \mathrm{~km}$, and between latitudes $30-65^{\circ} \mathrm{N} / \mathrm{S}$. This is very similar to the NCEP observational data (not shown). The trends show a general shift to increased eddy activity at higher latitudes. This is expected because there is a poleward shift in the eddy-maintained mean flow. However, there is also a notable increase in the percentage of total eddy activity attributable to eddies with wavelengths higher than those explaining the most variance in the climatology. This is indicative of an increase in the eddy length-scale. When $\bar{\lambda}(\phi)$ is calculated for the CMIP3 model ensemble, the wavelength increases by up to $350 \mathrm{~km}$ in the SH mid-latitudes, an increase of over six percent. Quantitative discussion of this change in $\bar{\lambda}$ is presented later. A similar analysis applied to the SH observational data shows a clear increase in length-scale in the troposphere (not shown).

Does the shift to longer wavelength eddies cause the poleward shift of the mean flow that the eddies maintain? The climatological northward flux of westerly momentum at $300 \mathrm{hPa}$ is shaded, as a function of $\phi, \lambda$ in Figure 6.2 (b), and may help to answer this question. Figure 6.2 (b) is qualitatively similar for output from any 
(a) Observed zonal wind-speed climatology and trend, 1979-2005

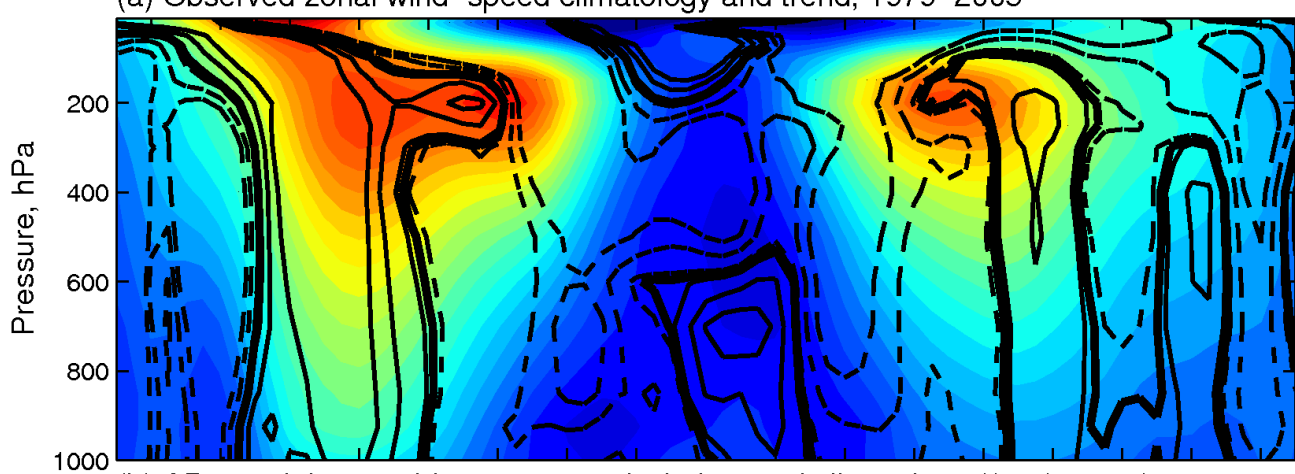

(b) AR4 model ensemble-mean zonal wind-speed climatology (1961-2000) and projected change (2081-2100)

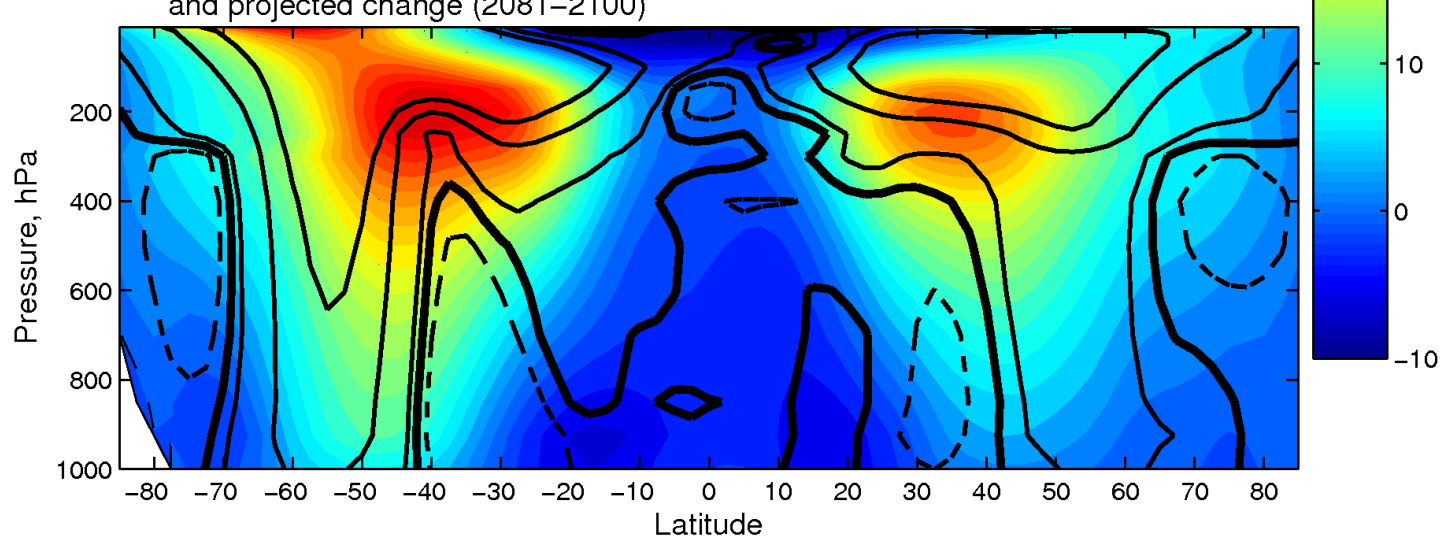

Figure 6.1: Zonal-mean zonal-wind climatology and trend. (a) The NCEP/NCAR reanalysis data. (b) Global circulation models (GCMs) used in the IPCC AR4 report. Contours show the trends for each dataset. Trends are calculated using linear regression for the reanalysis data, and differences in the means of the respective periods for the model output. Contour interval is $0.1 \mathrm{~m} \mathrm{~s}^{-1}$ decade $^{-1}$ and contours begin at \pm 0.025 with the zero contour bolded.

individual model run, and for both hemispheres, and so only the SH observational data are shown for brevity. It is also qualitatively insensitive to choice of level. The direction of the meridional flux of westerly momentum is opposite to the wave group velocity, so that positive (negative) fluxes correspond to waves propagating southward (northward). There is generally equatorward propagation at low lati- 


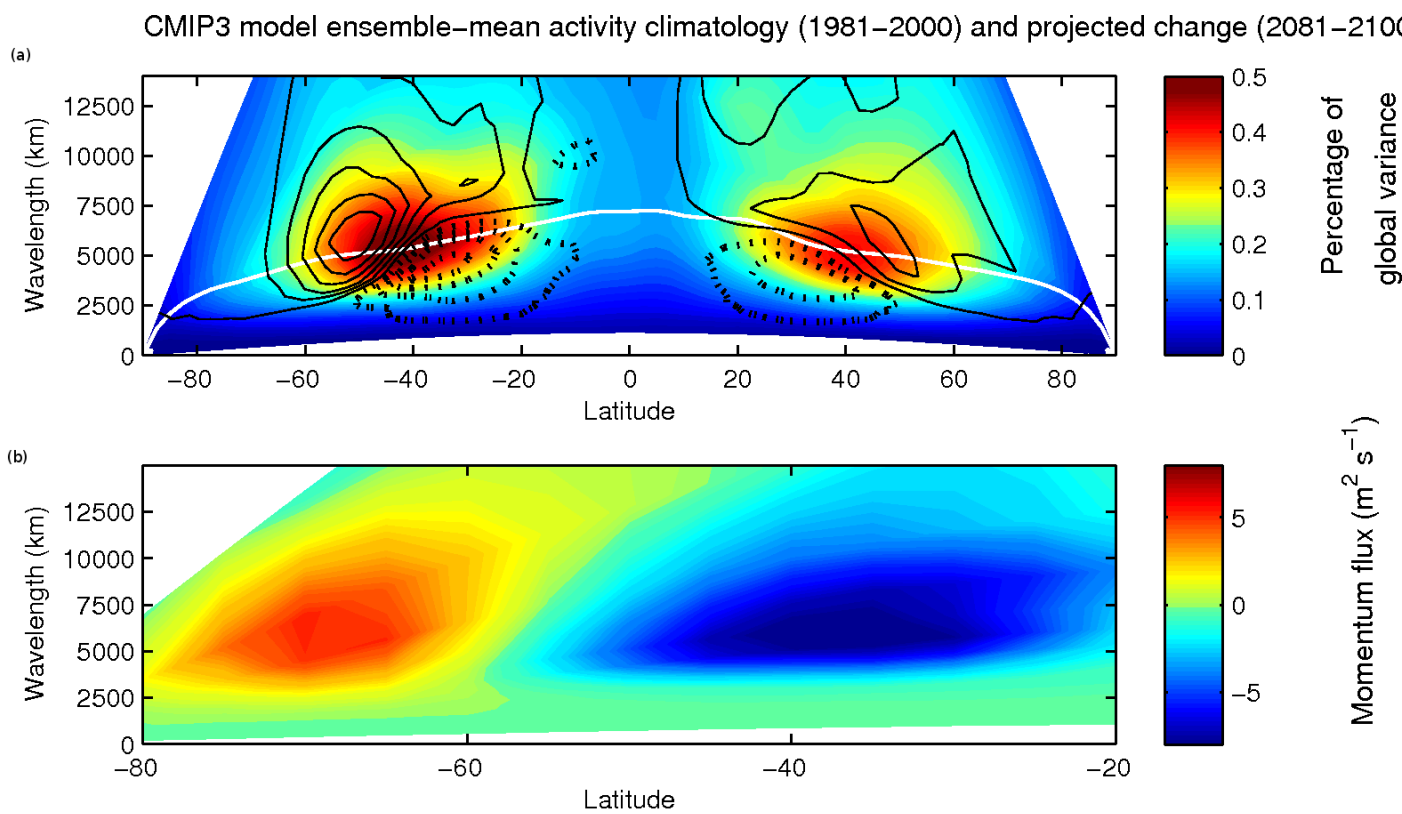

Figure 6.2: (a) Eddy activity climatology and trend (see text for definition) for the CMIP3 model ensemble at $300 \mathrm{hPa}$. Shading is the percentage of hemispheric variance explained. Contours are every $\pm 1 * 10^{-3}$ percent of the global variance per decade with the zero contour omitted, and solid (dotted) contours indicate a positive (negative) trend. The heavy white line shows the mean wavelength at each latitude $(\bar{\lambda}(\phi)$, see text)(b) Climatological zonal-mean meridional flux of zonal momentum by eddies at $300 \mathrm{hPa}$ in the $\mathrm{SH} \mathrm{NCEP} / \mathrm{NCAR}$ reanalysis data. The sign convention is positive for northward flux of westerly momentum.

tudes and poleward propagation at high latitudes, consistent with the idea that the meridional wind shear induces LC1 (anticyclonic) and LC2 (cyclonic) breaking on the equatorward and poleward flank of the jet respectively (Thorncroft et al., 1993). However, it is also clear from the slope of the zero line in the mid-latitudes in Figure 6.2 (b) that at latitudes $40-60^{\circ} \mathrm{S}$, longer waves propagate preferentially poleward. This result can also be realised by examining the Eliassen-Palm (E-P) flux (Edmon et al., 1980) stratified by $k$, who's vector points in the direction of the wave's group 
velocity (not shown).

The preferential poleward propagation of longer waves may be explained by variations in the refractive index $\left(n^{2}\right)$. Waves are refracted towards areas of high $n^{2}$. The general increase of the refractive index towards the equator (Vallis, 2006) is less pronounced for long waves ( $L i$ et al., 2006), and so long waves are expected to propagate less equatorward. Long waves can be supported by a smaller potential vorticity gradient than short waves, so are more likely to break in the direction dictated by the local barotropic shear, which would tend to make them propagate poleward on the poleward side of the jet core. Also, Hoskins and Karoly (1981) have shown that long waves emanating from a sub-tropical source propagate to higher latitudes than short waves.

A common measure of a storm-track is the high-pass filtered variance of the geopotential height of a surface of constant pressure (Trenberth, 1991; Holton, 1992), which is a measure of eddy activity. By this measure, a shift to waves that propagate preferentially poleward will immediately result in a poleward shift of the storm-tracks. To account for the poleward shift of the barotropic westerlies it is necessary to change the source latitudes of the baroclinic waves. It is possible that this follows from the fact that growing baroclinic waves are encouraged by phase locking between disturbances in the upper and lower troposphere (Bretherton, 1966). The presence of disturbances aloft has been shown to be crucial to eddy formation (Nakamura and Shimpo, 2004). It is hypothesized that the longer waves propagating preferentially poleward in the upper troposphere induce a poleward shift in the incidence of phase locking opportunities and thereby shift the eddy source region, and the entire eddydriven jet, poleward. Implicit in our hypothesis is that eddies propagate far enough meridionally that the easterly torque associated with eddy dissipation is separated from the source region, otherwise increased poleward propagation may induce an 
equatorward shift of the jet. This is consistent with the negative trend in $\bar{u}$ at high latitudes in Figure 6.1.

It is also important to ask whether the poleward shift of the storm track causes an increase in the eddy length-scale. Theoretical eddy length-scales have been developed based on linear baroclinic instability theory. The Rossby radius of deformation, $L_{R}=N H / f$, where $N$ is the buoyancy frequency, $H$ is the scale height and $f$ is the Coriolis parameter appears in the Eady model (Vallis, 2006). Inclusion of an environmental vorticity gradient $(\beta)$ in the problem, as in the Charney model, leads to an additional dependence on $U_{z}$, the thermal wind, and $\beta$, which is sometimes called the long-wave cutoff (Holton, 1992; Vallis, 2006). An alternative length-scale based on nonlinear dynamics and an inverse turbulent cascade of energy to larger spatial scales is the Rhines scale, $L_{\beta}=\left(U^{\prime} / \beta\right)^{1 / 2}$, where $U^{\prime}$ is the RMS eddy velocity (Rhines, 1975). It is an open question as to which of these length-scales is relevant to the real atmosphere (Frierson, 2006; Vallis, 2006). If $L_{R}$ is important in the real atmosphere, then one expects the length-scale to reduce with a poleward shift of the storm track (everything else being constant), as $f$ increases. However, if $\beta$ is important in the real atmosphere, one expects a coincident increase in length-scale with a poleward shift of the storm track as $\beta$ decreases. In this study the hypothesis is pursued that the increase in length-scale is not simply due to the coincidental decrease in $\beta$ towards the poles. One justification for this is that the climatological variation of the eddy length-scale with latitude shows a clear decrease towards the poles (Figure $6.2(\mathrm{~b})$ ).

Independent of a latitudinal shift of the storm track, there are three basic changes in state that might be expected to induce a change in the eddy length-scale under increasing greenhouse gasses. The first two can be realised by focusing on $L_{R}$; an increase in either $H$ or $N^{2}$ is expected to increase the length-scale. These have been 
shown to be important in GCMs (Williams, 2006; Frierson et al., 2006), and an increase in both of these variables is a robust prediction of increasing GHGs (Lorenz and DeWeaver, 2007; Meehl et al., 2007b; Frierson, 2006). The simplified GCM has been used to investigate the impact of increasing either $H$ or $N^{2}$.

As in other studies employing simplified GCMs, $H$ was increased by decreasing the stratospheric equilibrium temperature $\left(T_{e q}\right)$ (Haigh et al., 2005; Williams, 2006; Lorenz and DeWeaver, 2007), from $200 \mathrm{~K}$ in the control run (Control) to $197 \mathrm{~K}$ in the raised tropopause run $\left(H_{\text {increased }}\right)$. Relative to the control run (Control), the raised tropopause run $\left(H_{\text {increased }}\right)$ shows a shift to longer $\lambda$ (Figure $6.3(\mathrm{~d})$ ). An accompanying poleward shift of the eddy-driven jet is seen in Figure $6.3(\mathrm{~g})$. Previous studies have pointed out that increasing $H$ causes a poleward shift of the jet (Haigh et al., 2005; Lorenz and DeWeaver, 2007) and Williams (2006) also noted the accompanying shift to longer wavelengths, but the dynamical mechanism hypothesized here was not suggested.

In order to increase $N^{2}$ in the model, $T_{e q}$ was decreased near the surface rather than increased higher up (as happens under global warming), in order to keep $H$ approximately constant. This run is named $N_{\text {increased }}^{2}$. The temperature anomaly in $N_{\text {increased }}^{2}$ is dispersed (Figure $6.3(\mathrm{~b})$ ), a result of dynamics, making the troposphere generally more statically stable. There is also an increase in the meridional temperature gradient $(\nabla T)$, due to baroclinic adjustment. This is unfortunate as separating the influence of $N^{2}$ and $\nabla T$ becomes somewhat intractable in this model. Figure 6.3 (e) shows that relative to Control, $N_{\text {increased }}^{2}$ exhibits an increase in eddy length-scale. Given that lines of constant temperature difference between $N_{\text {increased }}^{2}$ and Control are primarily horizontal (Figure $6.3(\mathrm{~b})$ ), the difference between the runs is at least partly attributed to increased $N^{2}$.

A final change of state that would be expected to induce larger eddies is an increase 
in $\nabla T$ so that eddies have more kinetic energy and are better able to overcome $(\beta)$. This may be due to changes in fastest growing normal mode, as in the Charney model (Vallis, 2006), or due to a nonlinear turbulent cascade of energy to larger spatial scales (Rhines, 1975; Welch and Tung, 1998; Frierson et al., 2006). Under global warming $\nabla T$ should decrease near the surface due to polar amplification, but increase in the mid-troposphere (Frierson, 2006). In order to increase $\nabla T$ in the model, the the $e$-folding period of the Newtonian cooling constant was decreased. This run is named $\nabla T_{\text {increased }}$. Figure 6.3 (c) shows that $T$ was then closer to $T_{e q}$, thereby increasing $\nabla T$. This method was chosen over increasing $\nabla T_{e q}$ because, as can be seen from Figure 6.3 (c), it gave little baroclinic adjustment, and so minimal change in $N^{2}$. As is seen in Figure 6.3 (f) and (i), the eddy length-scale increased in $\nabla T_{\text {increased }}$, and there was a poleward shift of the eddy-driven jet. One robust prediction of the models used in the CMIP3 is that the surface decrease in $\nabla T$ is more pronounced for the $\mathrm{NH}$ than the $\mathrm{SH}$. This may then explain the greater shifts in length-scale and eddy-driven jet in the $\mathrm{SH}$ relative to the $\mathrm{NH}$ (Figures 6.16 .2 (a)).

The climatological variation of eddy wavelength with latitude in Control shown in Figure 6.3 (d) provides further insight as to whether an increase in the eddy length-scale is the cause of the poleward shifts shown in Figure 6.3 (g)-(i). As in the CMIP3 models (Figure 6.2 (a)) the mean wavelength decreases towards the pole, suggesting that perhaps $\beta$ does not exert a controlling influence on $\lambda$. An increase in eddy length-scale that is accompanied by a poleward shift of the jet varies in the opposite sense to this climatology, and so is suggestive of non-trivial underlying dynamics. Figure 6.4 shows the latitude of the eddy-driven jet plotted against the $\bar{\Lambda}$ for Control and nine different model experiments. In the experiments, the eddy length-scale was induced to vary by employing widely differing mechanisms. These ranged from those already described, to varying the spatial scale at which 
hyperdiffusivity removes energy from the model (see caption for details). There is a strong relationship between $\bar{\Lambda}$ and the latitude of the eddy-driven jet stream. Given that this relationship is not simply consistent with the climatological variation of wavelength with latitude, and as it has been argued, there exists a simple physical mechanism for such a relationship, Figure 6.4 is suggestive that an increase in the eddy length-scale may cause a poleward shift of the eddy-driven jet stream in this model. The fact that the relative changes in length-scale seen in Figure 6.4 are similar in magnitude to those seen in the CMIP3 models (i.e. a few percent) supports the hypothesis that the same mechanism is important in the real atmosphere.

As already mentioned, other hypothesized mechanisms for the poleward shift of the eddy-driven jet streams include the increase in the eastward phase-speed of transient eddies (Chen and Held, 2007; Chen et al., 2008; Lu et al., 2008). The eddy length-scale and eddy phase-speed are not independent. For a constant background wind-speed, an increase in eddy length-scale is associated with reduced eastward phase-speeds. It is a matter of ongoing research as to how these two mechanisms interact to affect the latitude of the barotropic westerlies under global warming.

\subsection{Discussion and Conclusions}

It has been shown that the poleward shift in the CMIP3 model output is associated with a spectral shift to waves of greater spatial extent. A similar shift has occurred in the $\mathrm{SH}$ over the past three decades (not shown). Longer waves were shown to propagate preferentially poleward. This inherently causes a poleward shift in the location of eddy activity, which is the common measure of storm tracks. A latitudinal shift in the eddy source region and the surface westerlies may also be expected because the opportunities for phase locking between disturbances in the 
upper and lower troposphere are shifted poleward.

A simplified atmospheric circulation model was used to argue that, as expected from linear baroclinic instability theory, increasing either the tropopause height, the static stability, or the meridional temperature gradient, results in an increase of the eddy length-scale. A poleward shift of the eddy-driven jet was observed in modeled examples of each of these changes. Finally a number of experiments were presented where differing mechanisms were employed to induce variations in the eddy lengthscale. A strong correlation was seen between the eddy length-scale and the latitude of the eddy-driven jet. Given the mechanism outlined above, and the fact that the relationship is opposite to the climatology for any one run, this may be suggestive of cause and effect.

An increase in both tropopause height and static stability are robust predictions of the impact of increasing GHGs. The near-surface meridional temperature gradient is expected to decrease in the $\mathrm{NH}$ relative to the $\mathrm{SH}$, which may explain why the projected increase in eddy length-scale and poleward shift of the jet is less pronounced in the NH.

As outlined above, it is also possible that the increase in eddy length-scale is caused by the poleward shift of the jet streams, and this fact is a significant caveat on this work. If further work indicates that this is the case, the work here still remains of general interest, as it becomes a strong argument that the environmental vorticity gradient is paramount to determining the eddy length-scale, one of the most fundamental aspects of mid-latitude atmospheric circulation. Furthermore, an increase in eddy length-scale would be expected to have other important consequences. For instance, the stratospheric overturning Brewer-Dobson circulation is projected to increase in the future due to increased wave driving (Garcia and Randel, 2008). The underlying cause of the increase in the stratospheric wave driving is as yet un- 
explained, but would be expected following an increase in eddy length-scale because long waves dissipate higher in the atmosphere (Holton, 1992; Vallis, 2006). Also, a host of properties such as energy transport and intensity of individual storms are expected to vary with eddy length-scale, determination of which could provide understanding of important climatic changes that are predicted to occur in the coming century. 

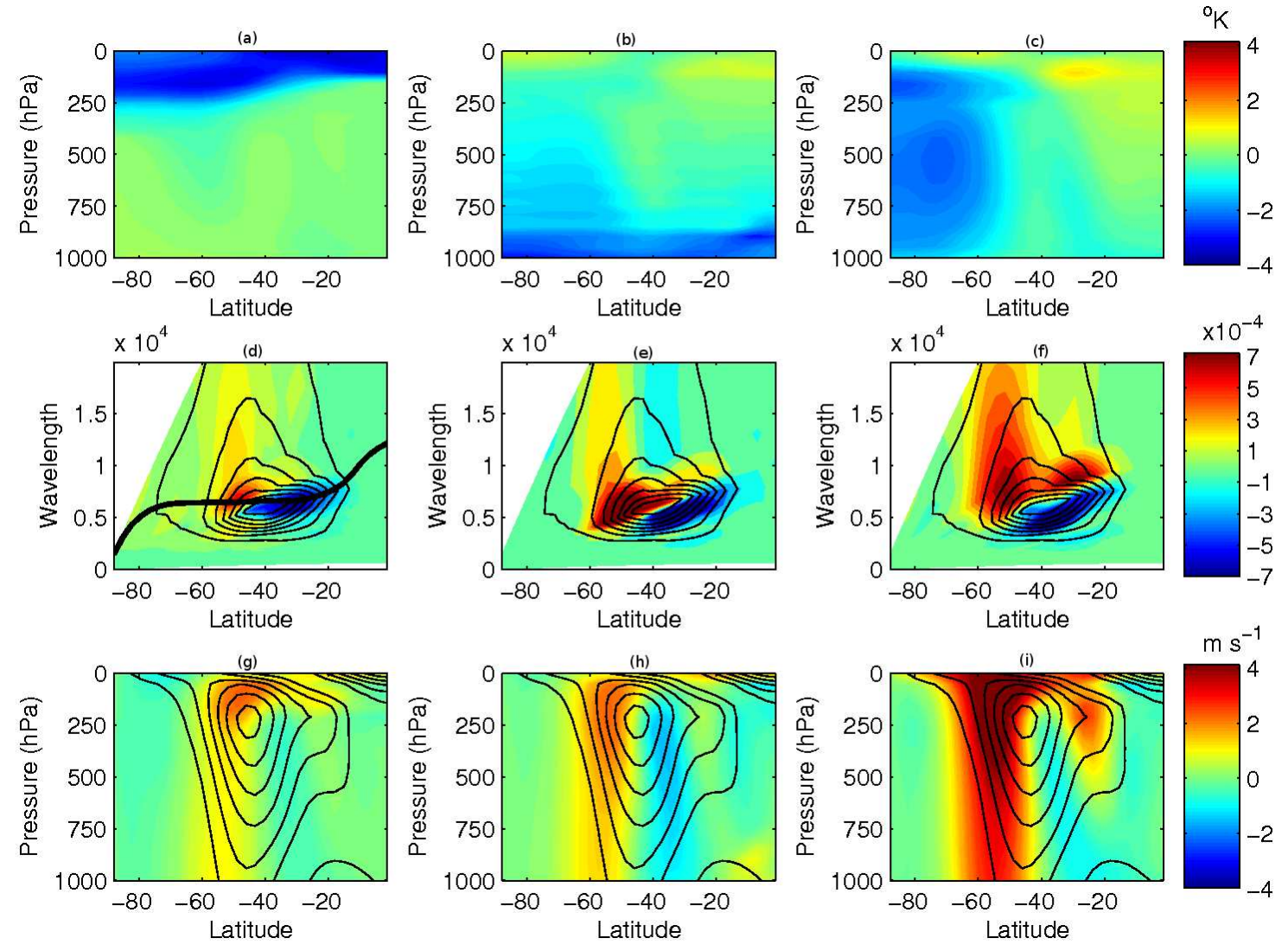

Figure 6.3: The upper panels show the difference in zonal-mean temperature between the experiments and the control. The center row of panels shows the wavenumber activity spectrum at $240 \mathrm{hPa}$. The contours are for the control run, starting at 0.1 with 0.1 interval. The shading is the difference between the experiment and the control run. The bold contour in the center left panel shows $\bar{\lambda}(\phi)$ for the control run. The bottom row of panels shows the zonal mean zonal wind in the control run as contours. The contour interval is $\pm 5 \mathrm{~m} \mathrm{~s}^{-1}$ with solid (dashed) contours representing positive (negative) values and the zero contour omitted. The shading is the difference between the experiments and the control run. The left column of panels corresponds to the experiment $H_{\text {increased }}$, where the stratospheric equilibrium $\left(T_{e q}\right)$ was reduced by $3 \mathrm{~K}$. The middle column corresponds to the experiment $N_{\text {increased }}^{2}$, where $T_{e q}$ was reduced by $3 \mathrm{~K}$ in the lowest three model layers. The right column corresponds to the experiment $\nabla T_{\text {increased }}$, where the $e$-folding time of the Newtonian cooling was reduced from 40 days to 30 days. 
(c) Jet latitude verus wavelength

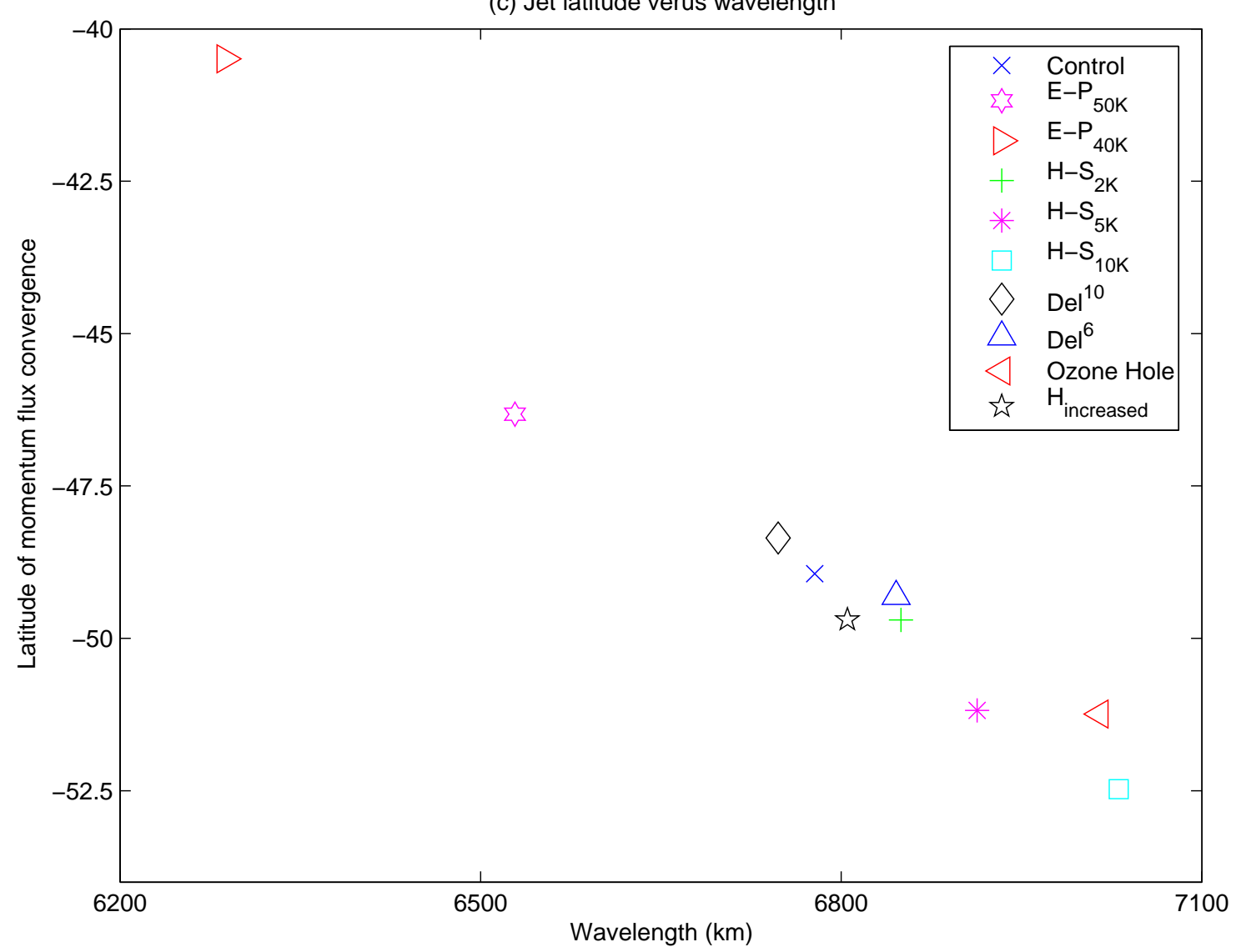

Figure 6.4: The variation of jet-latitude with eddy wavelength (at $240 \mathrm{hPa}$ ) for 10 different experiments. In the E-P experiments, the surface Equator-Pole difference in the equilibrium temperature $\left(T_{e q}\right)$ was changed to the subscripted value. In the H-S experiments, the subscripted value in the legend was added to $T_{e q}$ at the tropopause and stratosphere, and decreased to zero at the surface. In the Del experiments, the power of the hyperdiffusivity operator was changed to the superscripted value. In the Ozone Hole experiment, $T_{e q}$ was perturbed in the stratosphere by $-10 \mathrm{~K}$ at the pole, varying as $\cos ^{2}(\phi)$ to $0 \mathrm{~K}$ at the equator. The $H_{\text {increased }}$ experiment is the same as shown in Figure 6.3 (a). 


\section{Conclusions}

Various aspects of the annular modes have been addressed in this study, and the focus has been on the Southern Hemisphere. The underlying mechanism of such variability was considered, and then the dynamical causes of seasonal, inter-annual, and long-term changes were addressed.

The underlying mechanism of annular modes was examined in the context that eddy-driven jet streams may be self-maintaining. It was shown that the degree of self-maintenance of the jet stream determines the characteristic time-scale of the annular mode in a GCM. This led to the conclusion that annular modes should be thought of as the meridional wandering of a self-maintaining jet stream within a broad baroclinic zone. While this idea is not new, the work does appear to be the first attempt at understanding the variability in the $e$-folding period of the annular mode in a GCM, and also the first time that observational data has been brought to bear on the hypothesis.

The seasonally varying spatial structure of the SAM in the latitude-longitude plane was addressed. It was suggested that the seasonality of the surface temperature of Australia induces increased zonal symmetry in the mean wind field during summer relative to winter, resulting in a more zonally symmetric SAM. This is a new idea on the dynamics of the seasonally varying climatology of the SH circulation. It was argued that during winter the lack of an eddy-driven jet in the Southeast Pacific, and the Antarctic katabatic winds, contribute to a greater $k-2-3$ component in the SAM. 
It was argued that the seasonally varying response of the SAM to ENSO is not caused by a zonally symmetric response in the sub-tropics, but by the baroclinic forcing associated with the ENSO stationary wave, combined with a storm track climatology that is conducive to the zonal propagation of a forcing in the S. Pacific during the summer and autumn seasons. The increased eddy activity across the South Pacific associated with La Niña conditions may cause a poleward shift of the jet stream immediately downstream, and it was argued that a self-maintaining storm-track could then respond downstream. This mechanism represents a significant departure from ideas in the literature, and was motivated by the idea of a self-maintaining jet that may produce a zonally-symmetric response to an asymmetric forcing. Further modeling work is required to establish whether this is dynamically valid.

It was shown that the poleward shift of the jet streams in the CMIP3 model output is associated with a spectral shift to eddies of greater spatial extent. A simplified GCM was used to show that the jet latitude and eddy length-scale are not independent. The causal link between these two quantities remains uncertain. If the length-scale is forced by the jet latitude, this work speaks to the fundamental controls on the lengthscale, which has important ramifications for climate. On the other hand, several reasons were put forward as to why the eddy length-scale is expected to increase under global warming independently of a change in jet latitude. A mechanism was suggested whereby the increase in length-scale may cause the shift of the jet; longer waves propagate preferentially poleward, thereby inducing a poleward shift in the opportunities for phase locking between disturbances in the upper and lower troposphere, and the eddy source region. This hypothesis adds to the conversation on the underlying controls on the location of the mid-latitude jet stream, although further work is needed to ascertain the relative merit of this mechanism versus others. 


\section{List of Figures}

3.1 The left column shows data from the NCEP reanalysis and the right column shows output from the model control run. The top panels show the 'cross-planet cospectrum' (see text) for zonal wind-speed anomalies at $300 \mathrm{hPa}$. The central panels show the lead/lag correlation coefficient $(\mathrm{R})$ between PC1 (see text), the momentum flux forcing $F_{\text {tot }}$ (see text) and the poleward displacement of the eddy heat flux $H_{\text {tot }}$ (see text). The bottom panels show the power spectrum for $F_{h f}$ and $H_{h f}$ (see text), normalised so that the maximum spectral density is unity. ....................... 15

3.2 Model control run diagnostics. (a) The meridional gradient of the equilibrium temperature $\left(\nabla T_{e q}\right)$ and the output temperature $(\nabla T)$ averaged over the lower half of the model domain. (b) The climatological transformed Eulerian mean (T.E.M.) vertical velocity $\left(\bar{w}^{*}\right.$, see text). (c) The convergence of the meridional eddy heat flux $\left(-\frac{\partial}{\partial y} \overline{v^{\prime} T^{\prime}}\right)$. (d) The climatological divergence of the vertical eddy

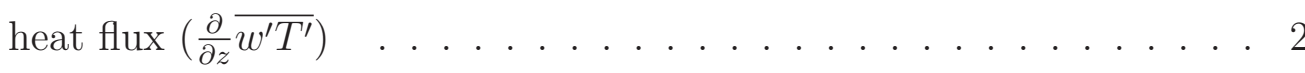


3.3 Comparison of a suite of model runs. Relative to the control run, in the H-S experiments, the subscripted value in the legend was added to $T_{e q}$ at the tropopause and stratosphere, and decreased to zero at the surface. In the Del experiments, the power of the hyperdiffusivity operator was changed to the superscripted value. In the Tstrat experiments $T_{e q}$ in the stratosphere was changed to the succeeding value. In the TFRC experiments the $e$-folding time of the linear drag operator was changed to the succeeding value. (a) The $e$-folding period of PC1 on the ordinate and the maximum value of $\nabla T(\max (\nabla T))$ on the abscissa. (b) $(\max (\nabla T))$ on the ordinate and the sum of the eddy-driven thermally indirect cooling $\left(\sum \bar{w}^{*} N^{2}\right.$, see text) on the abscissa. (c) e-folding period of PC1 on the ordinate and $\sum \bar{w}^{*} N^{2}$ on the abscissa. (d) $(\max (\nabla T))$ on the ordinate and $\sum-\frac{\partial}{\partial y} \overline{v^{\prime} T^{\prime}}$ on the poleward flank of the jet (see text) on the abscissa. . . . . . . . 26

3.4 (a) The climatological mean $\bar{w}^{*}$ for the NCEP reanalysis data is shaded with the zero contour bolded. The dashed line shows the T.E.M. meridional velocity required to balance the Eliassen-Palm flux divergence $\left(\frac{1}{f} \nabla \cdot \vec{F}\right)$, see text). (b) the climatological mean temperature tendency due to latent heating $\left(\left.\frac{\partial}{\partial t} T\right|_{\text {latent }}\right)$. Also shown is the

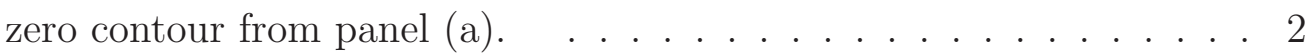

3.5 (a) The regression coefficient for $\bar{w}^{*}$ for the NCEP reanalysis data and PC1 is shaded. The dashed line shows the regression coefficient for $\frac{1}{f} \nabla \cdot \vec{F}$ averaged between 500-300 hPa and PC1. The solid horizontal line is the zero line for $\frac{1}{f} \nabla \cdot \vec{F}$. (b) The regression coefficient for $\left.\frac{\partial}{\partial t} T\right|_{\text {latent }}$ and PC1. . . . . . . . . . . . . . . . . . 28 
4.1 Regression coefficient for monthly mean $500 \mathrm{hPa}$ geopotential height anomalies and the southern annular mode (SAM) during summer (DJF, (a)) and winter (MJJ, (b)). The contour interval is $5 \mathrm{~m} \mathrm{std}^{-1}$ with the zero contour omitted and the $\pm 10 \mathrm{~m} \mathrm{std}^{-1}$ bolded. . . . . 32

4.2 Regression coefficient for monthly mean wind-speed anomalies at 500 $\mathrm{hPa}$ and the SAM during summer (a) and winter (b). The contour interval is every $0.5 \mathrm{~m} \mathrm{~s}^{-1} \operatorname{std}^{-1}$ with negative values dashed and positive values solid and the zero contour omitted. The contours \pm $1 \mathrm{~m} \mathrm{~s}^{-1} \mathrm{std}^{-1}$ are bold, and regions where the regression coefficient $<1.5 \mathrm{~m} \mathrm{~s}^{-1} \mathrm{std}^{-1}$ are hatched, and regions $>2 \mathrm{~m} \mathrm{~s}^{-1} \mathrm{std}^{-1}$ are shaded. Correlation coefficient (R) for the monthly mean wind-speed anomalies at $500 \mathrm{hPa}$ with the SAM during summer (c) and winter (d). Contour interval is every 0.2 with the zero contour omitted. 0.4 $>\mathrm{R}>0.6$ are hatched $/$ shaded. . . . . . . . . . . . . . 34

4.3 Mean windspeed at $500 \mathrm{hPa}$ during summer (a) and winter (b). Contours are every $3 \mathrm{~m} \mathrm{~s}^{-1}$ with the $15 \mathrm{~m} \mathrm{~s}^{-1}$ contour bolded and values over $21 \mathrm{~m} \mathrm{~s}-1$ shaded.

4.4 Mean baroclinicity between 700 and $850 \mathrm{hPa}$ during summer (a) and during winter (b). Contours are every 0.02 with the 0.1 contour bolded and values over 0.18 shaded. Mean temperature at 1000 $\mathrm{hPa}$ during summer (c) and during winter (d). Contours are every $5^{\circ} \mathrm{C}$ with the $20^{\circ} \mathrm{C}$ and $25^{\circ} \mathrm{C}$ contours bolded. (e),(f) as (c),(d), but meridional gradient of temperature. Contours are every $3 * 10^{-6}{ }^{\circ} \mathrm{C}$ $\mathrm{m}^{-1}$ with the $6 * 10^{-6}{ }^{\circ} \mathrm{C} \mathrm{m}^{-1}$ contour bolded and values above $9 * 10^{-6}$ ${ }^{\circ} \mathrm{C} \mathrm{m}{ }^{-1}$ shaded. The zero contour is omitted. 
4.5 Composite wind-speed at $500 \mathrm{hPa}$ during winter for the positive SAM phase (greater than the standard deviation, $\sigma$ ), (a) and the negative SAM phase $(<-\sigma)$, (b). Contours are every $2 \mathrm{~m} \mathrm{~s}^{-1}$, with the $16 \mathrm{~m}$ $\mathrm{s}^{-1}$ contour bolded and values over $18 \mathrm{~m} \mathrm{~s}^{-1}$ shaded. The latitude of the mean sea-ice edge during winter is shown in heavy dashed in (b).

4.6 (a) Vectors of mean wintertime wind. (b) Cross product of the gradient of mean wintertime surface temperature with a unit vector parallel to the local wind direction. Contours are every $3.8^{*} 10^{-4}{ }^{\circ} \mathrm{C} \mathrm{m}-1$ with the zero contour omitted. Values greater than $14 * 10^{-4}{ }^{\circ} \mathrm{C} \mathrm{m} \mathrm{m}^{-1}$ are shaded. In both plots the latitude of the mean wintertime sea ice edge is dashed bold. . . . . . . . . . . . . . . . . . . . 42

4.7 Near-surface wind anomaly vectors for SAM > 1 during summer (a) and winter (b). . . . . . . . . . . . . . . . 43

4.8 Regression coefficients of monthly total rainfall anomalies and the SAM index during summer (a) and winter (b). . . . . . . . . . . 45

4.9 Regression coefficients of monthly-mean maximum temperature anomalies and the SAM index during summer (a) and winter (b). . . . . . 46

4.10 The second EOF of monthly mean station data temperature anomalies. ............................ 4 
5.1 (a) Difference between mean DJF temperature $(T)$ at $300 \mathrm{hPa}$ for La Niña conditions and quiescent ENSO conditions (see text for the definition of La Niña, El Niño, and quiescent ENSO conditions. (b) Same as (a) but for El Niño conditions. (c) and (d) Same as (a) and (b), but for the zonal wind-speed $(u)$. The $T$ contours are from $\pm 0.1 \mathrm{~K}$ with $0.2 \mathrm{~K}$ interval, and the zero contour is bolded. The $u$ contours are from $\pm 0.5 \mathrm{~m} \mathrm{~s}^{-1}$ with $1 \mathrm{~m} \mathrm{~s}^{-1}$ interval and the zero contour is bolded. Dotted contours correspond to negative values and solid contours correspond to positive values throughout the chapter.

5.2 Fraction of composite DJF $u$ anomalies attributable to zonal wavenumber zero for La Niña (solid line) and El Niño (dashed line). Values have been smoothed with a running mean over $20^{\circ}$ of latitude. . . . 56

5.3 Difference between $u$ during La Niña and El Niño events during SON (a), MAM (b) and JJA (c). Contours are every $2 \mathrm{~m} \mathrm{~s}^{-1}$ with the zero contour omitted. . . . . . . . . . . . . . . . 57

5.4 Variance of the high-pass $(<8$ days) filtered $300 \mathrm{hPa}$ geopotential height $\left(Z_{300}\right)$ during SON (a), DJF (b), MAM (c) and JJA (d). Contours are every $1000 \mathrm{~m}^{2}$ and values over $5500 \mathrm{~m}^{2}$ are shaded. . . . . 58

5.5 Variance of the high-pass filtered $Z_{300}$ during DJF for La Niña events (a), El Niño events (b) and their difference (c). Contours in (a) and (b) are every $1000 \mathrm{~m}^{2}$ and values over $6000 \mathrm{~m}^{2}$ are shaded. Contours in (c) are every $300 \mathrm{~m}^{2}$ with the zero contour omitted Values less than $-1200 \mathrm{~m}^{2}$ or greater than $1200 \mathrm{~m}^{2}$ are hatched and shaded respectively. 60 
5.6 Correlation coefficient $(R)$ between the baroclinicity in the 850-700 $\mathrm{hPa}$ layer and the southern oscillation index during austral spring (a), summer (b), autumn (c) and winter (d). Contours are every 0.1 with the zero contour omitted. $|R|>0.25$ are red and blue for positive and negative $R$, respectively. . . . . . . . . . . . . 62

5.7 Lead-lag composites based on the strength of the La Niña-like forcing in the tropical Pacific ( $T S_{\text {nina }}$, see text for definition). The lag-zero $\left(\operatorname{lag}_{0}\right)$ day is all days during NDJF when $T S_{\text {nina }}>2 \sigma$ (standard deviations). $T S_{\text {nina }}$ (dashed line), time series of southern annular mode (SAM, see text for definition, solid line), and the mean $T$ at $300 \mathrm{hPa}$ between the equator and $15^{\circ} \mathrm{S}$ (dotted line). . . . . . . . 63

5.8 Lead-lag composite of $u$ anomaly (difference from the monthly-mean climatology) for $\operatorname{lag}_{-1}$ to $\operatorname{lag}_{0}$ (a), $\operatorname{lag}_{1}$ to $\operatorname{lag}_{2}$ (b) and $\operatorname{lag}_{3}$ to $\operatorname{lag}_{4}$ (c). See text for definition of $\operatorname{lag}_{0}$. Contours are every $1 \mathrm{~m} \mathrm{~s}^{-1}$, with the zero contour omitted, $\pm 2 \mathrm{~m} \mathrm{~s}^{-1}$ bolded, values less than $5 \mathrm{~m} \mathrm{~s}-1$ hatched, and greater than $8 \mathrm{~m} \mathrm{~s}^{-1}$ shaded.

5.9 Lead-lag composite of the anomalous (difference from the monthlymean climatology) high-frequency variance of $Z_{300}$ for $\operatorname{lag}_{1}$ to $\operatorname{lag}_{2}$ (a), $\operatorname{lag}_{3}$ to $\operatorname{lag}_{4}$ (b) and $\operatorname{lag}_{5}$ to $\operatorname{lag}_{6}$ (c). Contouring begins at $\pm 400 \mathrm{~m}^{2}$, with $200 \mathrm{~m}^{2}$ interval, and values over $1600 \mathrm{~m}^{2}$ shaded. 
6.1 Zonal-mean zonal-wind climatology and trend. (a) The NCEP/NCAR reanalysis data. (b) Global circulation models (GCMs) used in the IPCC AR4 report. Contours show the trends for each dataset. Trends are calculated using linear regression for the reanalysis data, and differences in the means of the respective periods for the model output. Contour interval is $0.1 \mathrm{~m} \mathrm{~s}^{-1}$ decade $^{-1}$ and contours begin at \pm 0.025 with the zero contour bolded. . . . . . . . . . . . . . . . 74

6.2 (a) Eddy activity climatology and trend (see text for definition) for the CMIP3 model ensemble at $300 \mathrm{hPa}$. Shading is the percentage of hemispheric variance explained. Contours are every $\pm 1 * 10^{-3}$ percent of the global variance per decade with the zero contour omitted, and solid (dotted) contours indicate a positive (negative) trend. The heavy white line shows the mean wavelength at each latitude $(\bar{\lambda}(\phi)$, see text)(b) Climatological zonal-mean meridional flux of zonal momentum by eddies at $300 \mathrm{hPa}$ in the $\mathrm{SH}$ NCEP/NCAR reanalysis data. The sign convention is positive for northward flux of westerly momentum. . . . . . . . . . . . . . . 75 
6.3 The upper panels show the difference in zonal-mean temperature between the experiments and the control. The center row of panels shows the wavenumber activity spectrum at $240 \mathrm{hPa}$. The contours are for the control run, starting at 0.1 with 0.1 interval. The shading is the difference between the experiment and the control run. The bold contour in the center left panel shows $\bar{\lambda}(\phi)$ for the control run. The bottom row of panels shows the zonal mean zonal wind in the control run as contours. The contour interval is $\pm 5 \mathrm{~m} \mathrm{~s}^{-1}$ with solid (dashed) contours representing positive (negative) values and the zero contour omitted. The shading is the difference between the experiments and the control run. The left column of panels corresponds to the experiment $H_{\text {increased }}$, where the stratospheric equilibrium $\left(T_{e q}\right)$ was reduced by $3 \mathrm{~K}$. The middle column corresponds to the experiment $N_{\text {increased }}^{2}$, where $T_{e q}$ was reduced by $3 \mathrm{~K}$ in the lowest three model layers. The right column corresponds to the experiment $\nabla T_{\text {increased }}$, where the $e$-folding time of the Newtonian cooling was reduced from 40 days to 30 days. . . . . . . . . . . . . . . . . . . . 83 
6.4 The variation of jet-latitude with eddy wavelength (at $240 \mathrm{hPa}$ ) for 10 different experiments. In the E-P experiments, the surface EquatorPole difference in the equilibrium temperature $\left(T_{e q}\right)$ was changed to the subscripted value. In the $\mathrm{H}-\mathrm{S}$ experiments, the subscripted value in the legend was added to $T_{e q}$ at the tropopause and stratosphere, and decreased to zero at the surface. In the Del experiments, the power of the hyperdiffusivity operator was changed to the superscripted value. In the Ozone Hole experiment, $T_{e q}$ was perturbed in the stratosphere by $-10 \mathrm{~K}$ at the pole, varying as $\cos ^{2}(\phi)$ to $0 \mathrm{~K}$ at the equator. The $H_{\text {increased }}$ experiment is the same as shown in Figure $6.3(\mathrm{a}) \ldots \ldots \ldots \ldots$. . . . . . . . . . . . . . . . . 84 


\section{List of Tables}

4.1 The percentage of the total variance of the regression patterns shown in Figure 4.1 attributed to the first five Fourier components. Values have been averaged over latitudes $35-75^{\circ}$ S. . . . . . . . . . . . . 33 


\section{References}

\section{References}

Ambaum, M. H. P., B. J. Hoskins, and D. B. Stephenson (2001), Arctic oscillation or north atlantic oscillation?, Journal of Climate, 14(16), 3495-3507.

Ambrizzi, T., and B. J. Hoskins (1997), Stationary rossby-wave propagation in a baroclinic atmosphere, Quarterly Journal of the Royal Meteorological Society, 123(540), 919-928, part B.

Andrews, D. G., J. R. Holton, and C. B. Leovy (1987), Middle Atmosphere Dynamics, Academic Press.

Arblaster, J. M., and G. A. Meehl (2006), Contributions of external forcings to southern annular mode trends, Journal of Climate, 19(12), 2896-2905.

Archer, C. L., and K. Caldeira (2008), Historical trends in the jet streams, Geopphysical Research Letters, 35, L08,803.

Baldwin, M. P. (2001), Annular modes in global daily surface pressure, Geophysical Research Letters, 28(21), 4115-4118.

Bals-Elsholz, T. M., E. H. Atallah, L. F. Bosart, T. A. Wasula, M. J. Cempa, and A. R. Lupo (2001), The wintertime southern hemisphere split jet: Structure, variability, and evolution, Journal of Climate, 14(21), 4191-4215.

Bengtsson, L., K. I. Hodges, and E. Roeckner (2006), Storm tracks and climate change, Journal of Climate, 19(15), 3518-3543. 
Bhaskaran, B., and A. B. Mullan (2003), El nino-related variations in the southern pacific atmospheric circulation: model versus observations, Climate Dynamics, 20(2-3), 229-239.

Bjerknes, J. (1969), Atmospheric teleconnections from the equatorial pacific1 atmospheric teleconnections from teh equatorial pacific1, Monthly Weather Review, $97(3), 163-172$.

Bjerknes, J. (1972), Large-scale atmospheric response to the 1964-65 pacific equatorial warming, Journal of Physical Oceanography, 2, 212-217.

Bradley, R. S., H. . F. Diaz, G. N. Kiladis, and J. K. Eischeid (1987), Enso signal in continental temperature and precipitation records, Nature, 327, 497-501.

Brandefelt, J., and E. Kallen (2004), The response of the southern hemisphere atmospheric circulation to an enhanced greenhouse gas forcing, Journal of Climate, $17(22), 4425-4442$.

Bretherton, F. (1966), Baroclinic instability and the short wavelength cut-off in terms of potential vorticity, Quarterly Journal of the Royal Meteorological Society, 92, 335-345.

Bromwich, D. H., R. L. Fogt, K. I. Hodges, and J. E. Walsh (2007), A tropospheric assessment of the era-40, ncep, and jra-25 global reanalyses in the polar regions, Journal of Geophysical Research-Atmospheres, 112(D10).

Cai, W. J., P. H. Whetton, and D. J. Karoly (2003), The response of the antarctic oscillation to increasing and stabilized atmospheric co2, Journal of Climate, 16(10), 1525-1538.

Cash, B. A., P. J. Kushner, and G. K. Vallis (2005), Zonal asymmetries, teleconnec- 
tions, and annular patterns in a gcm, Journal of the Atmospheric Sciences, 62(1), $207-219$.

Chen, G., and I. M. Held (2007), Phase speed spectra and the recent poleward shift of southern hemisphere surface westerlies, Geophysical Reseasrh Letters, 34, L21,805.

Chen, G., J. Lu, and D. M. W. Frierson (2008), Phase speed spectra and the latitude of surface westerlies: Interannual variability and global warming trend, Journal of Climate, 21(22), 5942-5959.

Codron, F. (2005), Relation between annular modes and the mean state: Southern hemisphere summer, Journal of Climate, 18(2), 320-330.

Codron, F. (2007), Relations between annular modes and the mean state: Southern hemisphere winter, Journal of the Atmospheric Sciences, 64(9), 3328-3339.

Edmon, H., B. Hoskins, and M. McIntyre (1980), Eliassen-palm cross sections for the troposphere, Journal of the Atmospheric Sciences, 37(12), 2600-2616.

Fogt, R. L., and D. H. Bromwich (2006), Decadal variability of the enso teleconnection to the high-latitude south pacific governed by coupling with the southern annular mode, Journal of Climate, 19(6), 979-997.

Frierson, D. M. W. (2006), Robust increases in midlatitude static stability in simulations of global warming, Geophysical Research Letters, 33, L24,816.

Frierson, D. M. W., I. M. Held, and P. Zurita-Gotor (2006), A gray-radiation aquaplanet moist GCM. part i: Static stability and eddy scale, Journal of the Atmospheric Sciences, 63(10), 2548-2566. 
Fyfe, J. C., G. J. Boer, and G. M. Flato (1999), The arctic and antarctic oscillations and their projected changes under global warming, Geophysical Research Letters, $26(11), 1601-1604$.

Garcia, R. R., and W. J. Randel (2008), Acceleration of the brewer-dobson circulation due to increases in greenhouse gases, Journal of the Atmospheric Sciences, $65(8), 2731-2739$.

Garreaud, R. D., and D. S. Battisti (1999), Interannual (enso) and interdecadal (enso-like) variability in the southern hemisphere tropospheric circulation, Journal of Climate, 12(7), 2113-2123.

Gerber, E. P., and G. K. Vallis (2007), Eddy-zonal flow interactions and the persistence of the zonal index, Journal of the Atmospheric Sciences, 64(9), 3296-3311.

Gillett, N. P., T. D. Kell, and P. D. Jones (2006), Regional climate impacts of the southern annular mode, Geophysical Research Letters, 33(23).

Gong, D. Y., and S. W. Wang (1999), Definition of antarctic oscillation index, Geophysical Research Letters, 26(4), 459-462.

Haigh, J. D., M. Blackburn, and R. Day (2005), The response of tropospheric circulation to perturbations in lower-stratospheric temperature, Journal of Climate, 18(17), 3672-3685.

Hartmann, D. L. (1994), Global Physical Climatology, International Geophsics, vol. 56, Accademic Press.

Hartmann, D. L. (1995), A pv view of zonal flow vacillation, Journal of the Atmospheric Sciences, 52(14), 2561-2576.

Hartmann, D. L. (2000), The key role of lower-level meridional shear in baroclinic wave life cycles, Journal of the Atmospheric Sciences, 57(3), 389-401. 
Hartmann, D. L., and F. Lo (1998), Wave-driven zonal flow vacillation in the southern hemisphere, Journal of the Atmospheric Sciences, 55(8), 1303-1315.

Hartmann, D. L., J. M. Wallace, V. Limpasuvan, D. W. J. Thompson, and J. R. Holton (2000), Can ozone depletion and global warming interact to produce rapid climate change?, Proceedings of the National Academy of Sciences of the United States of America, 97(4), 1412-1417.

Haynes, P. H., M. E. McIntyre, T. G. Shepherd, C. J. Marks, and K. P. Shine (1991), On the downward control of extratropical diabatic circulations by eddy-induced mean zonal forces, Journal of the Atmospheric Sciences, 48(4), 651-678.

Held, I. M. (1975), Momentum transport by quasi-geostrophic eddies., Journal of the Atmospheric Sciences, 32(7), 1494-1497.

Held, I. M., and M. J. Suarez (1994), A proposal for the intercomparison of the dynamical cores of atmospheric general circulation models, Bulletin of the American Meteorological Society, $75(10)$, 1825-1830.

Hendon, H. H., D. W. J. Thompson, and M. C. Wheeler (2007), Australian rainfall and surface temperature variations associated with the southern hemisphere annular mode, Journal of Climate, 20(11), 2452-2467.

Hoerling, M. P., and M. Ting (1994), Organization of extratropical transients during el ni\&\#241;o, Journal of Climate, 7(5), 745-766.

Holton, J. (1992), An Introduction to Dynamic Meteorology, Academic Press.

Horel, J. D., and J. M. Wallace (1981), Planetary-scale atmospheric phenomena associated with the southern oscillation, Monthly Weather Review, 109, 813-829. 
Hoskins, B. J., and T. Ambrizzi (1993), Rossby wave propagation on a realistic longitudinally varying flow, Journal of the Atmospheric Sciences, 50(12), 16611671.

Hoskins, B. J., and K. I. Hodges (2005), A new perspective on southern hemisphere storm tracks, Journal of Climate, 18(20), 4108-4129.

Hoskins, B. J., and D. J. Karoly (1981), The steady linear response of a spherical atmosphere to thermal and orographic forcing, Journal of the Atmospheric Sciences, 38(6), 1179-1196.

Hurrell, J., Y. Kushnir, G. Ottersen, and M. Visbeck (2003), The north atlantic oscillation: Climate significance and environmental impact., Geophysical Monograph Series, 134, 279.

Huth, R. (2007), Arctic or north atlantic oscillation? arguments based on the principal component analysis methodology, Theoretical and Applied Climatology, 89(12), 1-8.

Inatsu, M., and B. J. Hoskins (2004), The zonal asymmetry of the southern hemisphere winter storm track, Journal of Climate, 17(24), 4882-4892.

Johanson, C., and Q. Fu (2008), Hadley cell widening: model simulations versus observations, Submitted to Journal of Climate.

Kalnay, E., et al. (1996), The ncep/ncar 40-year reanalysis project, Bulletin of the American Meteorological Society, 77 (3), 437-471.

Kanamitsu, M., R. E. Kistler, and R. W. Reynolds (1997), Ncep/ncar reanalysis and the use of satellite data, in Satellite Data Applications: Weather and Climate, Advances in Space Research, vol. 19, pp. 481-489, Pergamon press. 
Karoly, D. J. (1989), Southern hemisphere circulation features associated with el nino-southern oscillation events, Journal of Climate, 2(11), 1239-1252.

Kidson, J. W. (1988), Interannual variations in the southern hemisphere circulation., Journal of Climate, 1, 1177-1198.

Kidson, J. W. (1999), Principal modes of southern hemisphere low-frequency variability obtained from ncep-ncar reanalyses, Journal of Climate, 12(9), 2808-2830.

Kidson, J. W. (2000), An analysis of new zealand synoptic types and their use in defining weather regimes, International Journal of Climatology, 20(3), 299-316.

Kidson, J. W., and J. A. Renwick (2002), The southern hemisphere evolution of enso during 1981-99, Journal of Climate, 15(8), 847-863.

Kidson, J. W., and I. G. Watterson (1999), The structure and predictability of the high-latitude mode in the csiro9 general circulation model, Journal of the Atmospheric Sciences, 56(22), 3859-3873.

Kidston, J., S. M. Dean, and J. A. Renwick (2009a), The southern annular mode and the zonally symmetric response to the el nino southern oscillation., Submitted to Journal of Climate.

Kidston, J., S. M. Dean, and J. A. Renwick (2009b), On the cause of the poleward shift of the mid-latitude jet-streams with global warming, Submitted to Geophysical Research Letters.

Kidston, J., D. M. W. Frierson, and J. A. Renwick (2009c), On the dynamical mechanism of mid-latitude jet stream variability and annular modes, Submitted, Journal of Climate, 22, Submitted. 
Kidston, J., J. A. Renwick, and M. J. (2009d), Hemispheric scale seasonality of the southern annular mode and impacts on the climate of new zealand., Submitted to Journal of Climate.

Kushner, P. J., I. M. Held, and T. L. Delworth (2001), Southern hemisphere atmospheric circulation response to global warming, Journal of Climate, 14(10), 2238 2249 .

Kwok, R., and J. C. Comiso (2002), Spatial patterns of variability in antarctic surface temperature: Connections to the southern hemisphere annular mode and the southern oscillation, Geophysical Research Letters, 29(14).

Lefebvre, W., H. Goosse, R. Timmermann, and T. Fichefet (2004), Influence of the southern annular mode on the sea ice-ocean system, Journal of Geophysical Research-Oceans, $109(\mathrm{C} 9)$.

L'Heureux, M. L., and D. W. J. Thompson (2006), Observed relationships between the el nino-southern oscillation and the extratropical zonal-mean circulation, Journal of Climate, 19(2), 276-287.

Li, Q., H. Graf, and M. Giorgetta (2006), Stationary planetary wave propagation in northern hemisphere winter climatological analysis of the refractive index, Atmospheric Chemistry and Physics, 6, 9033-9067.

Limpasuvan, V., and D. L. Hartmann (1999), Eddies and the annular modes of climate variability, Geophysical Research Letters, 26(20), 3133-3136.

Limpasuvan, V., and D. L. Hartmann (2000), Wave-maintained annular modes of climate variability, Journal of Climate, 13(24), 4414-4429.

Lorenz, D. J., and E. T. DeWeaver (2007), Tropopause height and zonal wind re- 
sponse to global warming in the IPCC scenario integrations., Journal of Geophysical Research., 112, D10,119.

Lorenz, D. J., and D. L. Hartmann (2001), Eddy-zonal flow feedback in the southern hemisphere, Journal of the Atmospheric Sciences, 58(21), 3312-3327.

Lorenz, D. J., and D. L. Hartmann (2003), Eddy-zonal flow feedback in the northern hemisphere winter, Journal of Climate, 16(8), 1212-1227.

Lu, J., G. Chen, and D. M. W. Frierson (2008), Response of the zonal mean atmospheric circulation to el nino versus global warming, Journal of Climate, 21(22), $5835-5851$.

Marshall, G. J. (2003), Trends in the southern annular mode from observations and reanalyses, Journal of Climate, 16(24), 4134-4143.

Marshall, G. J., A. Orr, N. P. M. van Lipzig, and J. C. King (2006), The impact of a changing southern hemisphere annular mode on antarctic peninsula summer temperatures, Journal of Climate, 19(20), 5388-5404.

Marshall, J., et al. (2001), North atlantic climate variability: Phenomena, impacts and mechanisms, International Journal of Climatology, 21(15), 1863-1898.

Meehl, G. A., C. Covey, T. Delworth, M. Latif, J. F. B. McAvaney, B.and Mitchell, R. J. Stouffer, and K. E. Taylor (2007a), The WCRP CMIP3 multi-model dataset: A new era in climate change research, Bulletin of the American Meteorological Society, 88, 1383-1394.

Meehl, G. T. S., et al. (2007b), Global Climate Projections. In: Climate Change 200\%: The Physical Science Basis. Contribution of Working Group I to the Fourth Assessment Report of the Intergovernmental Panel on Climate Change., Cambridge University Press, Cambridge, United Kingdom and New York, NY, USA. 
Meneghini, B., I. Simmonds, and I. N. Smith (2007), Association between australian rainfall and the southern annular mode, International Journal of Climatology, $27(1), 109-121$.

Miller, R. L., G. A. Schmidt, and D. T. Shindell (2006), Forced annular variations in the 20th century intergovernmental panel on climate change fourth assessment report models, Journal of Geophysical Research-Atmospheres, 111 (D18).

Mo, K. C. (2000), Relationships between low-frequency variability in the southern hemisphere and sea surface temperature anomalies, Journal of Climate, 13(20), 3599-3610.

Mo, K. C., and G. H. White (1985), Teleconnections in the southern hemisphere, Monthly Weather Review, 113(1), 22-37.

Monahan, A., J. C. Fyfe, M. H. Ambaum, D. B. Stephenson, and G. R. North (2009), Empirical orthogonal functions: The medium is the message, Journal of Climate, 22, Submitted.

Mullan, A. B. (1995), On the linearity and stability of southern oscillation-climate relationships for new zealand, International Journal of Climatology, 15(12), 13651386.

Nakamura, H., and T. Fukamachi (2004), Evolution and dynamics of summertime blocking over the far east and the associated surface okhotsk high, Quarterly Journal of the Royal Meteorological Society, 130(599), 1213-1233, part B.

Nakamura, H., and A. Shimpo (2004), Seasonal variations in the southern hemisphere storm tracks and jet streams as revealed in a reanalysis dataset, Journal of Climate, 17(9), 1828-1844. 
Orr, A., G. J. Marshall, J. C. R. Hunt, J. Sommeria, C.-G. Wang, N. P. M. van Lipzig, D. Cresswell, and J. C. King (2008), Characteristics of summer airflow over the antarctic peninsula in response to recent strengthening of westerly circumpolar winds, Journal of the Atmospheric Sciences, 65(4), 1396-1413.

Panetta, R. L. (1993), Zonal jets in wide baroclinically unstable regions: Persistence and scale selection, Journal of the Atmospheric Sciences, 50(14), 2073-2106.

Parish, T. R., and R. Walker (2006), A re-examination of the winds of adelie land, antarctica, Australian Meteorological Magazine, 55(2), 105-117.

Randel, W. J., and I. M. Held (1991), Phase speed spectra of transient eddy fluxes and critical layer absorption, Journal of the Atmospheric Sciences, 48, 688-697.

Raphael, M. N., and M. M. Holland (2006), Twentieth century simulation of the southern hemisphere climate in coupled models. part 1: large scale circulation variability, Climate Dynamics, 26(2-3), 217-228.

Rasmusson, E., and J. M. Wallace (1983), Meteorological aspects of the el nino/southern oscillation, Science, 222, 1195-1202.

Rayner, N. A., E. B. Horton, D. E. Parker, C. K. Folland, and R. B. Hackett (1996), Version 2.2 of the global sea-ice and sea surface temperature data set, 19031994.

Reason, C. J. C., and M. Rouault (2005), Links between the antarctic oscillation and winter rainfall over western south africa, Geophysical Research Letters, 32(7).

Renwick, J. A. (1998), Enso-related variability in the frequency of south pacific blocking, Monthly Weather Review, 126(12), 3117-3123.

Renwick, J. A. (2002), Southern hemisphere circulation and relations with sea ice and sea surface temperature, Journal of Climate, 15(21), 3058-3068. 
Renwick, J. A., and M. J. Revell (1999), Blocking over the south pacific and rossby wave propagation, Monthly Weather Review, 127(10), 2233-2247.

Renwick, J. A., and J. M. Wallace (1996), Relationships between north pacific wintertime blocking, el nino, and the pna pattern, Monthly Weather Review, 124(9), 2071-2076.

Rhines, P. (1975), Waves and turbulence on a beta-plane., J. Fluid Mech., 69, 417443.

Robinson, W. (2007), The Global Circulation of the Atmosphere - Ch. 5 - EddyMediated Interactions Between Low Latitudes and the Extratropics, Princeton University Press.

Robinson, W. A. (1994), Eddy feedbacks on the zonal index and eddy zonal flow interactions induced by zonal flow transience, Journal of the Atmospheric Sciences, $51(17), 2553-2562$.

Robinson, W. A. (1996), Does eddy feedback sustain variability in the zonal index?, Journal of the Atmospheric Sciences, 53(23), 3556-3569.

Robinson, W. A. (2000), A baroclinic mechanism for the eddy feedback on the zonal index, Journal of the Atmospheric Sciences, 57(3), 415-422.

Robinson, W. A. (2002), On the midlatitude thermal response to tropical warmth, Geophysical Research Letters, 29(8).

Robinson, W. A. (2004), Comments on the structure and composition of the annular modes in an aquaplanet general circulation model", Journal of the Atmospheric Sciences, 61(8), 949-953.

Robinson, W. A. (2006), On the self-maintenance of midlatitude jets, Journal of the Atmospheric Sciences, 63(8), 2109-2122. 
Roscoe, H. K., and J. D. Haigh (2007), Influences of ozone depletion, the solar cycle and the qbo on the southern annular mode, Quarterly Journal of the Royal Meteorological Society, 133(628), 1855-1864, part A.

Sardeshmukh, P. D., and B. J. Hoskins (1988), The generation of global rotational flow by steady idealized tropical divergence, Journal of the Atmospheric Sciences, $45(7), 1228-1251$.

Seager, R., N. Harnik, Y. Kushnir, W. Robinson, and J. Miller (2003), Mechanisms of hemispherically symmetric climate variability\&\#42, Journal of Climate, 16(18), 2960-2978.

Silvestri, G. E., and C. S. Vera (2003), Antarctic oscillation signal on precipitation anomalies over southeastern south america, Geophysical Research Letters, 30(21).

Simmons, A. J., and B. J. Hoskins (1978), The life cycles of some nonlinear baroclinic waves, Journal of the Atmospheric Sciences, 35(3), 414-432.

Sinclair, M. R. (1996), A climatology of anticyclones and blocking for the southern hemisphere, Monthly Weather Review, 124(2), 245-263.

Sinclair, M. R., J. A. Renwick, and J. W. Kidson (1997), Low-frequency variability of southern hemisphere sea level pressure and weather system activity, Monthly Weather Review, 125(10), 2531-2543.

Son, S.-W., et al. (2008), The impact of stratospheric ozone recovery on the southern hemisphere westerly jet, Science, 320(5882), 1486-1489.

Thompson, D., S. Lee, and M. P. Baldwin (2003), Atmospheric processes governing the northern hemisphere annular mode/ north atlantic oscillation, Geophysical monograph, $x, \mathrm{x}$. 
Thompson, D. W. J., and S. Solomon (2002), Interpretation of recent southern hemisphere climate change, Science, 296(5569), 895-899.

Thompson, D. W. J., and J. M. Wallace (1998), The arctic oscillation signature in the wintertime geopotential height and temperature fields, Geophysical Research Letters, 25(9), 1297-1300.

Thompson, D. W. J., and J. M. Wallace (2000), Annular modes in the extratropical circulation. part i: Month-to-month variability, Journal of Climate, 13(5), 10001016.

Thompson, D. W. J., and J. M. Wallace (2001), Regional climate impacts of the northern hemisphere annular mode, Science, $293(5527)$, 85-89.

Thompson, D. W. J., J. M. Wallace, and G. C. Hegerl (2000), Annular modes in the extratropical circulation. part ii: Trends, Journal of Climate, 13(5), 1018-1036.

Thorncroft, C. D., B. J. Hoskins, and M. E. McIntyre (1993), Two paradigms of baroclinic-wave life-cycle behaviour, Quarterly Journal of the Royal Meteorological Society, 119 (509), 17-55.

Trenberth, K., et al. (2007), Observations: Surface and Atmospheric Climate Change. In: Climate Change 200\%: The Physical Science Basis. Contribution of Working Group I to the Fourth Assessment Report of the Intergovernmental Panel on Climate Change, Cambridge University Press, Cambridge, United Kingdom and New York, NY, USA.

Trenberth, K. E. (1991), Storm tracks in the southern hemisphere, Journal of the Atmospheric Sciences, 48(19), 2159-2178.

Troup, A. J. (1965), The southern oscillation, Quarterly Journal of the Royal Meteorological Society, 91, 490-506. 
Ummenhofer, C. C., and M. H. England (2007), Interannual extremes in new zealand precipitation linked to modes of southern hemisphere climate variability, Journal of Climate, 20(21), 5418-5440.

Vallis, G. K. (2006), Atmospheric and Oceanic Fluid Dynamics: Fundamentals and Large-Scale Circulation., Cambridge University Press.

Vallis, G. K., and E. P. Gerber (2008), Local and hemispheric dynamics of the north atlantic oscillation, annular patterns and the zonal index, Dynamics of Atmospheres and Oceans, 44, 184-212.

Vallis, G. K., E. P. Gerber, P. J. Kushner, and B. A. Cash (2004), A mechanism and simple dynamical model of the north atlantic oscillation and annular modes, Journal of the Atmospheric Sciences, 61(3), 264-280.

van Lipzig, N. P. M., G. J. Marshall, A. Orr, and J. C. King (2008), The relationship between the southern hemisphere annular mode and antarctic peninsula summer temperatures: Analysis of a high-resolution model climatology, Journal of Climate, 21(8), 1649-1668.

Van Loon, H. (1972), Pressure in the southern hemisphere, Meteorological Monographs, $1(35), 59-86$.

Visbeck, M. H., J. W. Hurrell, L. Polvani, and H. M. Cullen (2001), The north atlantic oscillation: Past, present, and future, Proceedings of the National Academy of Sciences of the United States of America, 98(23), 12,876-12,877.

Wallace, J. M. (2000), North atlantic oscillation/annular mode: Two paradigms one phenomenon, Quarterly Journal of the Royal Meteorological Society, 126(564), 791-805, part A. 
Welch, W. T., and K.-K. Tung (1998), On the equilibrium spectrum of transient waves in the atmosphere, Journal of the Atmospheric Sciences, 55(17), 2833-2851.

Williams, G. P. (2006), Circulation sensitivity to tropopause height, Journal of the Atmospheric Sciences, 63(7), 1954-1961.

Yang, X. S., and E. K. M. Chang (2006), Variability of the southern hemisphere winter split flow - a case of two-way reinforcement between mean flow and eddy anomalies, Journal of the Atmospheric Sciences, 63(2), 634-650.

Yin, J. H. (2005), A consistent poleward shift of the storm tracks in simulations of 21st century climate., Geophysical Research Letters, 32, 1-4.

Yulaeva, E., and J. M. Wallace (1994), The signature of enso in global temperature and precipitation fields derived from the microwave sounding unit, Journal of Climate, 7(11), 1719-1736. 


\section{Acknowledgements}

I would like to acknowledge the supervision and support of Jim Renwick at NIWA, who was the primary supervisor for my Ph. D. work. The work was funded through the Marsden Fund of New Zealand, to which Jim submitted a successful proposal to examine the extra-tropical impacts of ENSO in the Southern Hemisphere. Jim has been supportive when needed, and also has given me wide ranging academic freedom to pursue ideas independently. Additional supervision was provided by Jim Mcgregor at VUW. I would also like to acknowledge the support of Sam Dean at NIWA, with whom I have had many stimulating discussions about atmospheric dynamics, and who has provided friendly support throughout. 